\title{
FHWA/IN/JTRP-2001/3
}

Final Report

DEVELOPMENT OF LOW COST RETAINING WALLS FOR INDIANA HIGHWAYS

Philippe L. Bourdeau

Patrick J. Fox

David J. Runser

Jin-Pyo Lee

August 2001 


\title{
Final Report
}

FHWA/IN/JTRP-2001/3

\section{DEVELOPMENT OF LOW COST RETAINING WALLS FOR INDIANA HIGHWAYS}

\author{
by \\ Philippe L. Bourdeau \\ Patrick J. Fox \\ David J. Runser \\ Jin-Pyo Lee \\ Joint Transportation Research Program \\ Project No.: C-36-36DD \\ File No.: 6-14-30 \\ SPR-2207 \\ Prepared as Part of an Investigation \\ Conducted by the \\ Joint Transportation Research Program \\ Purdue University \\ In Cooperation with the \\ Indiana Department of Transportation \\ and the \\ U.S. Department of Transportation \\ Federal Highway Administration
}

The contents of this report reflect the views of the author who is responsible for the facts and accuracy of the data presented herein. The contents do not necessarily reflect the official views or policies of the Indiana Department of Transportation and Federal Highway Administration. This report does not constitute a standard, specification, or regulation.

Purdue University

West Lafayette, IN 47907

August 2001 
TECHNICAL REPORT STANDARD TITLE PAGE

\begin{tabular}{|l|l|l|}
\hline $\begin{array}{l}\text { 1. Report No. } \\
\text { A/IN/JTRP-2001/3 }\end{array}$ & 2. Government Accession No. & 3. Recipient's Catalog No. \\
\hline $\begin{array}{l}\text { 4. Title and Subtitle } \\
\text { Development of Low Cost Retaining Walls for Indiana Highways }\end{array}$ & $\begin{array}{l}\text { 5. Report Date } \\
\text { August } 2001\end{array}$ \\
\cline { 2 - 3 }
\end{tabular}

\section{Performing Organization Code}

7. Author(s)

8. Performing Organization Report No.

Philippe L. Bourdeau, Patrick J. Fox, David L. Runser, and Jin-Pyo Lee FHWA/IN/JTRP-2001/3

9. Performing Organization Name and Address Joint Transportation Research Program

1284 Civil Engineering Building

Purdue University

West Lafayette, Indiana 47907-1284

\section{Sponsoring Agency Name and Address}

10. Work Univ No.

Indiana Department of Transportation

State Office Building

100 North Senate Avenue

Indianapolis, IN 46204

\section{Contract or Grant No.} SPR-2207

13. Type of Report and Period Covered Final Report

14. Sponsoring Agency Code

\section{Supplementary Notes}

Prepared in cooperation with the Indiana Department of Transportation and Federal Highway Administration.

\section{Abstract}

Low-cost alternatives to traditional modular facing reinforced soil retaining walls were reviewed, on the basis of published data and information. Technological information, design methods and observed performance of segmental facing reinforced soil walls were used for this review. Guidelines are proposed for selection, design and construction of such retaining walls, within a limited range of conditions, in Indiana highway projects.

\section{Key Words}

soils, compaction, retaining wall, gesynthetic reinforcement
18. Distribution Statement

No restrictions. This document is available to the public through the National Technical Information Service, Springfield, VA 22161

\begin{tabular}{|l|l|l|l|}
$\begin{array}{l}\text { 19. Security Classif. (of this report) } \\
\text { Unclassified }\end{array}$ & $\begin{array}{l}\text { 20. Security Classif. (of this page) } \\
\text { Unclassified }\end{array}$ & $\begin{array}{c}\text { 21. No. of Pages } \\
165\end{array}$ & 22. Price \\
\hline
\end{tabular}

Form DOT F 1700.7 (8-69) 


\section{TECHNICAL Summary}

INDOT Research

Technology Transfer and Project Implementation Information

TRB Subject Code: 62-6 Soil Compaction and Stabilization

August 2001

Publication No.: FHWA/IN/JTRP-2001/3, SPR-2207

Final Report

\section{Development of Low Cost Retaining Walls for Indiana Highways}

\section{Introduction}

Over the past two decades, reinforced soil structures have been increasingly used as design alternatives to traditional reinforced concrete retaining walls for supporting earth fills in civil infrastructure projects. A significant amount of information and data relating to the design and performance of various low-cost retaining walls already exists. However, until now, this data has not been assembled and analyzed systematically.

\section{Findings}

Two main categories of low cost reinforced soil retaining walls have been identified: (1) geosynthetic-reinforced soil walls with segmental facing and (2) geosynthetic-reinforced soil walls with wraparound facing. The latter category is used primarily for temporary structures. In the case of prolonged service, the geosynthetic facing must be protected against sunlight degradation, erosion, and vandalism by growing vegetation or by the addition of a non-structural architectural facing. The

\section{Implementation}

In view of using low-cost alternatives to traditional modular reinforced soil retaining walls for Indiana highways, the following guidelines are offered:

1) Segmental facing, geosynthetic-reinforced soil, retaining walls may be used as noncritical structures with height less than $6 \mathrm{~m}$ and no traffic or structural load.
The objective of this study was to technically evaluate low-cost retaining wall options for Indiana highways, and, where possible, to assist in the implementation of such technologies. The ultimate goal was to make available to INDOT engineers technical guidelines for the selection and design of the optimal retaining wall for a particular project. former category consists of dry stacked masonry units backfilled with geosyntheticreinforced soil. The reinforcement layers are connected to the facing through the units' interfaces. Segmental facing geosyntheticreinforced soil walls were introduced in North America in the mid-1980's and have been since increasingly used for temporary as well as permanent structures. They are an attractive cost-saving alternative to more traditional modular facing steel-reinforced soil walls.
2) The structural fill should consist in INDOT's B-Borrow material for walls placed above the 100-year flood elevation. Below the flood elevation, No. 8 stone should be used.

3) Segmental walls built with structural fill as permeable as B-Borrow do not need to include an internal drainage layer. 
4) Facing units should include active mechanical connections between blocks, and between blocks and reinforcement layers. Purely frictional connections are not recommended. It should be noted that the need for active mechanical connection makes the use of geotextiles as reinforcement inadequate for segmental facing walls. For this reason, geotextiles should be used only in wrap-around facing walls.

5) When seismic performance is of consideration, the reinforcements should be distributed in such a way that each facing units interface layer is connected to a reinforcement. This will result in leaving no row of facing units unreinforced.

6) The design methods of the FHWA and the NCMA are recommended. For numerical implementation of these methods, it is suggested to use the software program, MSEW (see Appendix C).

\section{Contact}

For more information:

Prof. Philippe Bourdeau

Principal Investigator

School of Civil Engineering

Purdue University

West Lafayette, IN 47907

Phone: (765) 494-5031

Fax: (765) 496-1364

\section{Indiana Department of Transportation}

Division of Research

1205 Montgomery Street

P.O. Box 2279

West Lafayette, IN 47906

Phone: (765) 463-1521

Fax: (765) 497-1665
7) Specification for segmental walls should follow the model presented in Appendix B.

8) Preference should be given to those systems evaluated by the Highway Innovative Technology Evaluation Center (HITEC), a service center of the Civil Engineering Research Foundation (CERF).

9) Geotechnical site investigations are of primary importance in order to assess the bearing capacity of the foundation soil and the final settlement of the structure.

(10) The present guidelines will need to be revised and updated as new data and experience become available. It would be highly beneficial to this process that, as part of a future Indiana highway project, a segmental facing reinforced soil wall be instrumented and its performance monitored during and after construction.
West Lafayette, IN 47907-1284

Phone: (765) 494-9310

Fax: (765) 496-1105

\section{Purdue University}

Joint Transportation Research Program

School of Civil Engineering 


\section{TABLE OF CONTENTS}

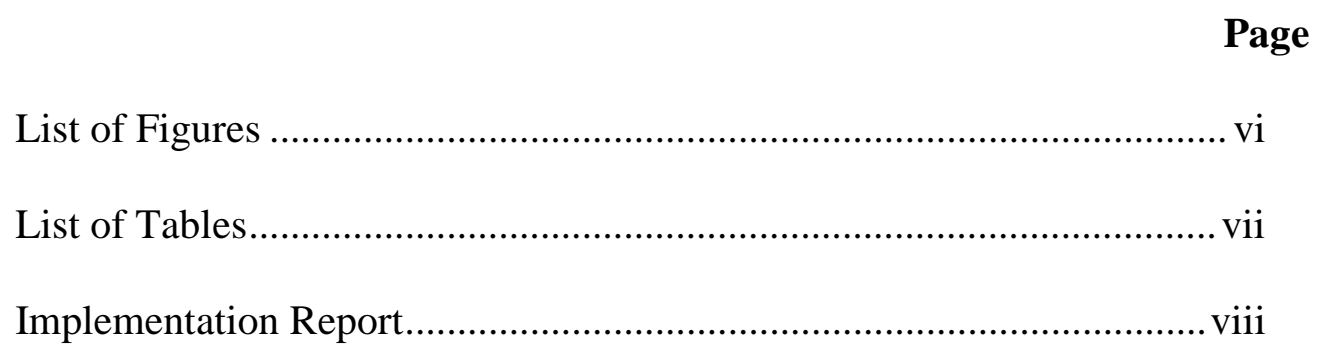

Acknowledgement...........................................................................

Chapter 1 Introduction ................................................................ 1

Chapter 2 Overview of Reinforced Soil Retaining Walls ...................... 5

2.1 General Concept ......................................................... 5

2.2 Advantages of Reinforced Soil Retaining Wall ................ 5

Chapter 3 Materials for Low Cost Reinforced Soil Walls ...................... 7

3.1 Geosynthetic Reinforcement ..................................... 7

3.2 Segmental Facing Units ............................................ 8

3.3 Other Types of Facing Units ........................................ 12

3.4 Connections Systems................................................... 13

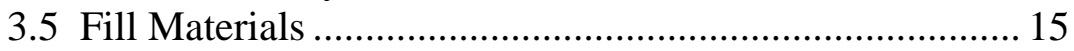

3.6 Fill Compaction (Collin, 1996) ................................... 18

3.6.1 Compaction equipment ..................................... 18

3.6.2 Compaction control ........................................... 19

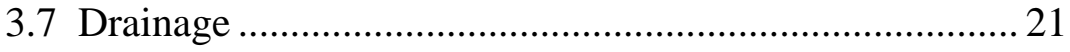

Chapter 4 Soil and Site Exploration ................................................... 26

4.1 Field Reconnaissance ................................................. 26

4.2 Subsurface Exploration .............................................. 27

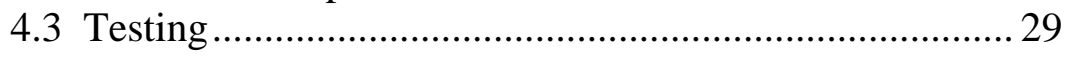

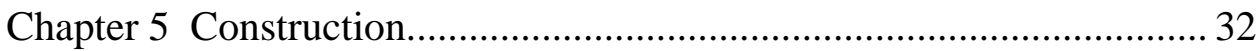

5.1 Procedures ............................................................. 32

5.1.1 Wall excavation and leveling pad construction

(Figs. 5.1 and 5.2)............................................... 32

5.1.2 Setting, leveling and backfilling the first course of facing units (Figs. 5.3 and 5.4)........................... 33 
5.1.3 Placement and backfilling of facing units (Figs. 5.5

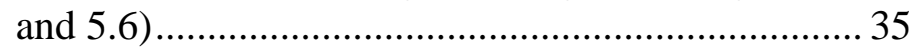

5.1.4 Placement, tensioning and backfilling of geosynthetic reinforcement (Figs. 5.7 and 5.8) .................. 36

5.1.5 Capping the wall and finish grading (Fig. 5.9) …....37

5.2 Construction Guidelines...................................................... 38

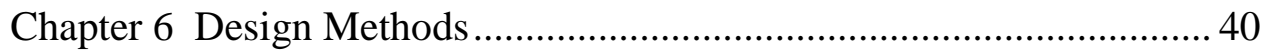

6.1 Input Information for Design Methods ............................. 40

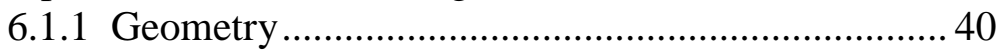

6.1.2 Materials........................................................... 40

6.1.2.1 Segmental units ....................................... 40

6.1.2.2 Geosynthetic reinforcement ..................... 42

6.1.2.3 Soil parameters ......................................... 42

6.2 National Concrete Masonry Association (NCMA)

Method (Collin, 1996)....................................................... 43

6.2.1 Design assumptions.............................................. 43

6.2.2 External stability ................................................... 43

6.2.2.1 External earth pressure and forces........... 43

6.2.2.2 Base sliding stability ................................ 46

6.2.2.3 Overturning ............................................ 47

6.2.2.4 Bearing capacity ....................................... 47

6.2.3 Internal stability ...................................................... 47

6.2.3.1 Tensile overstress of reinforcement layers........................................................ 49

6.2.3.2 Pullout of reinforcement ........................... 49

6.2.3.3 Internal sliding failure............................... 51

6.2.4 Local stability ...................................................... 52

6.2.4.1 Facing connection strength ...................... 52

6.2.4.2 Resistance to bulging ............................... 53

6.2.4.3 Maximum unreinforced segmental wall heights ..................................................... 53

6.3 Federal Highway Administration (FHWA) Method

(Christopher et al., 1990)..................................................5 54

6.3.1 Preliminary calculation .......................................... 54

6.3.1.1 Wall embankment depth $\left(\mathrm{H}_{\mathrm{emb}}\right)$............. 54

6.3.1.2 Determination of vertical spacing requirements ............................................. 54

6.3.1.3 Preliminary determination of reinforcement length ..............................................5 54

6.3.2 External stability ……………………………..... 55

6.3.2.1 External earth pressure and forces ......... 55 


\section{Page}

6.3.2.2 Base sliding stability ........................... 56

6.3.2.3 Overturning ...................................... 56

6.3.2.4 Bearing capacity ................................ 57

6.3.3 Internal stability analysis.............................. 57

6.3.3.1 Coefficient of lateral earth pressure for internal stability analysis .......................57

6.3.3.2 Maximum tensile forces in the reinforcement layers ........................................... 59

6.3.3.3 Tensile resistance of the reinforcement.. 62

6.3.3.4 Resistance to pullout ........................... 62

6.3.3.5 Reinforcement strength and spacing variations ...............................................6 65

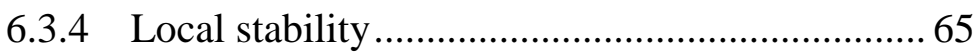

6.3.4.1 Facing connection strength................... 65

6.3.4.2 Resistance to bulging ........................... 66

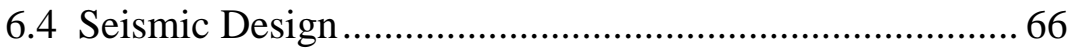

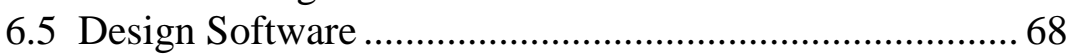

Chapter 7 Performance of Reinforced Soil Segmental Retaining Walls . 69

7.1 Wall in Algonquin, Illinois (Simac et al., 1990, Bathurst,

Et al., 1993a)

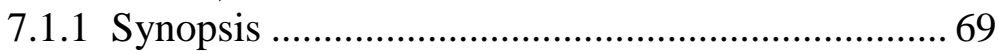

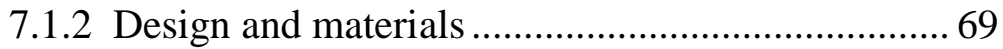

7.1.3 Performance ...................................................... 71

7.1.4 Lessons learned .................................................. 72

7.2 Wall at University of Wisconsin-Platteville (Wetzel et al.,

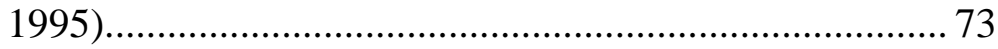

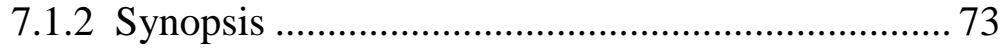

7.2.2 Design and materials ............................................ 73

7.2.3 Performance ...................................................... 75

7.2.4 Lessons learned ................................................. 76

7.3 Failure of Geogrid Reinforced Wall in Calgary, Alberta

(Burwash and Frost, 1991) ........................................... 76

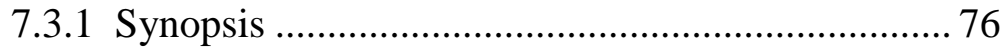

7.3.2 Design and materials ........................................... 77

7.3.3 Performance ......................................................... 77

7.3.4 Lessons learned ................................................... 79

7.4 Failure of a Segmental Reinforced Wall in Glasgow,

Kentucky (Leonards et al., 1994) .................................. 80

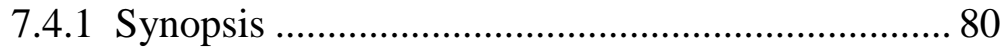

7.4.2 Performance ..................................................... 82

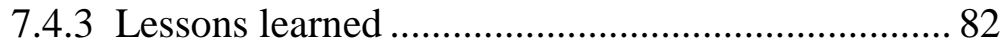


Chapter 8 Discussion and Recommendations .......................................... 83

8.1 Technological Differences between Low-Cost Reinforced

Soil Walls and Traditional Reinforced Soil Walls ........... 83

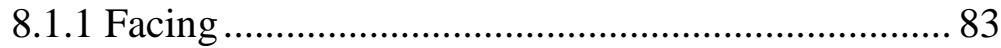

8.1.2 Reinforcement ................................................. 84

8.1.3 Structural fill material ............................................. 84

8.2 Performance of Low-Cost Reinforced Soil Walls............. 85

8.2.1 Range of current experience with segmental facing reinforced soil walls ................................................ 85

8.2.2 Cost Considerations .................................................. 87

8.3 Additional Consideration on Structural Fill ..................... 87

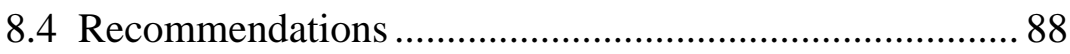

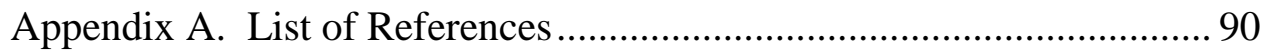

Appendix B. Specification Model......................................................... 98

Appendix C. Documentation on Computer Program, MSEW ................. 111

Appendix D. Performance Evaluation of a Reinforced Earth ${ }^{\mathrm{TM}}$ Modular Block Retaining Wall (US24 crossing of Minnow Creek, Near Logansport, Cass County, Indiana) ........................... 132 


\section{LIST OF FIGURES}

Figure No. Title Page

3.1 Examples of Commercially Available Segmental Units..... 9

3.2 Sources of Segmental Block Cracking (from Bathurst and

Simac, 1994).................................................................. 11

3.3 Shear Connector Types for Segmental Facing Units (from

Collin, 1996)................................................................. 14

3.4 Moisture-Density Relationships for Soils (from Peck,

Hanson and Thornburn, 1974) ………………………..... 20

3.5 Wall Face Drain (Case 1) (Collin, 1996) ...........................2 23

3.6 Wall Face and Blanket Drain (Case 2) (Collin, 1996) ...... 24

3.7 Complete Drainage System (Case 3) (Collin, 1996).......... 25

$5.1 \quad$ Wall Layout and Excavation ............................................. 32

5.2 Leveling Pad Construction ................................................. 33

5.3 Setting First Course of SRW Units …………………......... 33

5.4 Backing First Course of SRW Units ................................. 34

5.5 Installing Successive Courses of SRW Units...................... 35

5.6 Fill Placement and Compaction ..........................................35

5.7 Placement of Geosynthetic Reinforcement ........................ 36

5.8 Backfilling over Geosynthetic Reinforcement....................36

5.9 Completed Reinforced SRW ……………............................ 37

$6.1 \quad$ Retaining Wall Geometry................................................. 41

6.2 Forces and Geometry for External Stability....................... 44

6.3 Free Body Diagram for External Stability Analysis ......... 45

6.4 Forces for Internal Stability Calculation ............................. 48

6.5 Forces and Stresses Used for Internal Stability Analysis.. 50

6.6 Distribution of Earth Pressure in the Reinforced Soil Mass, FHWA Method................................................................58

6.7 Tensile Force in the Reinforcements and Schematic Maximal Tensile Force Line, FHWA Method ..................... 60

6.8 Method to Account for Concentrated Load Diffusion, FHWA Method................................................................. 61

6.9 Determination of the Tensile Force $\mathrm{T}_{\mathrm{o}}$ in the Reinforcement At the Connection with the Facing, FHWA Method ........ 63

7.1 Algonquin Wall Instrumentation Layout ........................... 70

7.2 Wall at University of Wisconsin Instrumentation Layout 74

7.3 Calgary Wall-Typical Cross Section and Details................ 78

7.4 Glasgow, Kentucky Wall ................................................. 81 


\section{LIST OF TABLES}

Table No. Title Page

3.1 Frost Susceptibility of Soils ....................................... 17

3.2 Gradation Range for Reinforced Fill Material in Segmented Reinforced Soil Walls Suggested by

NCMA (Collin, 1996) ................................................... 17

3.3 Summary of Friction Angle Data for Use in Preliminary Design (Collin, 1996) ...................................................... 18

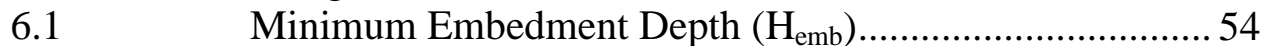




\section{Implementation Report}

In view of using low-cost alternatives to traditional modular reinforced soil retaining walls for Indiana highways, the following guidelines are offered:

(1) Segmental facing, geosynthetic-reinforced soil, retaining walls may be used as non-critical structures with height less than $6 \mathrm{~m}$ and no traffic or structural load.

(2) The structural fill should consist in INDOT's B-Borrow material for walls placed above the 100-year flood elevation (below the flood elevation, No. 8 stone should be used).

(3) Segmental walls do not need to include an internal drainage layer when they are built with structural fill as permeable as B-Borrow.

(4) Facing units should include active mechanical connections between blocks, and between blocks and reinforcement layers. Purely frictional connections are not recommended. It should be noted that the need for active mechanical connection makes the use of geotextiles as reinforcement inadequate for segmental facing walls. For this reason, geotextiles should be used only in wrap-around facing walls.

(5) When seismic performance is of consideration, the reinforcements should be distributed in such a way that each facing units interface layer is connected to a reinforcement. This will result in leaving no row of facing units unreinforced.

(6) The design methods of the FHWA and the NCMA are recommended. For numerical implementation of these methods, it is suggested to use the software program, MSEW (see Appendix C).

(7) Specification for segmental walls should follow the model presented in Appendix B.

(8) Preference should be given to those systems evaluated by the Highway Innovative Technology Evaluation Center (HITEC), a service center of the Civil Engineering Research Foundation (CERF).

(9) Geotechnical site investigations are of primary importance in order to assess the bearing capacity of the foundation soil and the final settlement of the structure. 
(10) The present guidelines will need to be revised and updated as new data and experience become available. It would be highly beneficial to this process that, as part of a future Indiana highway project, a segmental facing reinforced soil wall be instrumented and its performance monitored during and after construction. 


\section{Acknowledgement}

This study was funded by the Indiana Department of Transportation and the Federal Highway Administration.

The Study Advisory Committee was composed of Steve Morris (INDOT), Val Straumins (FHWA) and Dave Ward (INDOT). Their participation in this project, technical input and constructive criticism were deeply appreciated. 


\section{Introduction}

Over the past two decades, reinforced soil structures have been increasingly used as design alternative to traditional reinforced concrete retaining walls for supporting earth fills in civil infrastructure projects. Reinforced soil walls can retain earth fills of significant height and sustain surface applied loads at lower cost than reinforced concrete walls. Because they are flexible and mechanically redundant structures, reinforced soil walls are particularly suitable for difficult foundation soil conditions where differential settlements are anticipated. In general, reinforced soil retaining walls consist of structural fill reinforced with tensile-resistant inclusions that are connected to facing elements The internal stability of the reinforced soil structure is provided by mechanical interactions of its three components, i.e., fill material, reinforcement, and facing.

For transportation infrastructures in the United States, the predominant reinforced soil wall technology is a proprietary system, Reinforced Earth ${ }^{\circledR}$, made of self-draining selected granular fill, galvanized steel strip reinforcements, and precast reinforced concrete facing panels. In terms of both performance and cost, Reinforced Earth ${ }^{\circledR}$ represents the high end in the broad range of reinforced soil technologies. In recent years, however, the development of geosynthetic materials has made it possible to build reinforced soil walls at lower cost. The reinforcing inclusions for these low-cost systems are made of plastic polymer fabrics (i.e. geotextiles) or meshes (i.e., geogrids), the wall facing is made of elements smaller and lighter than traditional large precast concrete panels, and the structural fill may not consist exclusively of high quality granular soil.

The Colorado Transportation Institute has pioneered the use of low-cost reinforced walls for highways as an alternative to conventional wall designs. The system currently used in Colorado consists of geotextile reinforcement and timber or modular block facing. A number of different systems are now available if one considers the many possible combinations of fill material, reinforcement, and facing types. Implementation of these technologies would allow considerable savings in reduced construction costs. For instance, the Colorado Department of Transportation reports a $\$ 10$ million annual savings using low-cost walls and other DOT's may realize similar savings by using these systems. 
In Indiana, several proprietary wall systems, including Reinforced Earth ${ }^{\circledR}$, VSL ${ }^{\circledR}$ Corp., and Hilfiker ${ }^{\circledR}$, have been approved for highway applications. In each case, the design for internal wall stability is subcontracted to the manufacturer. Although this practice is convenient, the cost of these walls is high. Over the period 1995-1997, the annual average expenditure for reinforced soil walls totaled $\$ 3,110,000$. It is for this reason that the INDOT retaining walls committee developed specifications for lower cost modular block walls. However, these specifications have not yet been tested in the field. The committee has also developed a third set of specifications for temporary walls using wire mesh for both reinforcement and facing.

In addition to a lack of experience with low-cost wall designs, no technical guideline is currently available for INDOT engineers to assist them in comparing different technologies and selecting which is preferable for a given project. Currently, the many types of low-cost walls available make the choice difficult. In addition to cost, a number of other criteria must be taken into account, including the short-term and long-term safety and performance of the wall, the suitability of the technology for local soil and environmental conditions, and its aesthetics or landscape integration quality. The development of selection and design guidelines and technical specifications for these walls would enable INDOT engineers to take advantage of the whole range of existing technologies and result in significant cost savings.

The objective of the present study is to technically evaluate low-cost retaining wall options for Indiana highways, and, where possible, to assist in the implementation of such technologies. The ultimate goal is to make available to INDOT engineers technical guidelines for the selection and design of the optimal retaining wall for a particular project.

A significant amount of information and data relating to the design and performance of various low-cost retaining walls already exist. However, there is a need to assemble this data and analyze it systematically. For instance, experience gained by other state DOTs or other agencies may provide valuable knowledge. Additional sources of information are found in the published literature and documentation from the geosynthetics industry. For this study, relevant information and data was collected from the following sources: 
- State DOTs

- Published technical literature

- Geosynthetics industry

- Army Corps of Engineers

- Standardization organizations (e.g., ASTM)

- Others

Another resource for this investigation is the findings of another JTRP project entitled "Performance Evaluation of a Modular Block Retaining Wall", SPR-2181, also conducted by Professors Fox and Bourdeau in 1998. The SPR-2181 project consisted of monitoring the construction and performance of an actual reinforced earth retaining wall built as part of an INDOT project. Although the instrumented wall is not representative of the lower cost systems investigated in the present study, it's observed performance constituted a useful point of reference to comparatively evaluate other systems. A summary of this instrumentation and monitoring project, together with its main findings, are reported in the Appendix section of this report.

The types of information and data that will be of interest include:

- Design guidelines and specifications

- Construction and maintenance guidelines

- Proprietary systems and material databases, including geosynthetics index properties

- Materials or components test standards

- Case records of full-scale test walls, including performance data in relationship with geometry, applied loads, foundation soil, and climatic conditions.

- Facing appearance and aesthetics.

Among the many factors that can affect the performance and safety of retaining walls, the following items seem to be more critical in the case of low-cost reinforced soil structures and having been given special attention during this investigation:

- Connections between reinforcement and facing elements. Depending upon the system considered, these connections can vary from simple frictional contacts to 
sophisticated mechanical assemblies. If the facing plays a structural role in the stability of a wall, connection failures could lead to severe distress.

- Response of the structures to applied loads, such as traffic loads, accidental impact, and earthquake-induced ground motion.

- Long term structure performance related to possible aging, corrosion, and creep of the materials and components. 


\section{Overview of Reinforced Soil Retaining Walls}

\subsection{General Concept}

Gravity Retaining Walls rely on their mass and inertia to resist the destabilizing forces of the retained soil and the applied loads. They can be divided in two groups:

- Conventional Retaining Walls (CRWs) are made of traditional structural materials including masonry and reinforced concrete.

- Reinforced Soil Retaining Walls (RSRWs) are massive structures made of soil reinforced by tensile-resistant inclusions connected to facing elements. Reinforced Soil Retaining Walls are constructed by compacting selected fill layers and installing reinforcement on the horizontal surface of compacted lifts. The construction sequence proceeds from the bottom to the top. Reinforced soil retaining walls are also referred to as MSE walls. Mechanically Stabilized Earth (MSE) is a generic term applicable to any type of reinforced soil structures. It is noted that MSE walls include also in-situ reinforced soil walls such as soil nailing systems.

The modern technology of reinforced soil retaining walls was developed by H. Vidal in France in the mid-1960's. Since then, several thousand of such walls reinforced with steel strips have been successfully built around the world. The use of geosynthetics as reinforcing elements started in the 1970's with the development of polymer-based fabrics and meshes. Geosynthetic walls are generally less expensive than other reinforced soil retaining wall system. (Allen et al., 1991) Over the last decade, the technology of reinforced soil retaining wall has been developed into an attractive alternative to classical concrete gravity walls.

\subsection{Advantages of Reinforced Soil Retaining Wall}

Reinforced Soil Retaining Walls (RSRWs) have distinct advantages over conventional retaining walls, (Claybourn and Wu, 1993; Wu, 1994):

- When properly designed and constructed, RSRWs are remarkably stable.

- RSRWs are more flexible, therefore more tolerant to foundation deformation. 
- RSRWs do not require significant embedment into the foundation soil for their stability. This characteristic is especially important when an environmental problem (such as excavation of contaminated soil) is involved.

- The tensile inclusion of RSRWs significantly reduce the lateral earth pressure on the wall facing, provided that the movement of the facing will allow mobilization of tensile resistance in the inclusion.

- Construction of RSRWs is rapid and requires only "ordinary" or "light" construction equipment.

- $\quad$ RSRWs are generally less expensive to construct than conventional retaining walls. 


\section{Materials for Low Cost Reinforced Soil Walls}

\subsection{Geosynthetic Reinforcement}

To create a composite structure with the fill material the reinforcement layers must be of sufficient number, possess adequate tensile strength, and develop sufficient anchorage capacity to hold the composite mass (reinforced soil zone) together. Geosynthetics used as reinforcement include two broad classes: geotextiles and geogrids.

Description of geotextiles and geogrids, and their properties relevant to soil reinforcing can be found in a number of texts (e.g. Koerner, 1998):

- Geotextiles

Geotextiles are indeed textiles in the traditional sense, but consist of synthetic fibers rather than natural ones such as cotton, wool, or silk. Thus biodegradation should not be a problem. The polymer-based fibers are made into flexible, porous fabrics by standard weaving machines (i.e. woven geotextiles) or are matted together in a random manner (i.e. nonwoven geotextiles). The major point is that they are porous and highly permeable to liquid flow across their manufactured planes. They also conduct fluids within their plane.

- Geogrids

Geogrids are plastic meshes formed into a very open, gridlike configuration. Geogrid aperture sizes range from $\mathrm{mm}$ to inches, but are uniform for a given geogrid. Geogrids are generally manufactured by extruding holes from a large plain polymer sheet. Further processing may consist of stretching in one or two directions for improved mechanical properties of the grid (the terms one-directional or bi-directional are used in reference to these processing modes). Geogrids are obviously permeable to flow across their plane but, unlike geotextiles they do not conduct fluids along their plane. 


\subsection{Segmental Facing Units}

Facings made of dry-stacked concrete units or masonry blocks have become increasingly used. Reinforced soil walls with the segmental facings are called Segmental Reinforced Walls (SRW). Precast segmented units are available under the forms of generic elements or as proprietary technologies.

The structural integrity of dry-stacked segmental wall units is achieved by incorporating connections in their designs, in the form of shear keys, leading/trailing lips, or pins/clips as shown in Figure 3.1 and Figure 3.3. Shear connections will be discussed in more detail later. The units shown on the figures are a sample of those available and serve to illustrate their variety in size, shape and interlocking mechanism. There are no restrictions in the size and shape of a SRW unit but most proprietary units are 8 to $60 \mathrm{~cm}$ in height $\left(\mathrm{H}_{\mathrm{u}}\right), 15$ to $76 \mathrm{~cm}$ in width $\left(\mathrm{W}_{\mathrm{u}}\right)$ and 15 to $183 \mathrm{~cm}$ in length $\left(\mathrm{L}_{\mathrm{u}}\right)$ (Leschinsky et al., 1995). However, selecting units that are too high may impose constraints on the vertical spacing between consecutive reinforcement layers.

Typical facing batter angles are $3^{\circ}$ to $15^{\circ}$ from vertical (wall batter angles are positive towards the infill). The connections may also assist in aligning the blocks and hold the geosynthetic reinforcement in place (Collin, 1996).

Segmental units also provide the following functions:

- Formework: The segmental units provide a construction formwork to place and compact soil in the zone immediately behind the units.

- Facing stability: Segmental units provide permanent local support to the vertical or near vertical soil mass behind the units to prevent soil from raveling out or eroding. Additionally, the segmental units protect the retained soil zone from erosion due to flowing water or scour from adjacent creek or streams.

- Aesthetics: Segmental units offer architectural treatment and appearance that can be integrated in the environment surrounding the segmental retaining wall. 

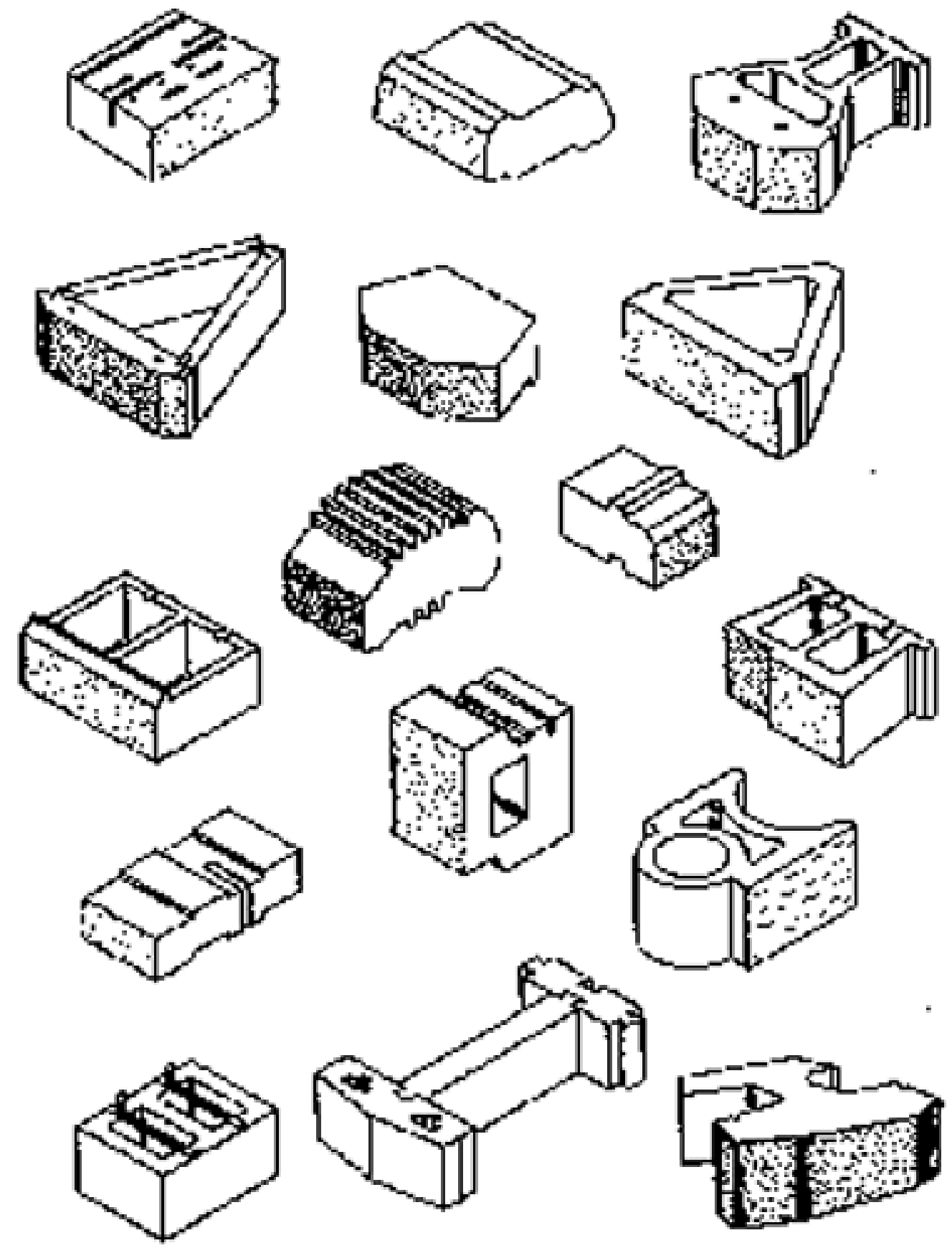

Figure 3.1. Examples of Commercially Available Segmental Units 
A concern with segmental concrete units is their potential for cracking. Potential sources of cracking are illustrated in Figure 3.2. According to Bathurst and Simac (1994), vertical cracking may occur due to tensile failure of the concrete or diagonal cracks may be generated by shear failure, particularly at the corners of the units. The source of cracking may be due to differential settlement of the foundation and/or construction-induced cracking. Potential sources of construction-induced cracking are: horizontal surface irregularities generated during casting; inadequate cleaning of the top surface of the units; and overfilling of hollow units. These problems can be overcome by strict attention to quality control during casting of the units and field construction. Also, achieving a level foundation pad is very important issue, since any irregularities in the base course of segmental block units will be carried up the height of the wall.

Durability of segmental concrete units under freeze-thaw cycles may also be a concern. The potential for segmental concrete degradation may be increased in presence of deicing chemical from snow clearing operations for walls below or otherwise in proximity to roadways. Waterproof coatings have been proposed for segmental units in these environments.

The types of wall facing units used in the walls control their aesthetics since they are the only visible parts of the completed structure. A wide range of finishes and colors are available with masonry blocks. In addition, the facing provides protection against backfill sloughing and erosion, and provides drainage paths. The type of facing units influences settlement tolerances. 


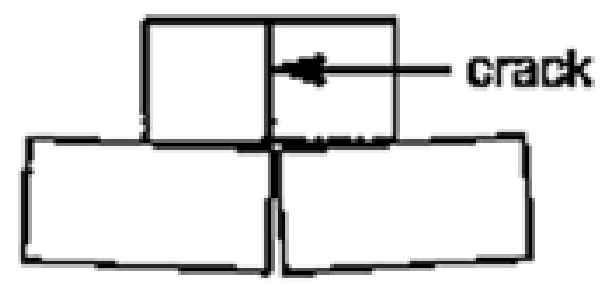

a) differential settlement at levclling pad

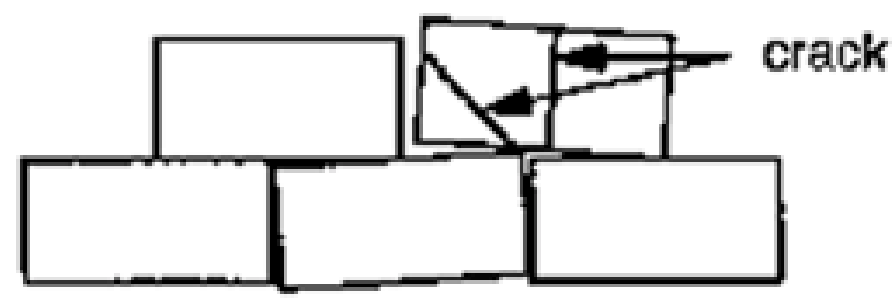

b) misalignmeat of modular units or uneven seating on levelling pad

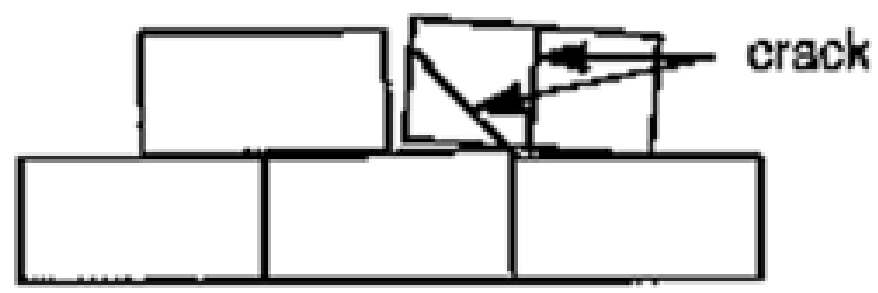

c) uneven modular unit dintensions

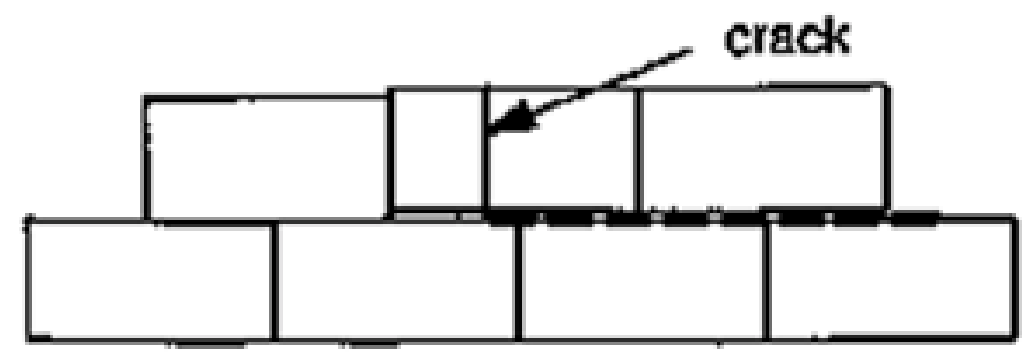

d) discuntinuous rainforcement layer inclusion

Figure 3.2. Sources of Segmental Block Cracking (from Bathurst and Simac, 1994) 


\subsection{Other Types of Facing Units}

In addition to the segmental facing units, other widely-used facing units are:

- Timber facing : Timbers have been successfully used as facing element, in particular by the Colorado Department of Transportation.

- Metallic facing : The original reinforced earth system had facing elements of galvanized steel sheet formed into half cylinders. Although precast concrete panels are now usually used in reinforced earth walls, metallic facings are still used in structures where difficult access or difficult handling requires lighter facing elements.

- Welded wire grids : Wire grid can be bent up at the front of the wall to form the wall face.

- Gabion facing : Gabion (rock-filled wire baskets) can be used as facing with reinforcing strips consisting of welded wire mesh, welded bar mats, polymer geogrids, or the double-twisted woven mesh used for gabion placed between the gabion baskets.

- Fabric facing : The geotextile reinforcement are wrapped around at the facing to form the exposed face of the retaining wall. These faces are susceptible to ultraviolet light degradation, vandalism (e.g. target practice) and damage due to fire.

- Plastic grids : The geogrid reinforcement can be wrapped around to form the face of the completed retaining structure in a similar manner to welded wire mesh and fabric facing. Vegetation can grow through the grid structure and can provide both ultraviolet light protection for the polymer and a pleasing appearance.

- Postconstruction facing : In cases of wrapped faced walls, whether geotextiles, geogrids, or wire mesh, an additional architectural facing can be placed after construction of the wall. Prefabricated facing panels made of concrete, wood, or masonry stones are typically used. 


\subsection{Connection Systems}

Connections between facing units and between the geosynthetic reinforcements and the units are needed to prevent slippage between these system components and to guarantee the facing stability.

The two common methods to create shear connections between successive vertical courses of segmental blocks are illustrated in Figure 3.3:

- Built-in mechanical concrete interlock: These wall units have a built-in mechanical interlock that is part of the segmental unit shape. Examples of this positive mechanical interlock are shear keys and leading/trailing lips.

- Flat interface: This type of wall unit develops shear capacity through interface friction.

In addition, the connection can be increased by using (Collin, 1995):

- Mechanical connectors: The specially manufactured connectors that link successive vertical courses of units together may be designed as a mechanical interlock to provide additional shear capacity, and are also used to assist with unit alignment and control the wall facing batter during wall construction. Examples of mechanical connectors are pins, clips, or wedges.

- Unit fill interlock: Wall unit cavities filled with drainage fill can develop significant shear resistance through soil to soil and soil to unit shear strength.

The connections between vertical course of facing blocks also serve as connections between the geosynthetic reinforcement layers and the facing. Current connection strength requirement by the AASHTO-AGC-ARTBA II Task Force 27 Joint Committee (1990) states that:

- Extensible reinforcement connection to the facing should be designed to carry $100 \%$ of the maximum design load at all levels within the wall. 

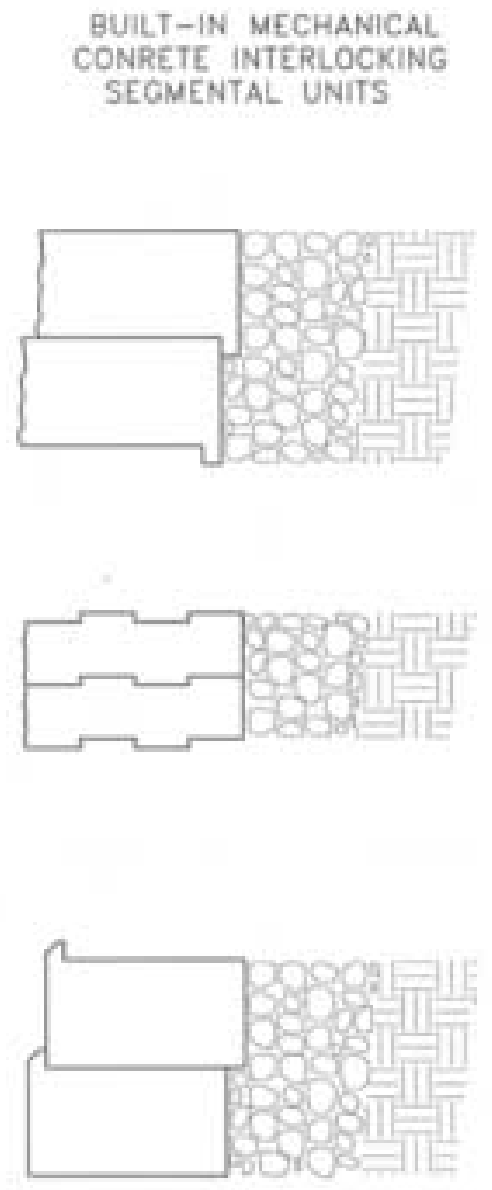

FLAT INTERFACE SEGMENTAL. UNITS
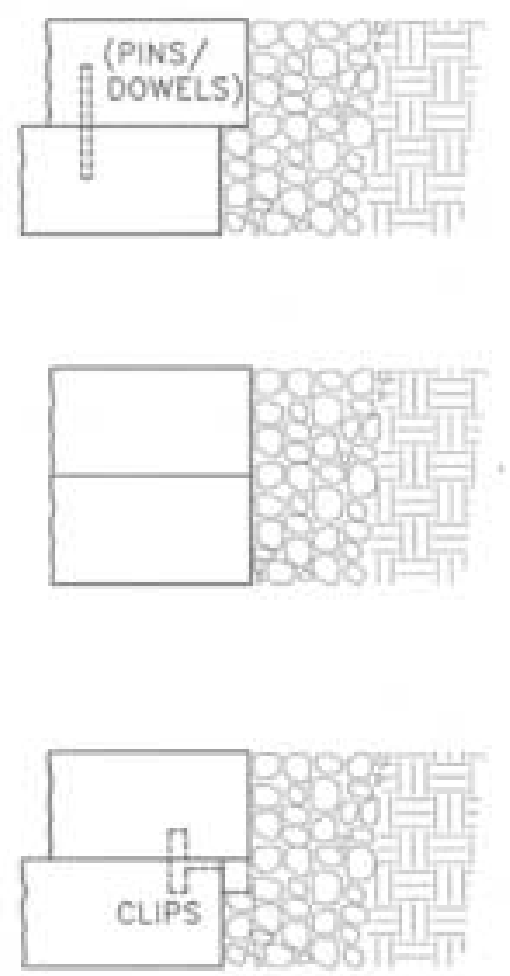

Figure 3.3. Shear Connector Types For Segmental Facing Units (from Collin, 1996) 
- A representative section of the connection type should be load-tested in order to determine the actual allowable connection-working load for the connection system.

- The allowable design strength of the reinforcement can not exceed that of the measured connection strength of the facing system.

- The load test shall be conducted on representative samples, which are at least $20 \mathrm{~cm}$ wide and tested at a rate of extension not exceeding $0.13 \mathrm{~cm}$ per minute.

Connections between geogrids and facing blocks were tested by Collin (1991). Their observations included the following prints:

- Segmental blocks with cavities where gravel or other soil material can be placed, appear to provide a greater mechanical connection strength than masonry blocks which have a solid configuration.

- Segmental block systems that include pin connectors provide more positive mechanical interlock when stiff geogrids are looped over the pins. This is particularly important during construction since little or no vertical overburden pressure is present at this stage.

- The stiff geogrids appeared to perform better than the more flexible geogrids.

- The pin connectors seemed to provide no added advantage when tested with flexible geogrid. This was due to the low junction strength between transverse and longitudinal elements of the flexible geogrids.

\subsection{Fill Material}

The soils within (i.e. structural fill) and behind (i.e. retained fill) a reinforced soil wall have a large influence on the design of the structure. The soil used as reinforced fill is a principal structural component of the system. The challenge is to select the soil, segmental unit and geosynthetic reinforcement to obtain compatibility between these system components and optimized design.

A potential economic advantage of Reinforced Soil is that on-site soils can often be used. This minimizes the costs associated with importing fill materials. Provided that 
groundwater condition is controlled properly, a wide variety of soil types can be considered for being used as reinforced fill material. The soil used in traditional reinforced soil wall systems is typically a good quality, well-graded, granular fill that possesses a high shear strength, is free draining, and can be compacted easily. Finegrained soils such as silt or clay can be a suitable alternative and are cost effective when no granular soil is available at the construction site or from a nearby borrow site. Tests performed in the laboratory on samples of reinforced clayey soil indicate that substantial improvement in strength and reduction in deformability can be obtained by including geosynthetics (Ingold, 1981, 1982, 1983). Similar improvements have been observed for reinforced clayey silt (Ashmawy and Bourdeau, 1997, Ashmawy et al., 1999). Use of fine-grained soil as reinforced fill has also been demonstrated for full-scale structures (e.g. Kharchafi and Dysli, 1994, Leshinsky and Smith, 1988). The application of reinforced clay is often limited to temporary structures because there is only little experience available and a lack of long-term performance data. When clay is used in reinforced soil, larger deformation than in granular fill must be anticipated. Furthermore, these deformations are time-dependent and require monitoring over a long period. Shortterm stability can be affected by excess pore pressure developed during construction and compaction of the fill. Investigations of failures of reinforced soil walls with clay fill suggest the shear strength of the reinforced fill can be strongly reduced after construction as a result of water infiltration and increase in water content (Burwash and Frost, 1991, Leonards et al., 1994).

According to the National Concrete Masonry Association (Collin, 1996), cohesionless free drainage materials (less than $10 \%$ fines) are preferred for segmental retaining walls. Soils with fines with low plasticity may also be used provided the following four additional design criteria are implemented:

- Proper internal drainage is installed.

- Only soils with low to moderate frost heave potential are utilized

- The internal cohesive shear strength parameter is conservatively ignored for stability analysis. 
- The final design is checked by a qualified geotechnical engineer to ensure that the use of cohesive soils does not result in unacceptable time-dependent deformation of the wall system.

For the soil types indicated by their USCS classification code (the most AASHTO classification is also indicated), their frost susceptibility is indicated in Table 3.1, according to Yoder and Witczak (1975) and Holtz and Kovacs (1981).

Table 3.1 Frost Suscpetibility of Soils

(NOTE: Organic soils and high plasticity clays are excluded for reinforced soil walls construction.)

\begin{tabular}{|l|l|}
\hline \multicolumn{1}{|c|}{ Frost Heave Potential } & \multicolumn{1}{|c|}{ Soil Types } \\
\hline High & ML (A-4,A-5), SM (A-2-4,A-2-5,A-2-7), \\
& SP-SM (A-2-4, A-2-5), SP with 15\% \\
& fines (A-2-4,A-2-5), CL with PI < 12 (A-4) \\
\hline Moderate & GM (A-1-b,A-2-4,A-2-5,A-2-7), GC (A-2- \\
& 6,A-2-7), SP (A-3,A-1-b), SC (A-2-6,A-2- \\
& 7), SC-SM (A-2-6,A-2-7), SW with > 15\% \\
& Fines (A-1-b), CL with PI > 12 (A-6) \\
\hline Low & GW (A-1-a), GP (A-1-a or A-1-b), GC (A- \\
& $2-6$ or A-2-7), SW with < 15\% fines (A-1- \\
& a) \\
\hline
\end{tabular}

The gradation requirements suggested by the NCMA (Collin, 1996) for reinforced fill material in segmental reinforced soil walls are shown in Table 3.2. The plasticity of the fine fraction (passing the \#200 sieve) should be less than 20.

Table 3.2 Gradation Range for Reinforced Fill Material in Segmented Reinforced Soil Walls Suggested by NCMA (Collin, 1996)

\begin{tabular}{|c|c|}
\hline Standard Sieve or Grain Size & Percent Passing or Small Than \\
\hline $20 \mathrm{~mm}$ & 100 \\
No. 4 & $100-20$ \\
No. 40 & $60-0$ \\
No. 200 & $35-0$ \\
\hline
\end{tabular}

The values of shear strength used for design computation should be determined from the results of direct shear tests (ASTM D3080, AASHTO T-236) for granular soils or standard triaxial compression tests (ASTM D 4767, AASHTO T-234) for granular and cohesive soils carried out using normal pressures that are representative of site condition. 
In the absence of project specific soils testing, the shear strength parameters may be estimated for preliminary design purposes. Typical peak shear strength values for variety of compacted soils are given in Table 3.3.

Table 3.3. Summary of friction angle data for use in preliminary design (Collin, 1996)

\begin{tabular}{|c|c|}
\hline Classification & Friction Angle \\
\hline Silt (nonplastic) & $26-30^{\circ}$ \\
\hline Uniform Fine to Medium Sand & $26-30^{\circ}$ \\
\hline Well-Graded Sand & $30-34^{\circ}$ \\
\hline Sand and Medium Gravel & $32-36^{\circ}$ \\
\hline
\end{tabular}

\subsection{Fill Compaction (Collin, 1996)}

Soil fills are compacted during retaining wall construction to ensure maximum soil shear strength and stiffness. Usually the degree of compaction is stated in the construction specification, typically at 95\% of maximum standard proctor (ASTM D 698, AASHTO T-99) or 90\% of maximum modified proctor (ASTM D 1557, AASHTO T180) density. The most effective compaction equipment and procedures to meet specifications are dictated by soil type.

\subsubsection{Compaction equipment}

Generally, for granular soils, the most effective compaction method is vibration. Vibratory compactors consist of drum rollers and steel plates that oscillate at a high frequency as they pass over soil layers. The grain size distribution and particle shape will greatly affect the in-place density that can be achieved.

For cohesive soils, the kneading type of compaction equipment using sheepsfoot or pneumatic-tired rollers is most effective. The key to achieving good compaction in cohesive soils is proper control of the water content $w$ during placement. Care must be exercised during use of this equipment to minimize and/or eliminate potential damage of geosynthetic reinforcement during construction. 


\subsubsection{Compaction control}

The maximum dry unit weight that is achievable in the field for a given compactive effort is controlled by the moisture content of the soil. The relationship between soil density, moisture content and compactive effort for a given soil type has been standardized based in ASTM/AASHTO methods of test. The standard Proctor and modified Proctor tests use different compactive energy to determine the optimum moisture content $w_{\text {opt }}(\%)$ required to achieve maximum dry unit weight $\left(\gamma_{\mathrm{d}}\right)$ of the compacted fill.

The influence of compactive effort and soil type is shown in Figure 3.4. The figure also illustrates that soils compacted on the wet side of optimum tend to approach the 100 percent saturation limit, whereby all available air voids are filled with water.

If the water content at the time of placement is greater than this 100 percent saturation limit, compaction will not be achieved regardless of the amount of compacted energy utilized, (e.g. pumping will occur.). If soil density is to be achieved by further compaction, the soils should be maintained within $+1 \%$ to $-3 \%$ of the optimum placement water content $w_{\text {opt }}$. Compaction specification dictate that the measured dry unit weight of the fill be a minimum percentage of the maximum density determined from one of the methods of test identified above. Compaction to the specified dry unit weight is critical to achieve the desired shear strength properties of the fill. Retaining wall design and performance are based on the minimum peak internal friction angle, as measured during laboratory testing, being available in the fill materials. Insufficient compaction may lead to less shear strength and result in unsafe retaining wall performance. Additionally, poorly compacted soils may creep over the time with water infiltration and, lead to unacceptable deformation. 


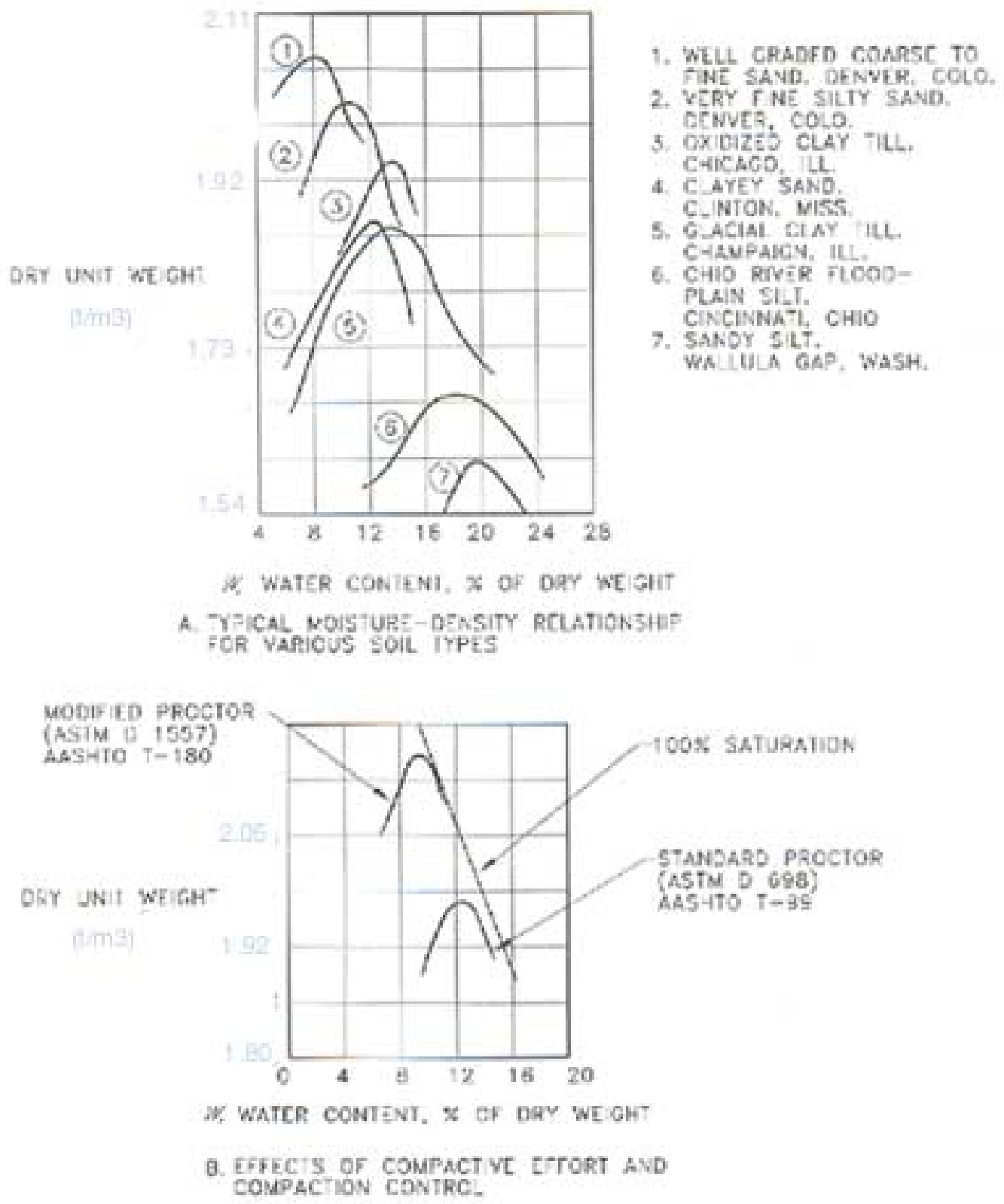

1

Figure 3.4. Moisture-Density Relationships for Soils (from Peck, Hanson and Thornburn, 1974) 


\subsection{Drainage}

Engineered drainage materials are an important part of reinforced soil walls. Drainage materials are generally well-graded aggregates (such as coarse sands and gravel (GW/SW). The drainage fill is often separated from the finer-grained reinforced fill by a geotextile and contains a drainage pipe to direct accumulated water away from the structure. A properly designed drainage system will have the following functions (Collin, 1996):

- Prevent the build up of pore water pressures in the retained soils and foundation soils in the vicinity of the wall toe.

- Prevent retained soils from washing through the face of the wall.

- Provide a stiff leveling pad to support the column of stacked facing units and provide a working surface for starting construction.

Many retaining wall failures are caused by poor drainage. Poor drainage leads to development of hydrostatic pressure or seepage forces in the retained soils that in turn generate additional destabilizing forces on the wall system and can reduce shear strength of the soil.

Segmental RSRWs should be constructed with provision for good drainage. A drainage layer comprising a coarse single size stone is routinely recommended behind the segmental units. Because of the shape of the segmental units and small gaps between adjoining units, a geotextile is recommended to prevent loss of materials through the facing. In addition, a geotextile may be required to act a separator between the reinforced soil zone and the drainage column behind the facing units. The drainage column should be integrated with a drainage layer at the base of the structure. A gravity flow geotextilewrapped pipe connected to outlets that direct water away from the foundation should be

used. The use of drainage swales behind the wall and appropriate surface grading behind the wall crest should be used to ensure that surface water is prevented from infiltrating the reinforced soil mass. (Bathurst and Simac, 1994)

Drainage fill materials should be selected to provide the following: 
- Sufficient permeability and cross-sectional area to carry anticipated flows.

- Filtration of fine-grained soil to prevent clogging of the aggregate drainage medium if a geotextile filter is not used.

Three strategies to prevent the infiltration of groundwater in s retaining wall structure are summarized below.

Case 1: Groundwater table remains a distance $0.66 \mathrm{H}$ below the base of the leveling pad elevation for the design life of the structure.

Case 2: Groundwater table rises to or remains just below the leveling pad elevation during the design life of the structure.

Case 3: Permanent or intermittent groundwater is present in the retained soils above the leveling pad elevation.

These 3 cases are represented in Figures 3.5, 3.6 and 3.7, respectively. 


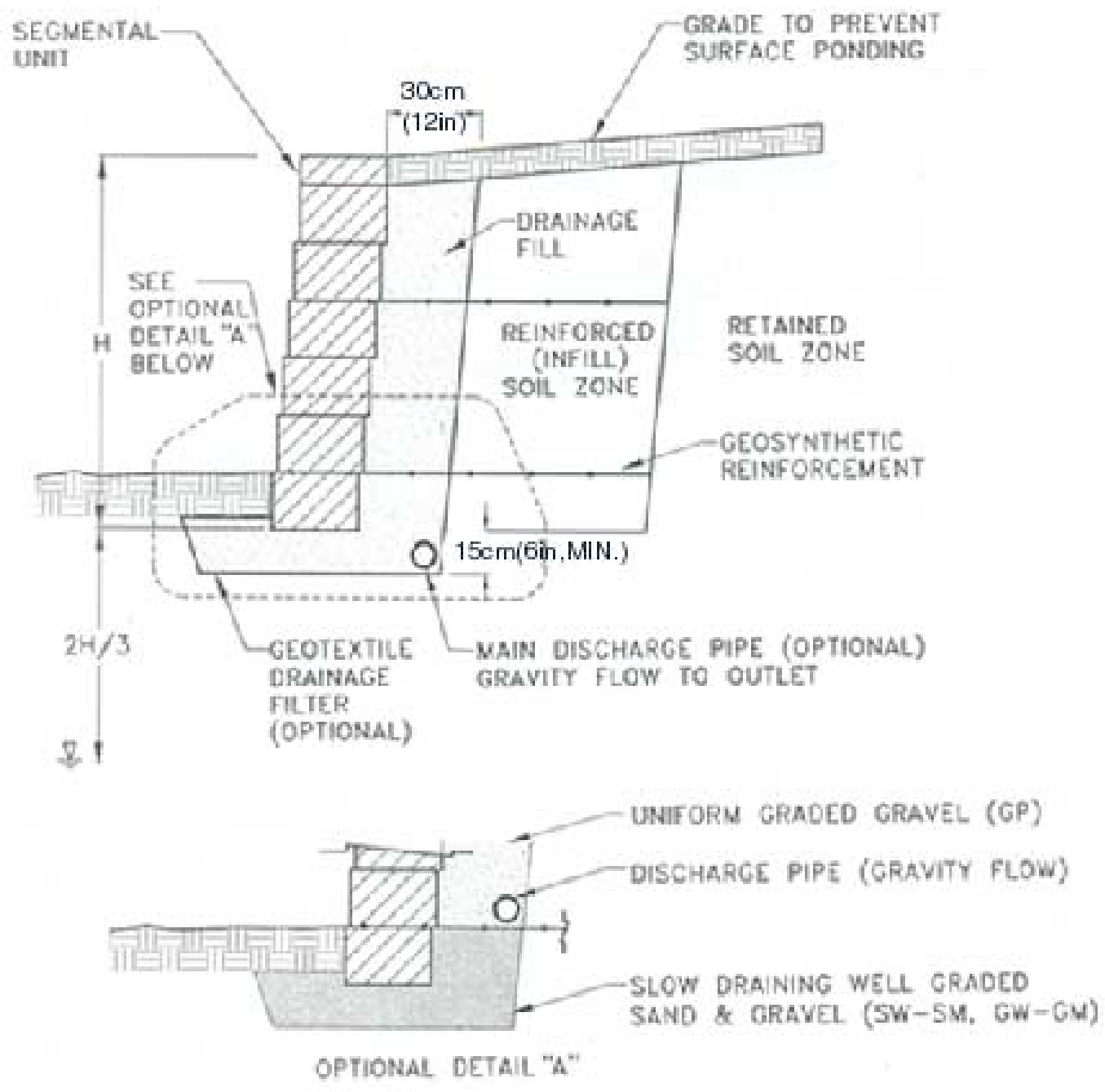

Figure 3.5 Wall Face Drain (Case 1) (Collin, 1996) 


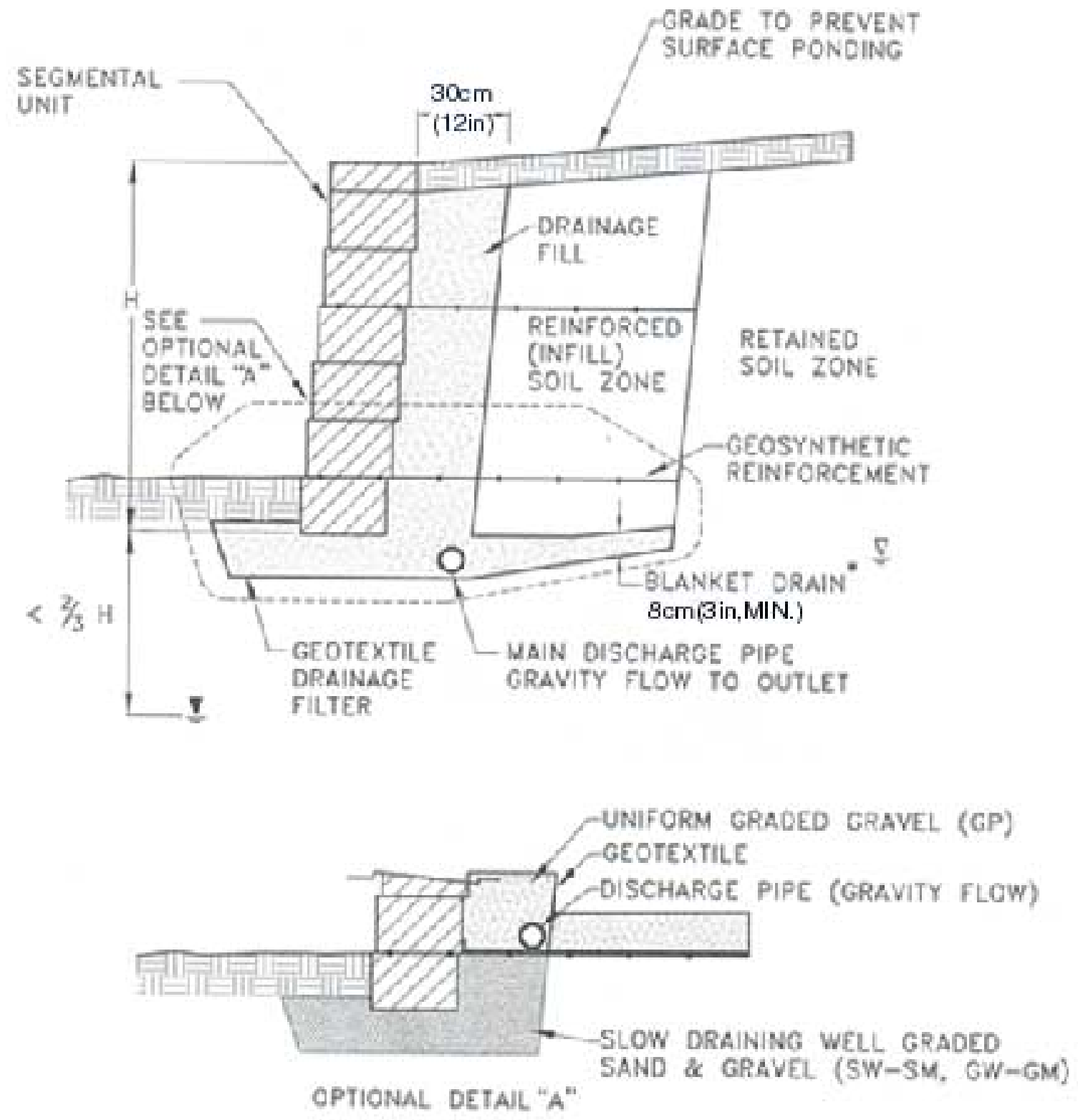

Figure 3.6 Wall Face and Blanket Drain (Case 2) (Collin, 1996) 


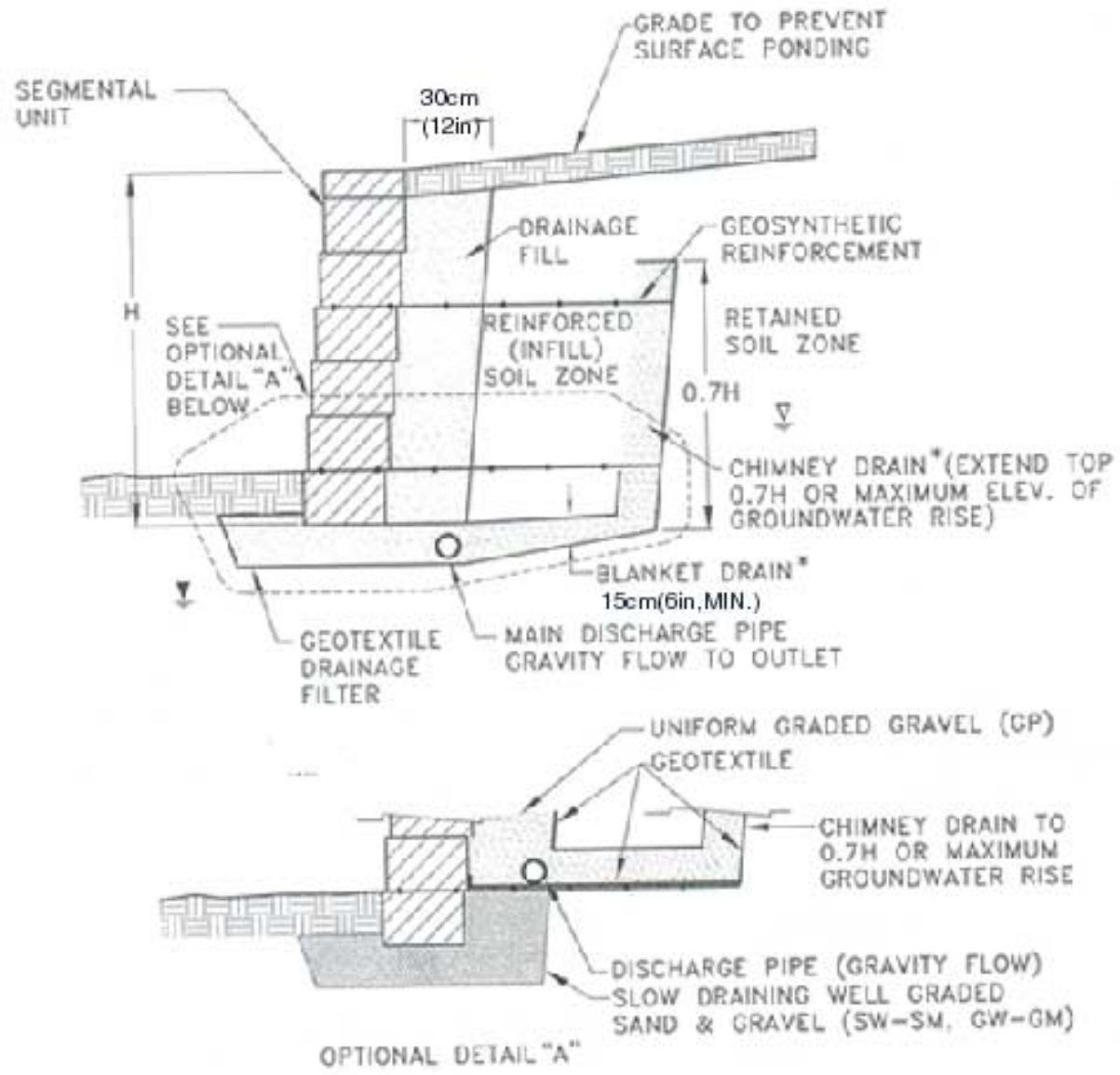

Figure 3.7 Complete Drainage System (Case 3) (Collin, 1996) 


\section{Soil and Site Exploration}

The feasibility of using a reinforced soil retaining structure or any other type of earth retention system depends on the existing topography, subsurface conditions, and soil/rock properties. It is necessary to perform a comprehensive subsurface exploration program to evaluate site stability, settlement potential, need for drainage, etc., before designing a new retaining wall or bridge abutment.

Subsurface investigations are required not only in the area of the construction but also $\mathrm{n}$ neighboring areas which may affect the stability of the excavation before the reinforced soil structure is installed. The subsurface exploration program should be oriented not only towards obtaining all the information which could influence the design and the stability of the final structure, but also to the conditions which prevail throughout the construction of the reinforced soil structure.

The engineer's concerns include the bearing capacity of the foundation soils, the deformations due to total and differential settlement, and the stability of the retained earth. Necessary parameters for these analyses must be obtained.

The cost of a reinforced soil structure is dependent greatly in the availability of the required type of backfill materials. Investigations must therefore be conducted to locate and test locally available materials which may be used for structural fill and backfill with the selected system.

\subsection{Field Reconnaissance}

Preliminary subsurface investigation or reconnaissance should consist of collecting any existing data relating to subsurface conditions and making a field visit in order to collect the following information:

- Limits and intervals for topographic cross sections.

- Access conditions for work forces and equipment.

- Surface drainage patterns, seepage, and vegetation characteristics.

- Surface geologic features including rock outcrops and landforms, and existing cuts or excavations which may provide information in subsurface conditions. 
- The extent, nature, and locations of existing or proposed below grade utilities and substrutures which may have an impact in the exploration or subsequent construction.

- Available right-of-way.

- Areas of potential instability such as deep deposits of organic soils, slide debris, areas of high ground water table, bedrock outcrops, etc.

Reconnaissance should be performed by a geotechnical engineer or by an engineering geologist. Before the start of field exploration, any data available from previous subsurface investigations at or near the site and those which can be inferred from geologic maps of the area should be studied. Topographic maps and aerial photographs, if available, should be studied. Such documents can reveal the existence of unstable ground, sinkholes, waste fill, etc.

\subsection{Subsurface Exploration}

The purpose of the investigation is to identify the soil and groundwater conditions, assess the overall stability, the bearing capacity and the settlements anticipated for the projected structure. There is no difference between the site exploration requirements of a low-cost reinforced soil wall and the exploration required for other types of reinforced soil walls or any type of retaining wall.

The subsurface exploration program generally consists of soil soundings, borings, test pits, and indirect methods including geotechnical exploration techniques such as seismic refraction, electrical resistivity, or other special tests. The type and extent of the exploration should be decided after review of the preliminary data obtained from the field reconnaissance, consultation with a geotechnical engineer, or an engineering geologist. In any event, the exploration must be sufficient to evaluate the geologic and subsurface profile in the area of construction.

The following minimum guidelines are suggested for the subsurface exploration:

- Soil borings should be performed at intervals of: 
- $30 \mathrm{~m}$ along the alignment of the wall.

- $30 \mathrm{~m}$ along the back of the reinforced section of the wall.

- $30 \mathrm{~m}$ in the area in front of the wall.

and be distributed over an area, at least $125 \%$ the area covered by the wall or embankment.

The width of the reinforced soil wall may be assumed as 0.8 times the anticipated height. For wall heights in excess of $15 \mathrm{~m}$, the back borings should be spaced at $30 \mathrm{~m}$ intervals, and, in addition, another row of borings should be performed along the midpoint between the face of the wall and the back if the reinforcement, at intervals of about $46 \mathrm{~m}$.

- The boring depth should be controlled by the general subsurface conditions. Where bedrock is encountered within a reasonable depth, rock cores should be obtained for a length of about $3 \mathrm{~m}$. This coring will be useful to distinguish between solid rock and boulders. Deeper coring may be necessary to better characterize rock slopes behind new retaining structures. In areas of soil profile, the borings should extend at least to a depth equal to twice the height of the wall. If subsoil conditions within this depth are found to be weak and unsuitable for the anticipated pressures from the wall height, or for providing an adequate medium for anchorage of soil nails in case of an in-situ reinforced soil, then the borings must be extended until reasonable soils are encountered.

- In each boring, soil sample should be obtained at $1.5 \mathrm{~m}$ depth intervals and at changes in strata for visual identification, classification, and laboratory testing. Methods of sampling may follow ASTM D-1586 or D-1587 (SPT and Thin-Walled Shelby Tube Sampling, respectively), depending on the type of soil. In granular soils, the SPT can be used to obtain disturbed samples. In cohesive soils, undisturbed samples should be obtained by thin-walled sampling procedures. In each boring, careful observation should be made for the prevailing water table, which should be observed not only at the time of sampling, but also at later ties to get a good record of prevailing water 
table conditions. If necessary, piezometers should be installed in a few borings to observe long-term water levels.

- Both the SPT and the CPT data can be used to assess the strength and density of granular soils through empirical correlations published in the literature are developed using local or regional databases. In some situations, it may be desirable to perform in-situ tests using a dilatometer, pressuremeter, or similar means to determine soil modulus values.

- Adequate bulk samples of available soils should be obtained and evaluated as indicated in the following testing section to determine the suitability of the soil for use as backfill in the reinforced soil wall. Such materials should be obtained from all areas from which preliminary reconnaissance indicates that borrow materials will be used.

- Test pit explorations should be performed in area showing instability or to explore further availability of the borrow materials for backfill. The locations and number of test pits should be decided for each specific site, based in the preliminary reconnaissance data.

\subsection{Testing}

Each soil sample should be visually examined and appropriate tests performed to allow the soils to be classified according to the Unified Soil Classification System (ASTM D-2488-69). A series of index property tests are sometimes performed which further aid in classification of the materials into categories and permit the engineer to decide what further field or laboratory tests will best describe the engineering behavior of the soil at a given project site. The index testing includes determination of moisture content, Atterberg limits, compressive strength, and gradation. The dry unit weight of representative undisturbed samples of cohesive soils should also be determined. 
Shear strength determination by unconfined compression tests, direct shear tests, or triaxial compression tests will be needed for external stability and bearing capacity analyses of reinforced soil walls. Both undrained and drained (effective stress) parameters should be obtained for cohesive soils. At sites where fine-grained soils are encountered below the foundations of the reinforced soil structure, it is necessary to perform consolidation tests to obtain compressibility parameters needed for settlement analyses.

All samples of rock recovered in the field exploration should be examined in the laboratory to make an engineering classification including rock type, joint spacing ad orientation, stratification, location of fissures, joints and discontinuities and strength. Representative cores should be tested for compressive strength. Any joint fill materials recovered from the cores should be tested to evaluate their effect on potential failure along the weakened planes. Determined field investigation by an engineering geologist is advisable if rock stability is important at the site.

Of particular significance in the evaluation of any material for possible use as backfill are the grain size distribution and plasticity. Laboratory permeability tests should be performed on representative samples compacted to the specified density. Additional testing should include direct shear tests on a few similarly prepared samples to determine shear strength parameters under long-term and shot-term conditions. Triaxial tests are also appropriate for this purpose. The compaction behavior of potential fill materials should be investigated by performing laboratory compaction tests according to AASHTO standards.

Properties to indicate the potential corrosiveness of the fill material must be measured. Tests include:

- $\mathrm{pH}$

- Electrical resistivity

- Salt content including sulfate, sulfide, and chlorides

- Oxidation agents such as containing $\mathrm{Fe}_{2} \mathrm{SO}_{4}$, calcareous soils, and acid sulfate soils. 
The test results will provide necessary information for planning corrosion protection measures and help in the selection of reinforcement elements with adequate durability. 


\section{Construction}

Long-term structural performance of segmental retaining walls is directly influenced by the construction procedures. Following is a summary of construction procedures recommended for segmental retaining walls.

\subsection{Procedures}

According to the guidelines of the National Concrete Masonry Association (Collin, 1996) segmental retaining walls should be constructed by following the five main stages described below.

\subsubsection{Wall excavation and leveling pad construction (Figs. 5.1 and 5.2)}
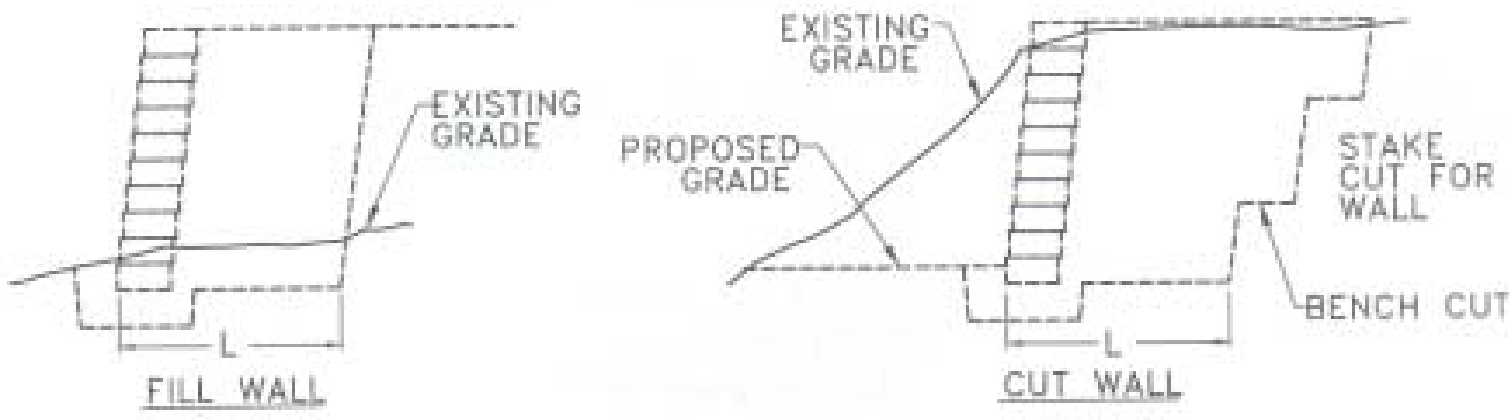

Figure 5.1 Wall layout and excavation

(a) Survey SRW location and excavation limits for wall construction.

(b) Ensure SRW is along proper alignment, and within proper property boundaries, and construction easiness.

(c) Perform general excavation for wall. 


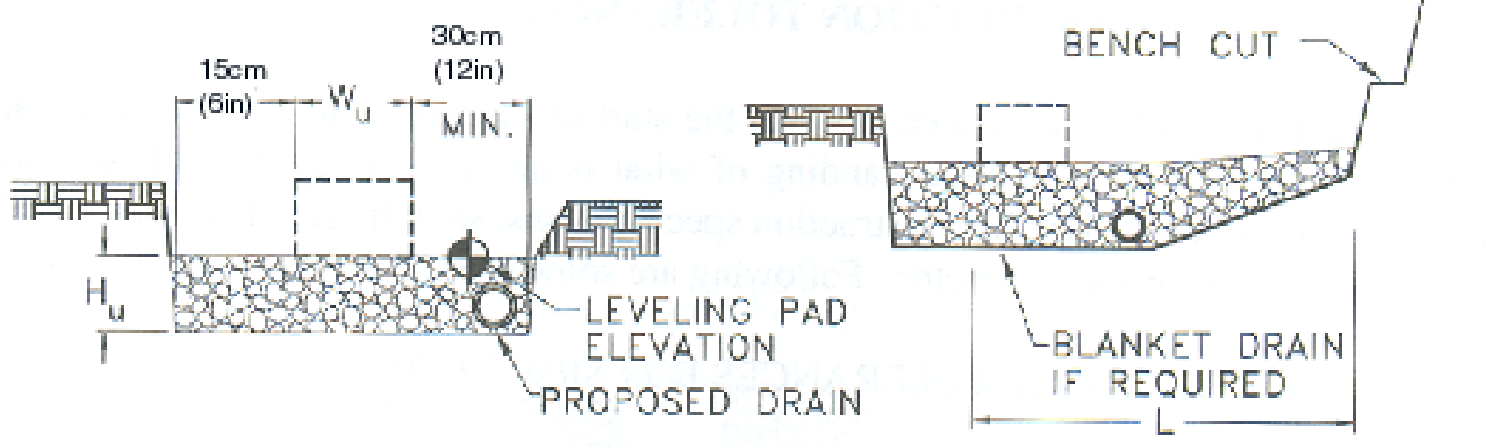

Figure 5.2 Leveling pad construction

(a) Stake wall location for leveling pad excavation.

(b) Excavate trench to create a minimum leveling pad thickness of 6" and to the minimum width shown.

(c) Install drain pipe with positive gravity flow to outlet.

(d) Place, level and compact leveling pad material for SRW units.

(e) Place and compact aggregate blanket drain, install geotextile if required.

\subsubsection{Setting, leveling and backfilling the first course of facing units (Figs. 5.3 and} 5.4)

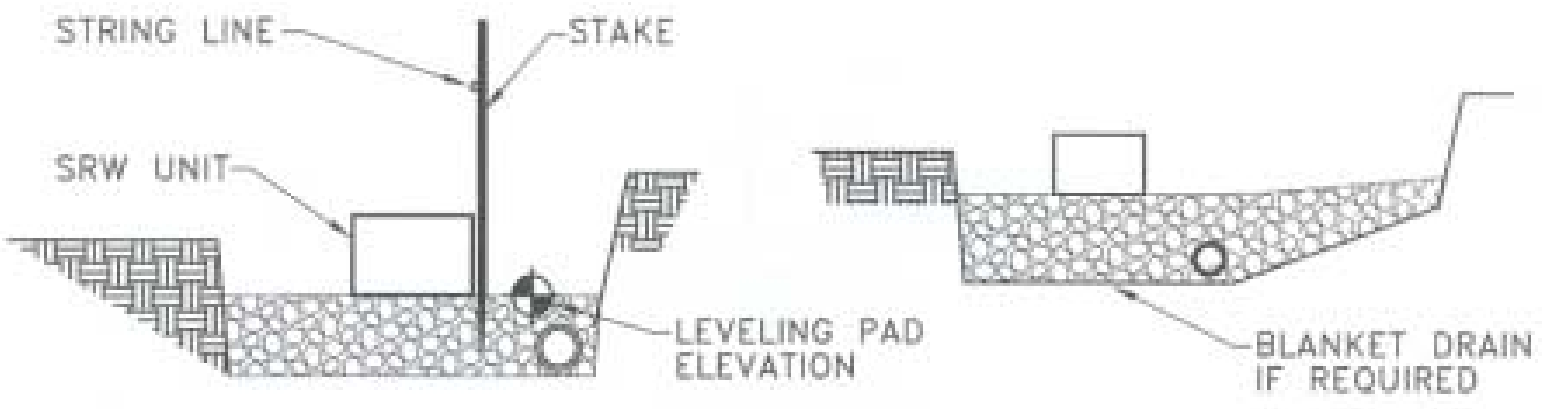

Figure 5.3 Setting first course of SRW units. 
(a) Check leveling pad elevation and smooth leveling pad surface.

(b) Stake and stringline the wall location, pay careful attention to exact location of curves, corners, vertical and horizontal steps, string line must be along a molded face of the SRW unit, and not along a broken block finish surface.

(c) Install first course of SRW units, checking level as placed.

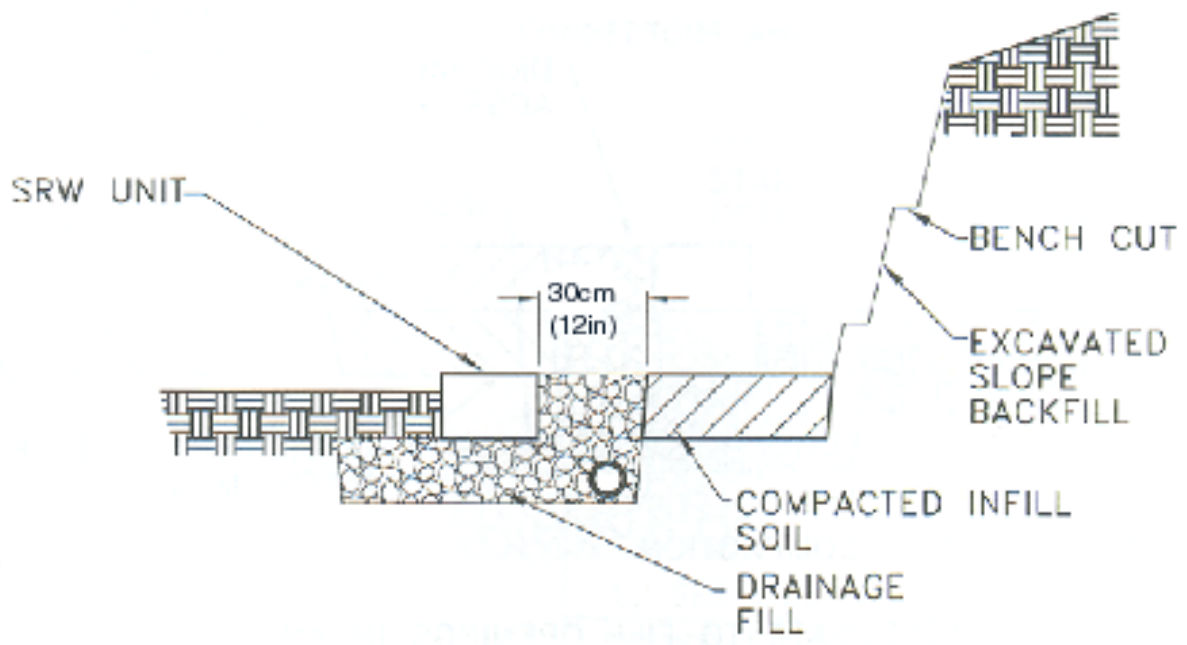

Figure 5.4 Backing first course of SRW units.

(a) Recheck wall location.

(b) Use drainage fill to fill any openings in and between SRW units.

(c) Carefully place drainage fill behind and up to the height of SRW unit to create wall face drain. (Install geotextile filter, if required.)

(d) Place and compact infill soil behind wall drain.

(e) Place fill soil in front of SRW unit.

(f) Compact drainage fill and infill soil. 


\subsubsection{Placement and backfilling of facing units (Figs. 5.5 and 5.6)}

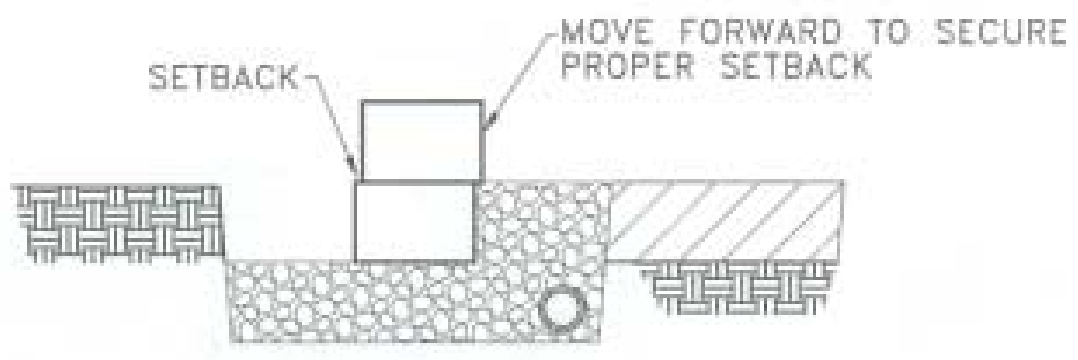

Figure 5.5 Installing successive courses of SRW units.

(a) Ensure that the drainage aggregate is level with, or slightly below the top of SRW unit below.

(b) Clean debris off top of unit.

(c) Place SRW unit shear connectors if applicable.

(d) Move SRW unit to engage shear connectors and establish proper setback, consistent with manufacturer's recommendations.

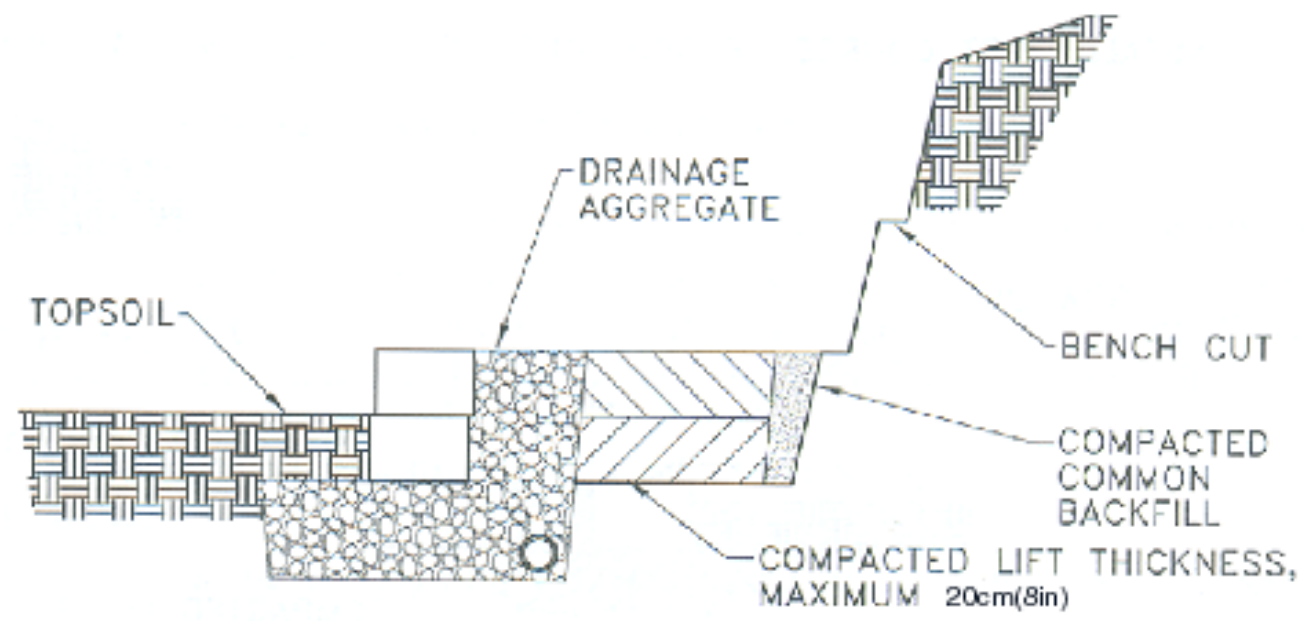

Figure 5.6 Fill placement and compaction.

(a) Use drainage aggregate to fill opening in and between SRW units.

(b) Place drainage aggregate behind and up to height of SRW unit to continue wall face drain. Install geotextile filter, if required.

(c) Place and compact infill soil behind wall drain.

(d) Compact drainage aggregate and infill soil. 


\subsubsection{Placement, tensioning and backfilling of geosynthetic reinforcement (Figs.}

5.7 and 5.8)

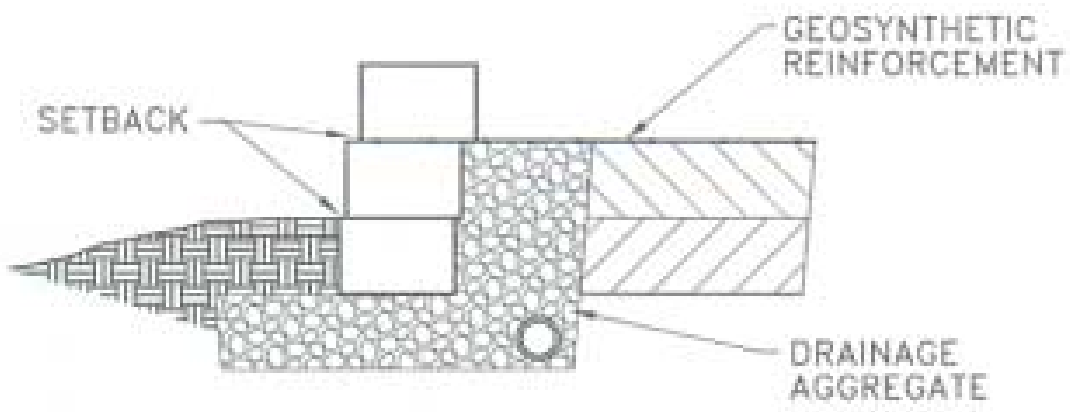

Figure 5.7 Placement of geosynthetic reinforcement.

(a) Ensure wall face drainage aggregate is level with, or slightly above the top of SRW unit.

(b) Clean debris off top of unit.

(c) Cut geosynthetic reinforcement to design length $\mathrm{L}$ as shown on plans and install with strength direction perpendicular to wall face.

(d) Place SRW unit on top of geosynthetic.

(e) Move SRW unit to enlarge shear connectors and establish proper setback.

Notes:

1. Sequence of backfilling steps may vary and are dependent on type of SRW unit and geosynthetic reinforcement used.

2. Alignment of stright walls should be checked every other course.

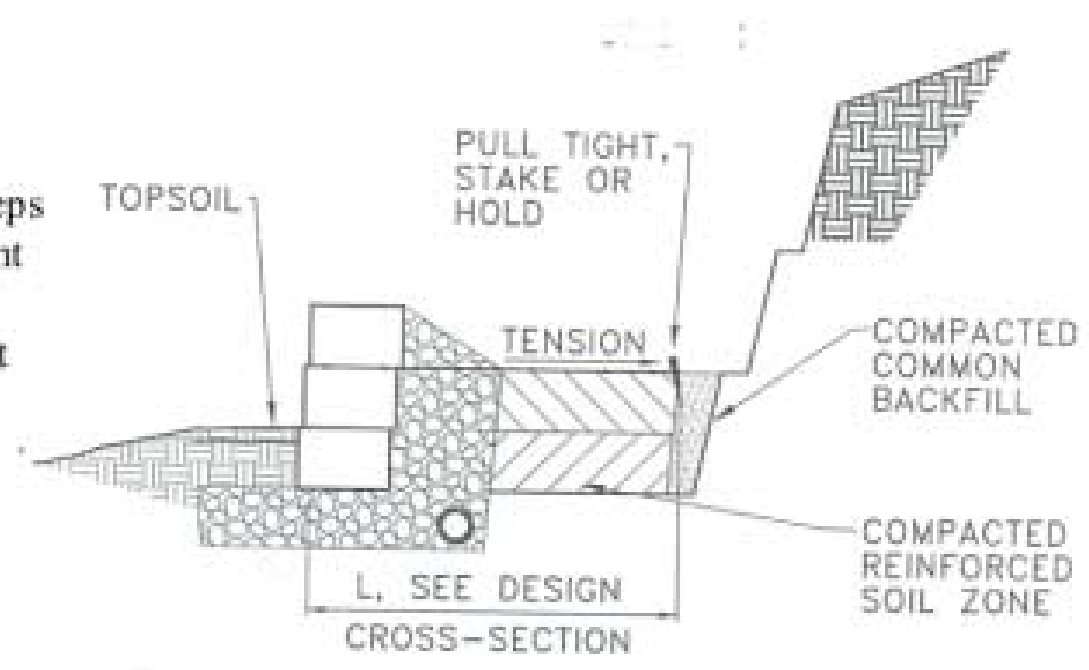

Figure 5.8 Backfilling over geosynthetic reinforcement. 
(a) Pull geosynthetic reinforcement taut, using uniform tension, hold or stake to maintain tension throughout fill placement process.

(b) Place drainage aggregate for wall face drain in and between SRW units as required.

(c) Place infill soil.

(d) Compact infill soil.

(e) Compact drainage aggregate.

(f) Place remainder of aggregate drain.

\subsubsection{Capping the wall and finish grading (Fig. 5.9)}

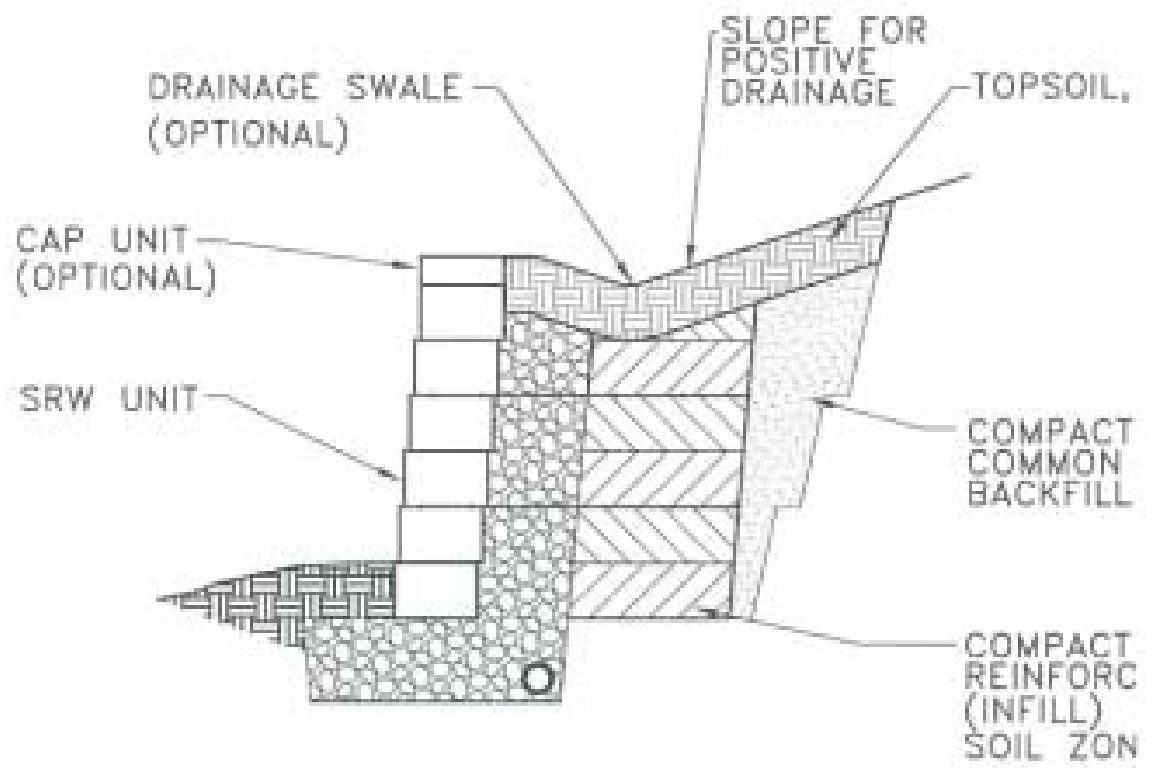

Figure 5.9 Completed reinforced SRW

(a) Continue wall to full height.

(b) Install SRW cap/coping unit (optional). Secure per manufacture recommendations.

(c) Place and compact final backfill.

(d) Finish grade for positive drainage away from wall face, drainage swale is optional.

(e) Place topsoil and vegetate slopes above and around wall terminations. 


\subsection{Construction guidelines}

The following guidelines should be followed when constructing a segmental reinforced retaining wall:

- It is recommended the leveling pad beneath the wall units be constructed of drainage fill or sand. An advantage of using drainage fill is that it is free draining and allows placement of the drain pipe in the lower, inward corner of the pad. Caution should be exercised in leveling the drainage fill to ensure intimate contact between the units and aggregate. A sand material is easier to level and ensure intimate contact with wall units. The sand should be a free draining material and be in contact with a geotextile wrapped discharge pipe. The drain fill above a sand bearing pad may be more permeable which could result in water flowing out the face of the wall. A designer or a contractor may opt to use an unreinforced concrete leveling pad on some projects when the foundation soil is relatively incompressible and not susceptible to significant shrinkage and swell due to moisture change. Use of unreinforced concrete should be limited to sites with firm foundations. The potential disadvantages of using unreinforeced concrete for the leveling pad are difficulty in layout of vertical and horizontal steps; maintaining intimate contact between the leveling pad and wall unit; and a lack of flexibility.

- Walls with curves along their length require that the leveling pad be poured to the proper radius. In general, a curve radius of $3 \mathrm{~m}$ or greater is not a problem; however, tight curves of 1 to $2 \mathrm{~m}$ radius require special consideration. In some cases, field modification of the blocks may be necessary for tight curves.

- The blocks should be laid from one end of the wall to the other to preclude laborious block cutting and fitting in the middle. When curves are involved in a wall, the blocks on the curves should be laid first as their alignment is more critical and less forgiving. Tight curves often require cutting block to fit or breaking off the block tail.

- When shear pins are used, they should be tapped into well-seated position immediately after setting each block to avoid getting fill into the block's pin holes. 
- Leveling of the first course of blocks is especially important for wall alignment. A string line set over the pins from one end of the wall to the other will help leveling the blocks.

- Geosynthetic reinforcement should be placed up to front of the blocks to ensure maximum interface contact with the blocks.

- After front of the geosynthetic reinforcement is properly secured, the reinforcement should be pulled tight and pre-tensioned while the backfill is being placed.

- Care should be exercised when placing backfill over geosynthetic reinforcement. The backfill should be emplaced from the wall face to the back of the wall to ensure that no slack is left in the reinforcement.

- To avoid movement of blocks during construction, a hand-operated tamper should be used to compact the soil within $1 \mathrm{~m}$ of the wall face, and no construction vehicles is allowed within the $1 \mathrm{~m}$ region. 


\section{Design Methods}

Two design methods are presented in this section. The first one is recommended by the National Concrete Masonry Association and is tailored to segmental facing reinforced soil walls. The second method is recommended by the Federal Highway Administration and is of more general applicability to a broad range of reinforced soil wall types and reinforcement materials.

\subsection{Input Information for Design Methods}

\subsubsection{Geometry}

The retaining wall design starts with the known geometry.

$$
\begin{array}{ll}
\mathrm{H} & \text { Total height to be design }(\mathrm{m}) \\
\mathrm{H}^{\prime} & \text { Exposed height of wall }(\mathrm{m}) \\
\mathrm{H}_{\mathrm{emb}} & \text { Wall embedment }(\mathrm{m}) \\
\beta & \text { Backslope angle (deg.) } \\
\mathrm{q}_{\mathrm{d}} & \text { Dead load surcharge }\left(\mathrm{t} / \mathrm{m}^{2}\right) \\
\mathrm{q}_{1} & \text { Live load surcharge }\left(\mathrm{t} / \mathrm{m}^{2}\right) \\
\mathrm{Z} & \text { Distance to the start of the slope }(\mathrm{m})
\end{array}
$$

Reinforced soil retaining wall and soil zones are illustrated in Figure 6.1.

\subsubsection{Materials}

\subsubsection{Segmental Units}
$\mathrm{H}_{\mathrm{u}} \quad$ Unit Height (m)
$\mathrm{W}_{\mathrm{u}} \quad$ Unit width $(\mathrm{m})$
$\mathrm{G}_{\mathrm{u}} \quad$ Center of gravity referenced from face (m)
$\omega \quad$ Unit inclination due to segmental unit setback $\left(\Delta_{\mathrm{u}}\right)$ per course (deg.) 


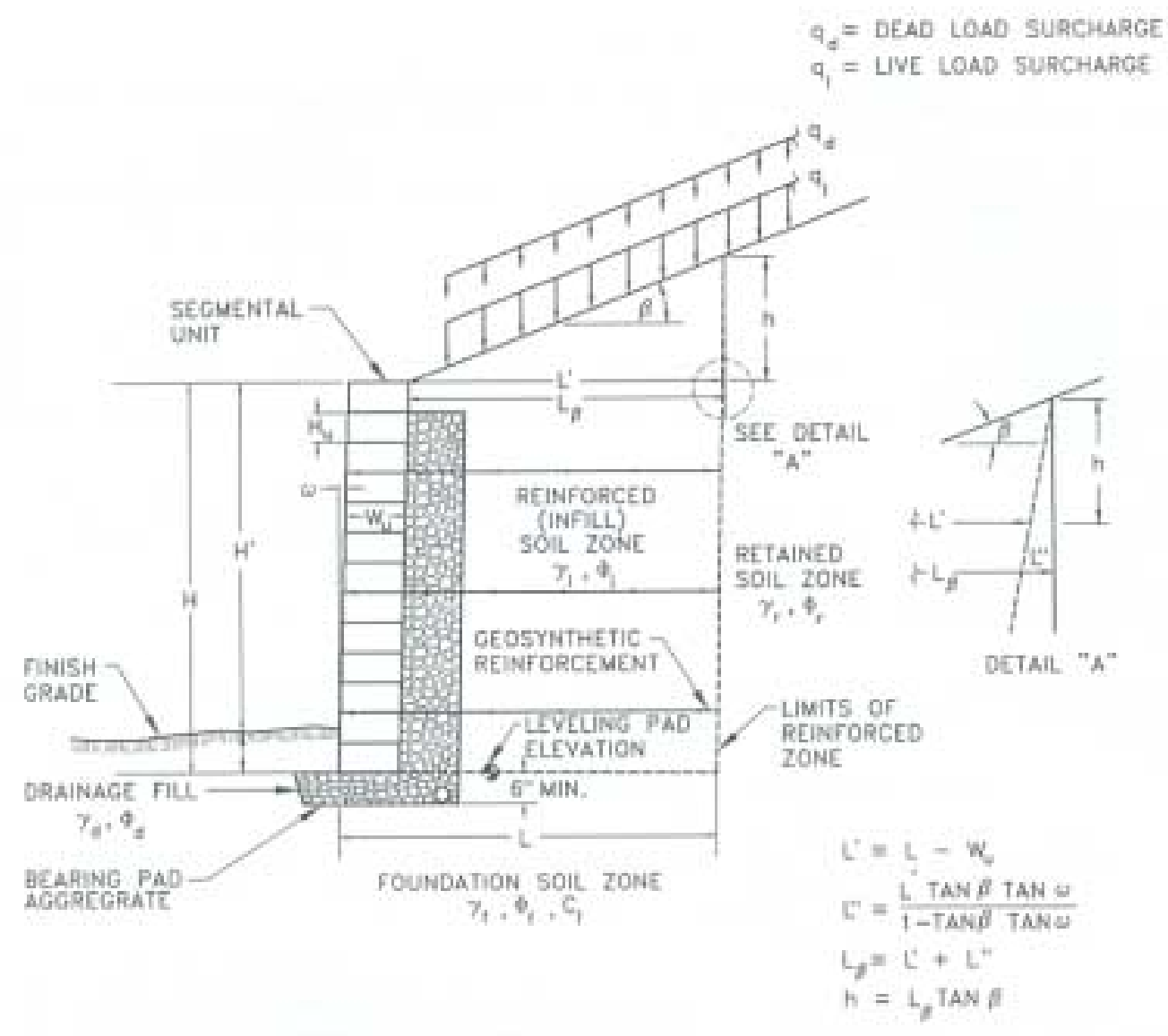

Figure 6.1. Retaining wall geometry 

$\Delta_{\mathrm{u}} \quad$ Set back per course (m)
$\gamma_{u} \quad$ Unit weight of block (core filled if applicable, $\mathrm{t} / \mathrm{m}$ )
$\mathrm{a}_{\mathrm{u}} \quad$ Minimum shear capacity between two units $(\mathrm{t} / \mathrm{m})$
$\lambda_{\mathrm{u}} \quad$ Friction angle of the shear capacity between two units (deg.)
$\mathrm{V}_{\text {umax }}$ Maximum shear developed between two units $(\mathrm{t} / \mathrm{m})$
$\mu_{\mathrm{b}} \quad$ Interface friction coefficient for base segmental unit sliding on bearing soil
๘ Wall inclination off vertical clockwise positive (deg.)

\subsubsection{Geosynthetic reinforcement}
$\mathrm{T}_{\mathrm{a}} \quad$ Allowable tensile capacity of geosynthetic ( $\left.\mathrm{t} / \mathrm{m}\right)$
$\mathrm{T}_{\text {ult }} \quad$ Ultimate tensile capacity of geosynthetic $(\mathrm{t} / \mathrm{m})$
$\mathrm{RF}_{\mathrm{d}} \quad$ Reduction factor for durability (Min. 1.10)
$\mathrm{RF}_{\text {id }} \quad$ Reduction factor for installation damage (Min. 1.10)
$\mathrm{RF}_{\mathrm{cr}} \quad$ Reduction factor for creep
FS Factor of safety for uncertainties (1.5)
$\mathrm{C}_{\mathrm{i}} \quad$ Coefficient of interaction for pullout of geosynthetic
$\mathrm{C}_{\mathrm{ds}} \quad$ Coefficient of direct sliding between geosynthetic and reinforced soil
$\mathrm{CR}_{\mathrm{u}} \quad$ Connection strength reduction factor
$\mathrm{CR}_{\mathrm{s}} \quad$ Connection strength reduction factor at $3 / 4$ " displacement

$$
T_{a}=\frac{T_{u l t}}{R F_{c r} R F_{d} R F_{i d} F S}
$$

\subsubsection{Soil parameters}

The required parameters used in the wall design are:
c Cohesion coefficient $(\mathrm{t} / \mathrm{m})$
$\phi \quad$ Angle of friction (deg.)
$\gamma \quad$ Unit weight $(\mathrm{t} / \mathrm{m})$ 
These properties are required for the four types of soil used in the construction of the wall: infill soil (subscripted i), retained soil (subscripted $r$ ), foundation soil (subscripted f), and drainage soil (subscripted d)

\subsection{National Concrete Masonry Association (NCMA) Method (Collin, 1996)}

\subsubsection{Design assumptions}

Several design assumptions were made in the NCMA method:

- Coulomb's earth pressure theory is applicable.

- The groundwater table is located well below the base of the wall.

- Only dead loads are considered as contributing to the structure's stability.

- RSRWs subjected to seismic and dynamic loading will, in general, perform well due to their nature and enhanced ductility.

- For most standard facing units, a differential movement of one percent is acceptable. In situations where movement greater than one percent is expected, special precautions should be taken.

\subsubsection{External stability}

In external stability analyses of segmental reinforced soil walls, the reinforced zone and the dry-stacked column of facing units are assumed to act as a monolithic gravity mass. The purpose of this stability analysis is to determine the minimum length (L) of geosynthetic reinforced mass by checking (1) Base sliding, (2) Overturning and (3) Bearing sliding.

The Figure-6 is the free body for reinforced soil SRW external stability calculation.

\subsubsection{External earth pressure and forces}

The distribution of earth pressure acting at the back of the reinforced zone due to the retained soil self-weight and surcharge loading are shown in Figure 6.2. The resultant 
forces for the rigid body equilibrium analysis are shown in Figure 6.3. Following are the basic equations required for the external stability analysis.

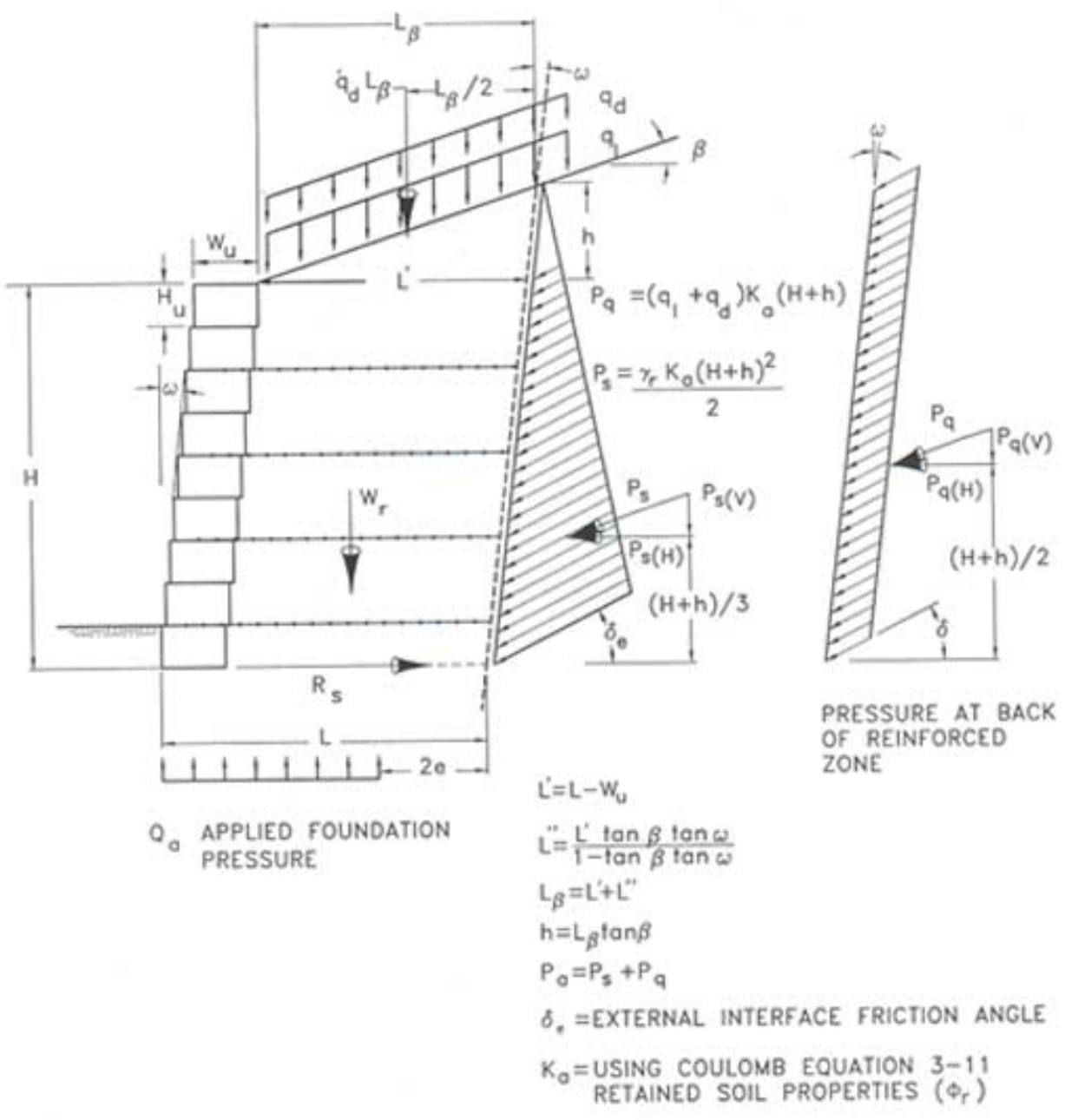

Figure 6.2. Forces and Geometry for external stability 


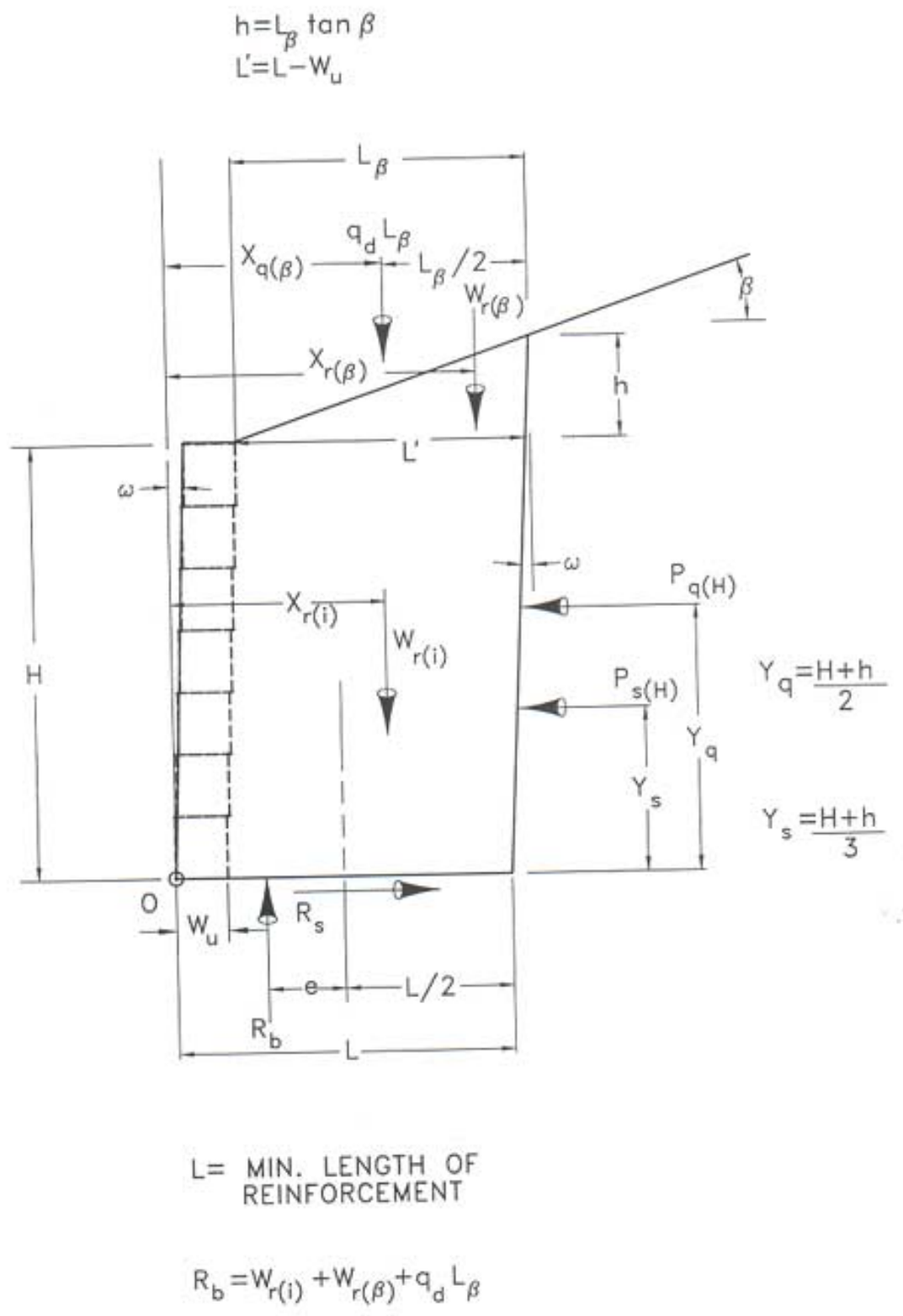

Figure 6.3. Free Body Diagram for external stability analysis 
- Coefficient of active earth pressure $\left(\mathrm{K}_{\mathrm{a}}\right)$

$$
K_{a}=\frac{\cos ^{2}(\phi+\omega)}{\cos ^{2} \omega \cos (\omega-\delta)\left[1+\sqrt{\frac{\sin (\phi+\delta) \sin (\phi-\beta)}{\cos (\omega-\delta) \cos (\omega+\beta)}}\right]}
$$

For the case of $\delta=\beta$ and $\omega=0$,

$$
K_{a}=\cos \beta\left[\frac{\cos \beta-\sqrt{\cos ^{2} \beta-\cos ^{2} \phi}}{\cos \beta+\sqrt{\cos ^{2} \beta-\cos ^{2} \phi}}\right]
$$

For the case of a horizontal backslope $(\beta=0, \delta=0)$

$$
K_{a}=\frac{1-\sin \phi}{1+\sin \phi}
$$

- $\quad$ The earth force due to the retained soil self-weight $\left(\mathrm{P}_{\mathrm{s}}\right)$

$$
\begin{aligned}
& P_{s}=0.5 K_{a} \gamma_{r}(H+h)^{2} \\
& P_{s(H)}=0.5 K_{a} \gamma_{r}(H+h)^{2} \cos \delta_{e}
\end{aligned}
$$

- The earth force due to a uniformly distributed live and dead load surcharge

\subsubsection{Base sliding stability}

$$
F S_{s l}=\frac{\operatorname{Min} \cdot\left[\begin{array}{l}
C_{d s}\left(q_{d} L_{\beta}+W_{r(i)}+W_{r(\beta)}\right) \tan \phi_{i} \\
C_{d s}\left(q_{d} L_{\beta}+W_{r(i)}+W_{r(\beta)}\right) \tan \phi_{d} \\
C_{d s}\left[c_{f} L+\left(q_{d} L_{\beta}+W_{r(i)}+W_{r(\beta)}\right) \tan \phi_{f}\right]
\end{array}\right]}{P_{a(H)}}
$$

If the factor of safety against sliding $F S_{s l}$ is less than the target design value (typically 1.5) then the trial base reinforcement length $\mathrm{L}$ should be increased and the analysis repeated.

$$
\begin{aligned}
& P_{q}=\left(q_{l}+q_{d}\right) K_{a}(H+h) \\
& P_{q(H)}=\left(q_{l}+q_{d}\right) K_{a}(H+h) \cos \delta_{e}
\end{aligned}
$$




\subsubsection{Overturning}

$$
F S_{o t}=\frac{W_{r(i)} X_{r(i)}+W_{r(\beta)} X_{r(\beta)}+q_{d} L_{\beta} X_{q(\beta)}}{P_{s(H)} Y_{s}+P_{q(H)} Y_{q}}
$$

The magnitude of $F S_{o t}$ is typically controlled in any design section by adjusting the length of the base reinforcement length $\mathrm{L}$. A typical minimum recommended value $F S_{o t}$ is 2.0 .

\subsubsection{Bearing capacity}

$$
F S_{b e}=\frac{c_{f} N_{c}+0.5 \gamma_{f} B N_{\gamma}+\gamma_{f} H_{e m b} N_{q}}{\left[W_{r(i)}+W_{r(\beta)}+\left(q_{d}+q_{d}\right) L_{\beta}\right] / B}
$$

If the value of the $F S_{b e}$ is less than the minimum design value (typically 2.0), the usual strategy is to incrementally increase the reinforced soil base width $\mathrm{L}$ and repeat the calculation set.

$$
\begin{aligned}
& B=L-2 e \\
& \text { where, } e=\frac{P_{s(H)} Y_{s}+P_{q(H)} Y_{q}-W_{r(i)}\left(X_{r(i)}-L / 2\right)-W_{r(\beta)}\left(X_{r(\beta)}-L / 2\right)-q_{d} L_{\beta}\left(X_{q(\beta)}-L / 2\right)}{W_{r(i)}+W_{r(\beta)}+q_{d} L_{\beta}}
\end{aligned}
$$

\subsubsection{Internal stability}

Internal stability calculations are carried out to evaluate the integrity of the reinforced zone as a composite comprised of geosynthetic reinforcement, soil and facing units. The purpose of internal stability is to determine the minimum strength, number and vertical spacing of reinforcement layers by examining (1) tensile overstress of the reinforcements, (2) pullout of the reinforcements and (3) internal sliding.

For internal stability calculations, the lateral earth pressure due to reinforced (infill) soil self-weight and imposed surcharge loadings $\left(\mathrm{q}_{\mathrm{d}}\right.$ and $\mathrm{q}_{\mathrm{t}}$ ) is assumed to be linearly distributed with depth based on $\mathrm{K}_{\mathrm{a}}$ and act at an angle $\delta_{\mathrm{i}}$ to the horizontal direction are the back of the segmental facing units (Figure 6.4). 


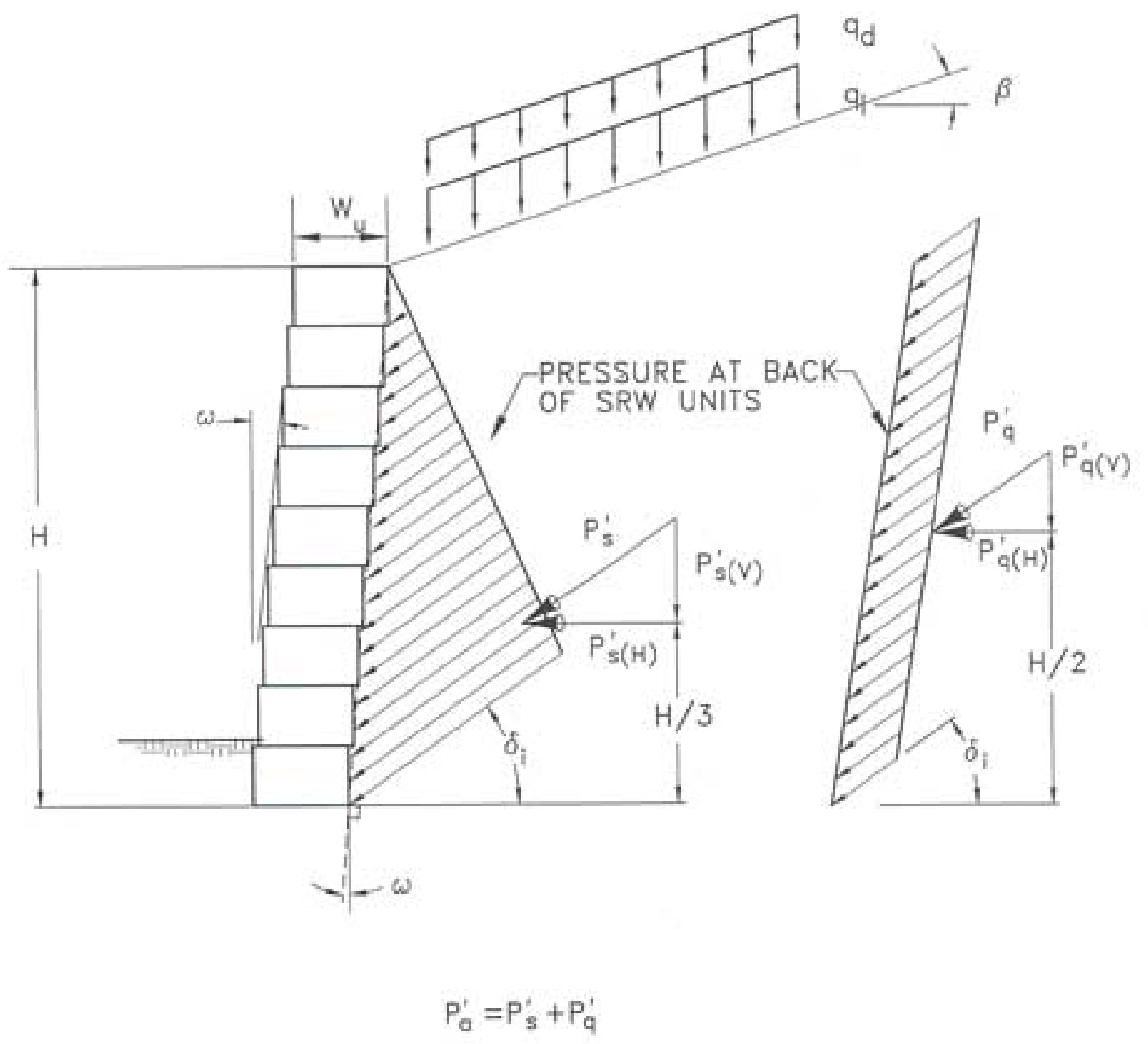

Figure 6.4. Forces for internal stability calculation 


\subsubsection{Tensile overstress of reinforcement layers}

The tensile load developed in a layer of geosynthetic reinforcement is based on the contributory area $A_{c(n)}$ if the layer and the integration of lateral pressure over the effective height of the wall defined by the contributory area. (Figure 6.5) The total applied tensile force in the geosynthetic reinforcement $\mathrm{F}_{\mathrm{g}(\mathrm{n})}$ can be calculated using the average horizontal pressure at the average horizontal pressure at the midpoint of the contributory area as follows,

$$
\begin{aligned}
& F_{g(n)}=\left[\gamma_{i} D_{n}+q_{i}+q_{d}\right] K_{a} \cos \delta_{i} A_{c(n)} \\
& A_{c(n)}=\left(E_{(n+1)}-E_{(n-1)}\right) / 2
\end{aligned}
$$

For the topmost layer N,

$$
A_{c(n)}=H-\left\lfloor\left(E_{(n)}+E_{(n-1)}\right) / 2\right\rfloor
$$

The applied force in any geosynthetic reinforcement layer, $F_{\mathrm{g}}$, should not exceed its maximum allowable working stress $T_{a}$.

$$
F_{g(n)} \leq T_{a(n)}
$$

\subsubsection{Pullout of Reinforcement}

Pullout of reinforcement layers is prevented by sufficient anchorage capacity which maintains a coherent mass of soil in the reinforced zone. The ratio of the developed anchorage capacity $\mathrm{AC}_{\mathrm{n}}$ to the applied force $\mathrm{F}_{\mathrm{g}(\mathrm{n})}$ in any geosynthetic reinforcement layer is designated by the factor of safety against pullout $F S_{p o}$.

$$
F S_{p o}=A C_{n} / F_{g(n)}
$$




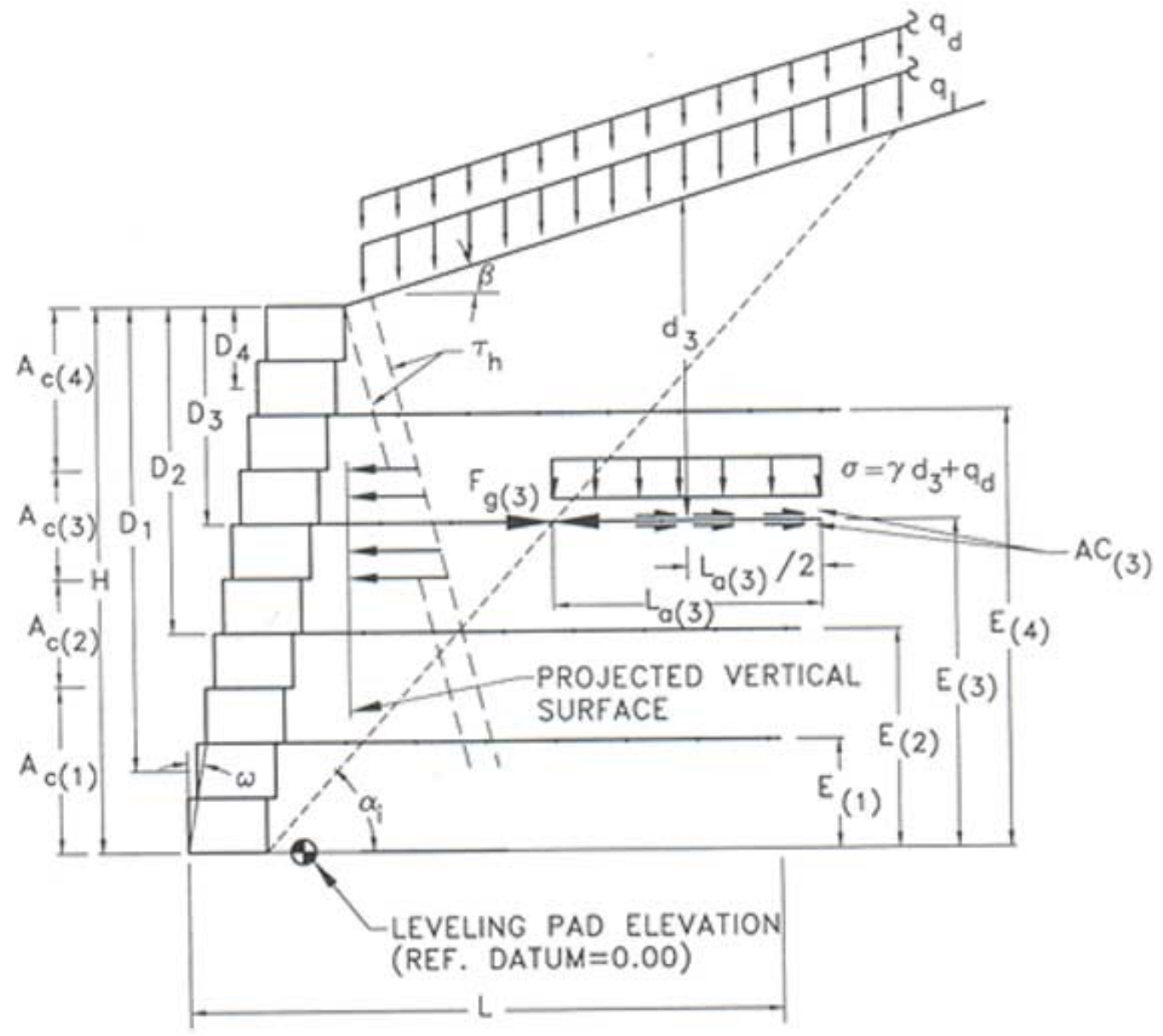

Figure 6.5. Forces and stresses used for internal stability analysis 
where,

$$
\begin{aligned}
& A C_{n}=2 L_{a(n)} C_{i}\left(d_{n} \gamma_{i}+q_{d}\right) \tan \phi_{i} \\
& L_{a(n)}=L-W_{u}-E_{(n)} \tan \left(90-\alpha_{i}\right)+E_{(n)} \tan \omega \\
& d_{n}=\left(H-E_{(n)}\right)+\left[\left(E_{(n)} / \tan \alpha_{i}\right)-H \tan \omega+\left(L_{a(n)} / 2\right)\right] \tan \beta
\end{aligned}
$$

The factor of safety against reinforcement pullout should be greater than the minimum required for design (typically 1.5 ).

\subsubsection{Internal sliding failure}

The potential for an internal sliding failure to propagate along the surface of a reinforcement layer increases as the shear resistance between the soil and reinforcement material and additional shear capacity from facing units decreases.

The factor of safety against sliding $F S_{s l}$ can then be calculated as follows:

$$
F S_{s l(n)}=\left\lfloor R_{s(n)}^{\prime}+V_{u(n)}\right\rfloor / P_{a(H, n)}
$$

The $\mathrm{FS}_{\mathrm{sl}(\mathrm{n})}$ at each geosynthetic reinforcement level should be greater than that required (typically 1.5$)$.

- Sliding resistance over geosynthetic reinforcement $\left(\mathrm{R}_{\mathrm{s}(\mathrm{n})}\right)$

$$
\begin{aligned}
& R_{s(n)}^{\prime}=C_{d s}\left(q_{d} L_{\beta(n)}+W_{r(i, n)}+W_{r(\beta, n)}\right) \tan \phi_{i} \\
& L_{\beta(n)}=L_{s(n)}^{\prime}+L_{s(n)}^{\prime \prime} \\
& L_{s(n)}^{\prime}=L-\left(W_{u}\right)-\Delta L \\
& L_{s(n)}^{\prime \prime}=\left[\frac{L_{s\left(n^{\prime}\right)}^{\prime} \tan \beta \tan \omega}{1-\tan \beta \tan \omega}\right] \\
& W_{r(i, n)}=L_{s(n)}^{\prime}\left(H-E_{(n)}\right) \gamma_{I} \\
& W_{r(\beta, n)}=\left(\gamma_{i} L_{\beta(n)} L_{s(n)}^{\prime} \tan \beta\right) / 2
\end{aligned}
$$


- Shear capacity between SRW units $\left(\mathrm{V}_{\mathrm{u}(\mathrm{n})}\right)$

$$
V_{u(n)}=a_{u}+W_{W(n)} \tan \lambda_{u}
$$

\subsubsection{Local stability}

The purpose of local stability analysis is to ensure that the column of segmental facing units remains intact and does not bulge excessively. This is done by checking (1) the facing connection resistance, (2) the resistance to bulging and (3) that the maximum unreinforced height between reinforcement layers is not excessive.

\subsubsection{Facing connection strength}

The facing between the geosynthetic reinforcement and segmental facing units at each reinforcement elevation $\mathrm{E}_{(\mathrm{n})}$ must have sufficient connection strength to preclude rupture or slippage of the reinforcement due to the applied tensile force.

There are two criteria which should be addressed when designing the connection: the limit state strength of the connection at failure, and the strength of the connection at a specified deformation. By considering both these criteria the connection will have the required long-term strength and will have acceptable deformation.

- Limit state criteria

$$
T_{c l(n)}=T_{\text {ultconn }(n)} / F S_{c s}
$$

- Service criteria

$$
T_{c s(n)}=T_{\text {conn @ } \frac{3}{4}(n)}
$$


The allowable connection strength $\mathrm{T}_{\mathrm{aconn}(\mathrm{n})}$ shall be the least of the limit state connection strength; the service state connection strength and the allowable strength of the geosynthetic $\left(\mathrm{T}_{\mathrm{a}(\mathrm{n})}\right)$.

$$
\operatorname{Min} .\left[T_{c l(n)}, T_{c s(n)}, T_{a(n)}\right\rfloor \geq F_{g(n)}
$$

\subsubsection{Resistance to bulging}

Resistance to bulging is controlled by the magnitude of applied pressure, vertical spacing of geosynthetic reinforcement, and shear capacity between segmental facing units.

The factor of safety against sliding $F S_{s l}$ and/or shear capacity $F S_{s c}$ would apply to the calculation of bulging resistance. Since the resistance component of greatest concern is shear capacity, the bulging resistance is computed as:

$$
F S_{s c(n)}=\frac{a_{u}+W_{w(n)} \tan \lambda_{u}}{P_{a(H, n)}^{\prime}-\left(F_{g(n+1)}+F_{g(n+2}+\Lambda\right)}
$$

The factor of safety against shear capacity $F S_{s c(n)}$ should be greater than the required minimum (typically 1.5) for peak load criteria using parameters $a_{u}$ and $\lambda_{u}$.

\subsubsection{Maximum unreinforced segmental wall heights}

The design is acceptable when the $F S_{s l}$ and $F S_{o t}$ for the intended maximum unreinforced height exceed the minimum required safety factors (typically, 1.5). Otherwise, if an unacceptable $F S_{s l}$ and $F S_{o t}$ is obtained, the maximum unreinforced height should be reduced by incorporating an additional layer of reinforcement near the top of the wall or adjusting the vertical spacing of the existing reinforcement layout. 


\subsection{Federal Highway Administration (FHWA) Method (Christopher et al., 1990)}

\subsubsection{Preliminary calculation}

\subsubsection{Wall embedment depth $\left(\mathrm{H}_{\mathrm{emb}}\right)$}

The minimum embedment depth $\mathrm{H}_{\mathrm{emb}}$ at the front of the wall recommended FHWA is shown in Table 6.1.

Table 6.1. Minimum Embedment Depth $\left(\mathrm{H}_{\mathrm{emb}}\right)$

\begin{tabular}{|c|c|}
\hline Slope in front of wall & Min. $\mathrm{H}_{\mathrm{emb}}$ to top of leveling Pad \\
\hline Horizontal (walls) & $\mathrm{H}^{\prime} / 20$ \\
\hline Horizontal (abutments) & $\mathrm{H}^{\prime} / 10$ \\
\hline $3 \mathrm{H}: 1 \mathrm{~V}$ & $\mathrm{H}^{\prime} / 10$ \\
\hline $2 \mathrm{H}: 1 \mathrm{~V}$ & $\mathrm{H}^{\prime} / 7$ \\
\hline $3 \mathrm{H}: 2 \mathrm{~V}$ & $\mathrm{H}^{\prime} / 5$ \\
\hline
\end{tabular}

* $\mathrm{H}^{\prime}$ is the exposed height of the wall.

Large values may be required, depending on depth of frost penetration, shrinkage and swelling of foundation soils, seismic activity, and scour. Minimum in any case is $0.5 \mathrm{~m}$.

\subsubsection{Determination of vertical spacing requirements}

For convenience, an initial uniform spacing of 0.3 or $0.6 \mathrm{~m}$ could be selected. Following the internal stability analysis, alternative spacing can easily be evaluated by analyzing the reinforcement strength requirements at different wall levels and modifying the spacing accordingly or by changing the strength of the reinforcement to match the spacing requirement.

\subsubsection{Preliminary determination of reinforcement length}

Traditionally, the minimum length of reinforcement has been empirically limited to 0.7H. FHWA indicates that walls on firm foundations which meet all external stability requirements can be safely constructed using length as short as $0.5 \mathrm{H}$. 


\subsubsection{External stability}

\subsubsection{External earth pressure and forces}

The lateral earth pressure at the back of the reinforced soil wall due to the retained fill increases linearly from the top.

- Coefficient of active earth pressure $\left(\mathrm{K}_{\mathrm{a}}\right)$

For the case of a wall retaining an infinite slope inclined at the angle $\beta$ $\lambda=\phi_{\mathrm{i}}\left[1-\left(1-\beta / \phi_{\mathrm{i}}\right)(\mathrm{L} / \mathrm{H}-0.2)\right] \quad$ for inextensible reinforcement (e.g. steel) $\lambda=\beta \quad$ for extensible reinforcement (e.g. geotextile)

$$
K_{a}=\left[\frac{\sin \left(\theta-\phi_{r}\right) / \sin \theta}{\sqrt{\sin (\theta+\lambda)}+\sqrt{\sin \left(\phi_{b}+\lambda\right) \sin \left(\phi_{b}-\beta\right) / \sin (\theta-\beta)}}\right]^{2}
$$

For the case of horizontal surface

$\lambda=[1.2-\mathrm{L} / \mathrm{H}] \phi_{\mathrm{b}} \quad$ for inextensible reinforcement

$\lambda=0 \quad$ for extensible reinforcement

$$
K_{a}=\tan ^{2}\left(45-\phi_{i} / 2\right)
$$

- Horizontal force $\left(\mathrm{P}_{\mathrm{a}}\right)$

$$
\mathrm{P}_{\mathrm{a}}=0.5 * \mathrm{~K}_{\mathrm{a}} * \gamma_{\mathrm{b}} * \mathrm{H}^{2}
$$

- Vertical stress on the base $\left(\sigma_{\mathrm{v}}\right)$

$$
\begin{aligned}
& \sigma_{v}=\frac{\gamma_{r} H L+W^{\prime}+P_{a} \sin \lambda}{L-2 e} \\
& e=\frac{P_{a} \cos \lambda\left(H^{\prime} / 3\right)-P_{a} \sin \lambda(L / 2)-W^{\prime *}(d-L / 2)}{\gamma_{r} H L+W^{\prime}+P_{a} \sin \lambda}
\end{aligned}
$$




\subsubsection{Base sliding stability}

The length of the reinforcement must be adequate to resist the horizontal driving force from the retained backfill. The driving force comes from the height of soil at the back of the reinforced zone, including any additional height caused by a slope and from any surcharge loading. The resistance is taken as the weight of the reinforced section, the weight of the slope above the reinforced section and the vertical component of the active earth pressure.

$$
F S_{s l}=\frac{\left[\left(H L \gamma_{i}+\frac{1}{2}(L-Z)^{2} \tan \beta \gamma_{i}+q_{d} L+\frac{1}{2} \gamma_{r} K_{a}(H+(L-Z) \tan \beta)^{2} \sin \lambda\right) \mu\right]}{\left[\frac{1}{2} \gamma_{r} K_{a}(H+(L-Z) \tan \beta)^{2} \cos \lambda+\left(q_{d}+q_{l}\right) K_{a}(H+(L-Z) \tan \beta) \cos \lambda\right]}
$$

Here, $\mu=\min .\left[\tan \phi_{\mathrm{f}}, \tan \phi_{\mathrm{i}}, \tan \rho\right]$

If the factor of safety against sliding $F S_{s l}$ is less than the target design value (typically 1.5) then the trial base reinforcement length $L$ should be increased and the analysis repeated. The required reinforcement length to satisfy this failure mode should be decided.

\subsubsection{Overturning}

Due to the flexibility of reinforced soil structure, it is unlikely that a block overturning failure could occur. Nonetheless, an adequate factor of safety against this classical failure mode will limit excessive outward tilting and distortion of a suitably designed wall.

$$
F S_{o t}=\frac{\left[\left(\frac{1}{2} \gamma H_{i} L+\frac{1}{3}(L-Z)^{2} \gamma_{i}+\frac{1}{2} q_{d} L^{2}+\frac{1}{2} \gamma_{r} K_{a}(H+(L-Z) \tan \beta)^{2} \sin \lambda L\right)\right]}{\left[\frac{1}{6} \gamma_{r} K_{a}(H+(L-Z) \tan \beta)^{3} \cos \lambda+\frac{1}{2}\left(q_{d}+q_{l}\right) K_{a}(H+(L-Z) \tan \beta)^{2} \cos \lambda\right]}
$$


The magnitude of $F S_{o t}$ is typically controlled in any design section by adjusting the length of the base reinforcement length L. A typical minimum recommended value $F S_{o t}$ is 2.0. The required reinforcement length to satisfy this failure mode should be decided.

\subsubsection{Bearing capacity}

Terzaghi's bearing capacity model is used (assuming a strip footing). The bearing pressure is assumed to act over an effect width $\mathrm{B}=\mathrm{L}-2 \mathrm{e}$, where e is the eccentricity of the resultant loads. The minimum factor of safety with respect to bearing capacity is 2.0.

$$
\begin{aligned}
q_{u} & =c_{f} N_{c}+\frac{1}{2} \gamma_{f}(L-2 e) N_{\gamma} \\
\sigma_{v} & =\frac{\left[\frac{1}{6} \gamma_{r} K_{a}(H+(L-Z) \tan \beta)^{3} \cos \lambda+\frac{1}{2}\left(q_{d}+q_{l}\right) K_{a}(H+(L-Z) \tan \beta)^{2}\right]}{L-2 e}
\end{aligned}
$$

With the above-calculated values, check that:

\subsubsection{Internal stability analysis}

\subsubsection{Coefficient of lateral earth pressure for internal stability analysis}

In the FHWA method, the lateral earth pressure distribution in the reinforced mass is function of the reinforcement deformability and of the density of reinforcement, as shown in Figure 6.6. 


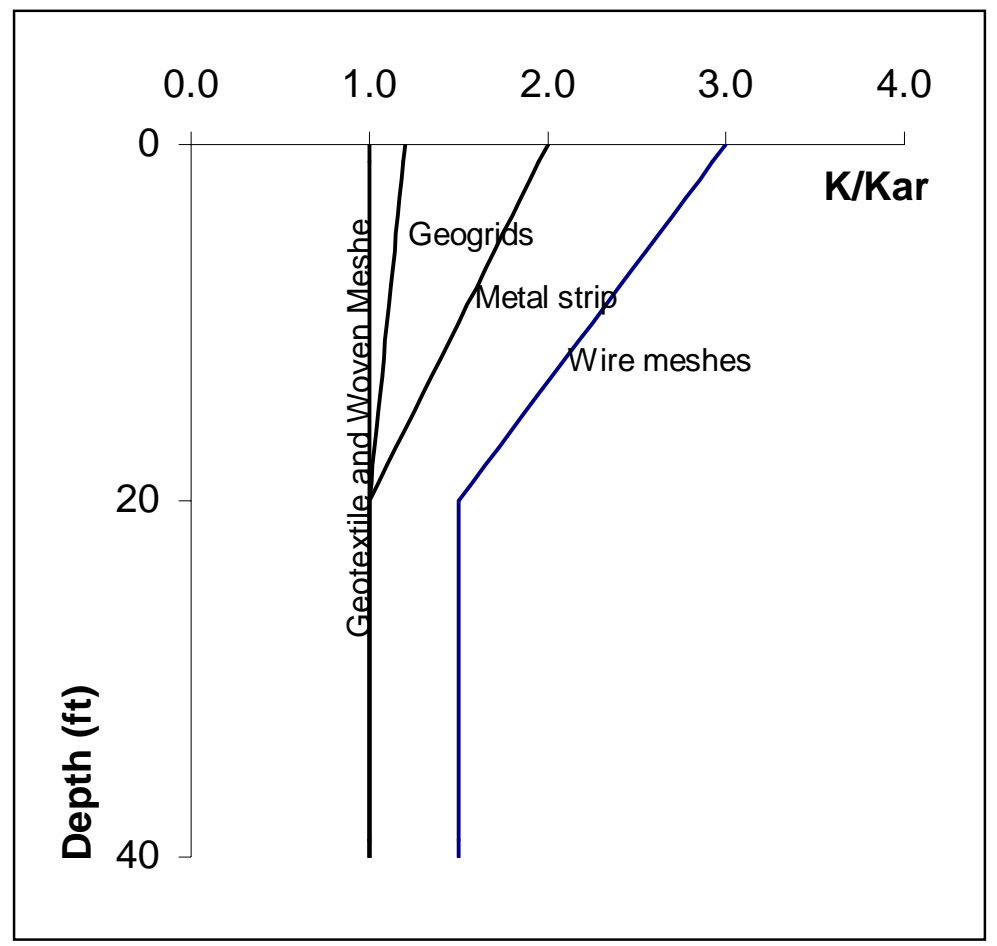

Figure 6.6. Distribution of Earth Pressure in the Reinforced Soil Mass, FHWA Method

$$
\begin{array}{ll}
\mathrm{K} / \mathrm{K}_{\mathrm{ar}}(\mathrm{z})=\Omega_{1}\left(1+0.4 * \mathrm{~S}_{\mathrm{r}} / 1000\right) *(1-\mathrm{z} / 20)+\Omega_{2} * \mathrm{z} / 20 & \mathrm{z} \leq 6.0 \mathrm{~m} \\
\mathrm{~K} / \mathrm{K}_{\mathrm{ar}}(\mathrm{z})=\Omega_{2} & \mathrm{z}>6.0 \mathrm{~m}
\end{array}
$$

with $\Omega_{1}, \Omega_{2}=$ geometry factors.

$\Omega_{1}=1$ for linear reinforcements

$\Omega_{1}=1.5$ for grids and mats.

$\Omega_{2}=1$ if $S_{\mathrm{r}} \leq 1000$

$\Omega_{2}=\Omega_{1}$ if $S_{r}>1000$

where,

$$
\begin{aligned}
\mathrm{K}_{\mathrm{ar}} & =\text { Active lateral earth pressure coefficient } \\
& =\tan ^{2}\left(45-\phi_{\mathrm{r}} / 2\right) \text { for horizontal surface }
\end{aligned}
$$




$$
=\cos \beta\left(\frac{\cos \beta-\sqrt{\cos ^{2} \beta-\cos ^{2} \phi_{r}}}{\cos \beta+\sqrt{\cos ^{2} \beta-\cos ^{2} \phi_{r}}}\right)
$$

for sloped surface at angle $\beta$

$S_{R}=$ Global reinforcement stiffness factor in units of $F / L^{2}$

$=\mathrm{EA}^{\prime} /(\mathrm{H} / \mathrm{n})$ for inextensible reinforcement

$\mathrm{E}=$ Modulus of reinforcement in units of $\mathrm{F} / \mathrm{L}^{2}$

$\mathrm{A}^{\prime}=$ Average area of the reinforcement per unit width of wall

$=\mathrm{b} * \mathrm{t} / \mathrm{S}_{\mathrm{h}}=\mathrm{R}_{\mathrm{c}} * \mathrm{t}$ for strip reinforcement

$=\mathrm{A}_{\mathrm{c}} / \mathrm{S}_{\mathrm{h}}=\mathrm{A}_{\mathrm{c}} * \mathrm{R}_{\mathrm{c}} / \mathrm{b}$ for bar mat and steel grids

$\mathrm{H} / \mathrm{n}=$ average vertical spacing based on the number of layers $\mathrm{n}$ over height $\mathrm{H}$

$\mathrm{S}_{\mathrm{R}}=\mathrm{J} * \mathrm{R}_{\mathrm{c}} /(\mathrm{H} / \mathrm{n})$ for geosynthetic reinforcement

$\mathrm{J}=$ Modulus of geosynthetic in units of $\mathrm{F} / \mathrm{L}$ usually determined from width test (ASTM D-4595) as secant modulus at 5\% strain

$=(\mathrm{T}$ at $5 \% \varepsilon) / 0.05$

\subsubsection{Maximum tensile forces in the reinforcement layers}

The location of the maximum tensile force line is influenced by the extensibility of the reinforcement as well as the overall stiffness of the facing. Figure 6.7 shows the limiting locations of the maximum tensile forces line in walls with inextensible and extensible reinforcements.

The maximum tension force developed in the reinforcement is equivalent to the horizontal stress, calculated at the reinforcement elevation being considered, multiplied by the vertical spacing between the reinforcement layers.

$\mathrm{T}_{\max }=\sigma_{\mathrm{h}} * \mathrm{~S}_{\mathrm{v}}$

Here, $\sigma_{\mathrm{h}}=\mathrm{K}^{*}\left(\gamma_{\mathrm{I}}^{*} \mathrm{z}+\left(\mathrm{q}_{\mathrm{d}}+\mathrm{q}_{\mathrm{l}}\right)+\Delta \sigma_{\mathrm{v}}\right)+\Delta \sigma_{\mathrm{h}}$

The procedure used to account for concentrated loads on the surface of the reinforced soil wall is represented in Figure 6.8. 


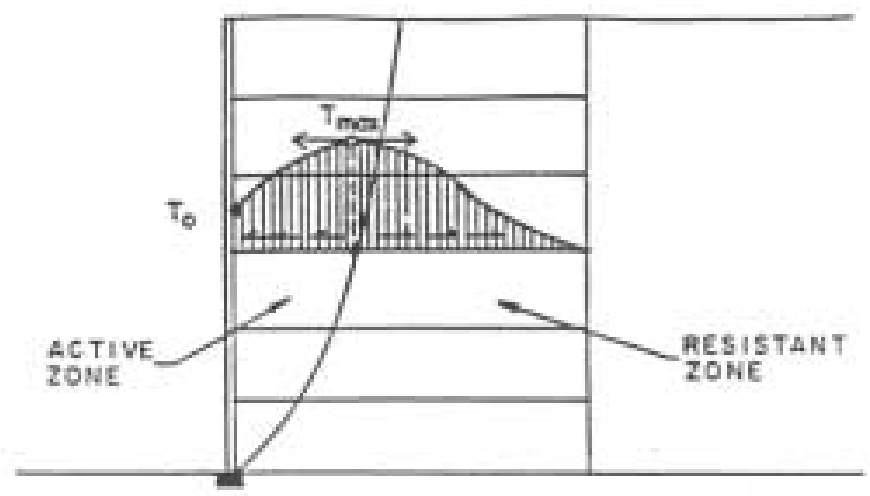

(a) general case

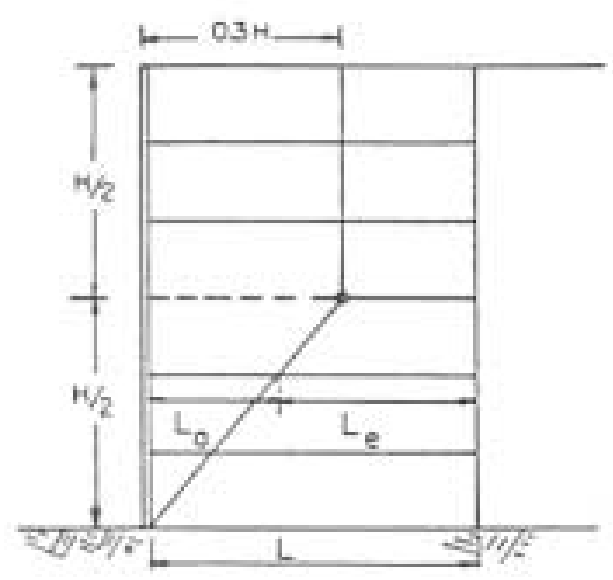

(b) inextensible teinforcements

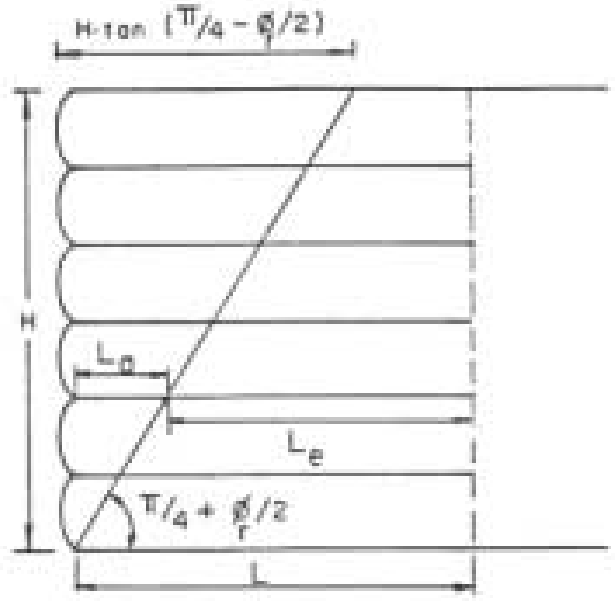

(c) extensible reinforcenents

Figure 6.7. Tensile Force in the Reinforcements and Schematic Maximal Tensile Force Line, FHWA Method 


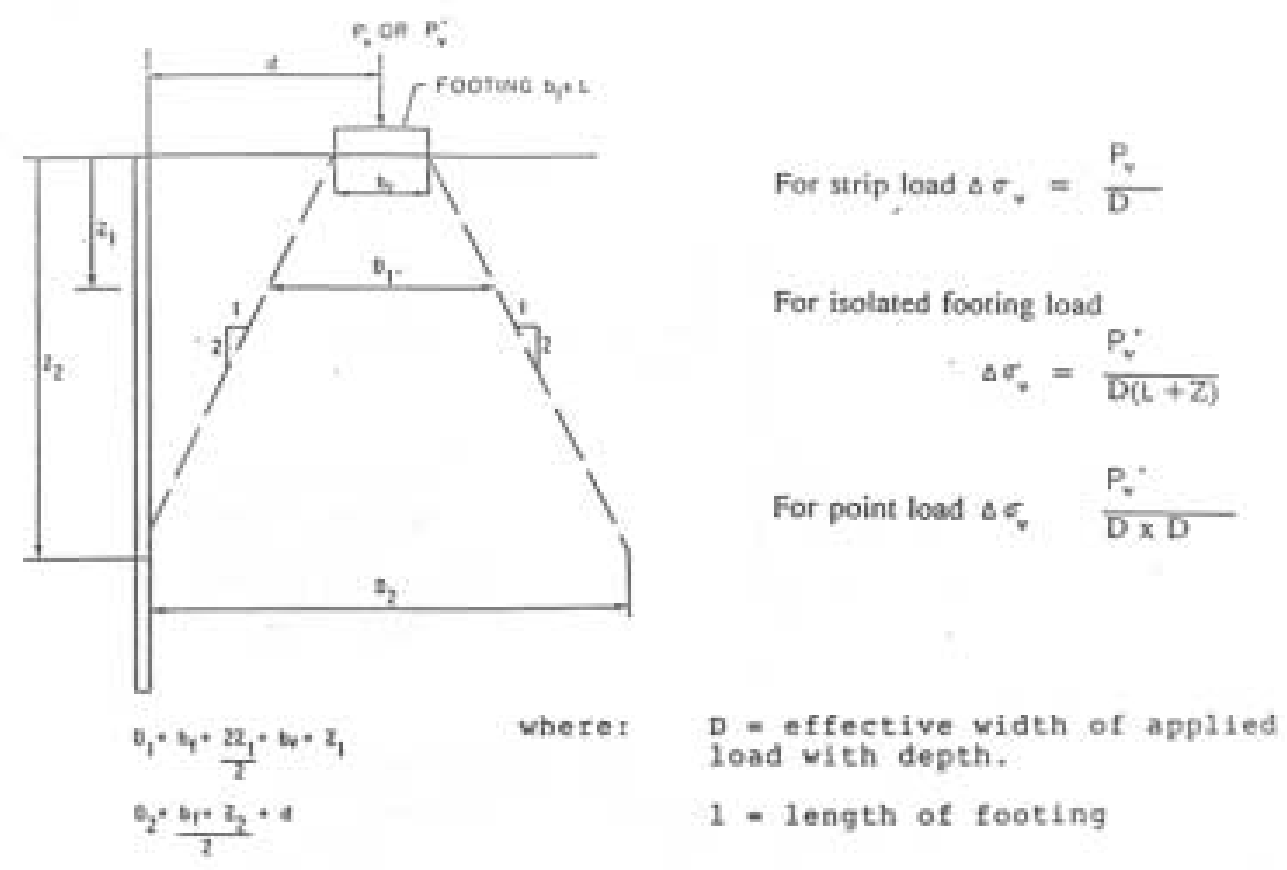

A. Distribseion of stress from concentrated vertical load PV

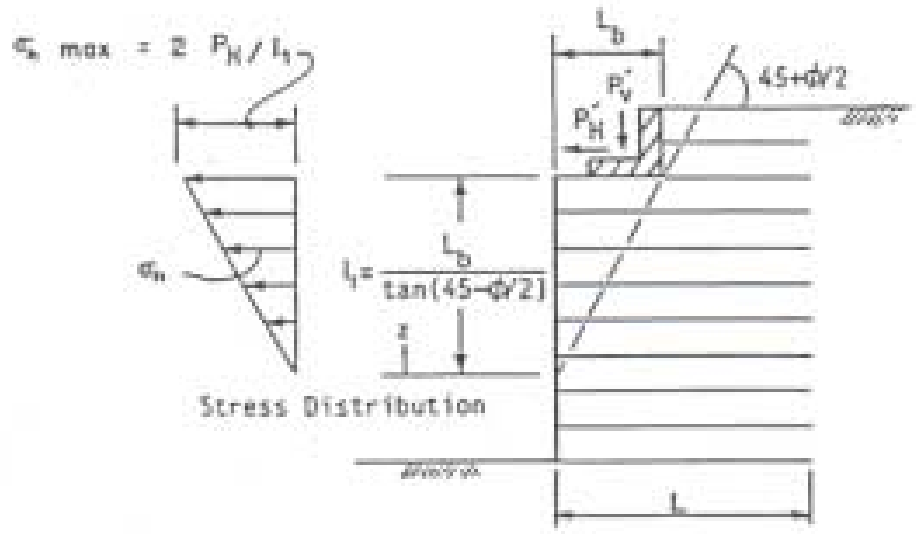

B. Distribation of stross from concentrated horizopeal load Ph

Figure 6.8. Method to Account for Concentrated Load Diffusion, FHWA Method 


\subsubsection{Tensile resistance of the reinforcement}

For the reinforcement not to fail under tension, it is necessary that:

$\mathrm{T}_{\max }<\mathrm{T}_{\mathrm{a}} * \mathrm{R}_{\mathrm{c}}$

where, $\quad \mathrm{R}_{\mathrm{c}}$ is the coverage ratio, equal to $\mathrm{b} / \mathrm{S}_{\mathrm{H}}$. The gross width of the reinforcing element is $b$, and $S_{H}$ is the center-to-center horizontal spacing between reinforcements. $T_{a}$ is the allowable tension force per unit width of the reinforcement.

At the connection of the reinforcements with the facing, check that tensile force, $T_{o}$, determined as indicated in Figure 6.9, is not greater than the allowable tensile strength of the connection. The connection strength will depend in the structural characteristics of the facing system used.

\subsubsection{Resistance to pullout}

Pullout stability of the reinforcement requires that the following criteria be satisfied:

$$
\begin{aligned}
& T_{\max } \leq \frac{1}{F S_{P O}}\left(F^{*} \alpha \gamma_{i} z L_{e} C\right) R_{c} \\
& \text { where, } \quad \begin{aligned}
\mathrm{FS}_{\mathrm{po}} & =1.5 \\
\mathrm{C} & =2 \text { for strip, grid, and sheet type reinforcement and } \\
& \pi \text { for circular bar reinforcements } \\
\mathrm{F}^{*}= & \text { The pullout resistance factor } \\
\alpha & =\text { Scale effect correction factor } \\
\gamma_{\mathrm{Z} Z} & =\text { The overburden pressure, including distributed surcharges. } \\
\mathrm{L}_{\mathrm{e}} & =\text { The length of embedment in the resisting zone }
\end{aligned}
\end{aligned}
$$




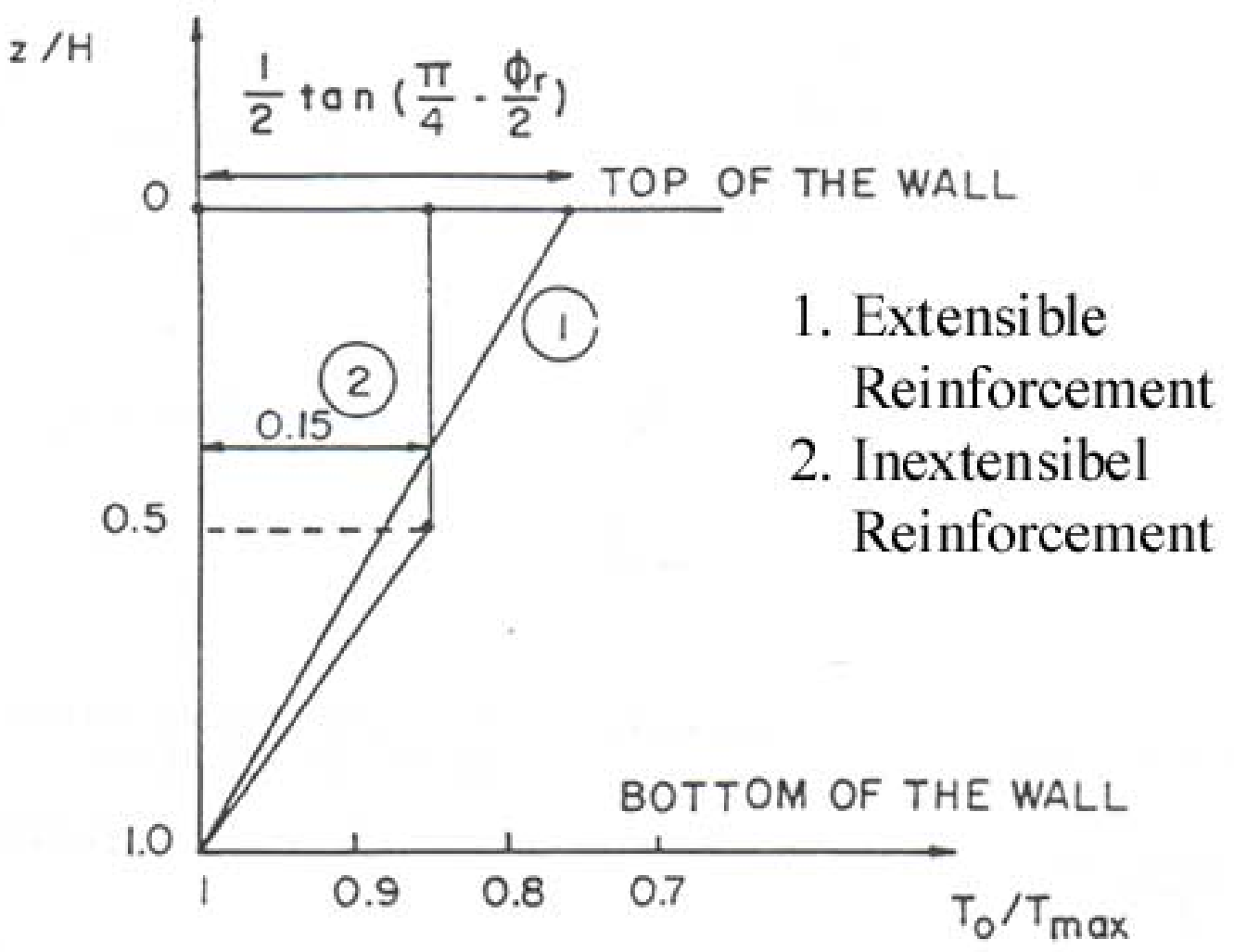

Figure 6.9. Determination of the Tensile Force $T_{o}$ in the Reinforcement at the Connection with the Facing, FHWA Method 
In the case of a reinforced soil wall with a slopping surcharge,

$$
T_{\max } \leq \frac{1}{F S_{P O}}\left(F^{*} \alpha \gamma_{i} z_{\text {ave }} L_{e} C\right) R_{c}
$$

where, $\mathrm{z}_{\mathrm{ave}}$ is the distance from the wall top surface to the midpoint in the resisting zone.

The total length of reinforcement, $\mathrm{L}_{\mathrm{T}}$, required for internal stability is then determined from,

$\mathrm{L}_{\mathrm{T}}=\mathrm{L}_{\mathrm{a}}+\mathrm{L}_{\mathrm{e}}$

where, $L_{a}$ is obtained from Figure 6.7 for simple structures (i.e., not supporting concentrated external loads such as bridge abutments).

For the total height of a reinforced soil wall with extensible reinforcement.

$$
\mathrm{L}_{\mathrm{a}}=(\mathrm{H}-\mathrm{z})^{*} \tan \left(45-\phi_{\mathrm{t}}^{\prime} / 2\right)
$$

where, $\mathrm{z}$ is the depth to the reinforcement level.

For a wall with inextensible reinforcements from the base up to $\mathrm{H} / 2$ :

$$
\mathrm{L}_{\mathrm{a}}=0.6 *(\mathrm{H}-\mathrm{z})
$$

For the upper half of a wall with inextensible reinforcements:

$$
\mathrm{L}_{\mathrm{a}}=0.3 * \mathrm{H}
$$




\subsubsection{Reinforcement strength and spacing variations}

Use of a constant reinforcement density and spacing for the full height of the wall usually leads to more reinforcement near the top of the wall then is required for stability. Therefore, a more economical design may be possible by varying the reinforcement density with depth.

There are generally two practical ways to do this:

- In the case of reinforcements consisting of strips, grids, or mats, which are used with precast concrete facing panels, the vertical spacing is maintained constant and the reinforcement density is increases with depth by increasing the number and/or the size of the reinforcements.

- In the case of planar reinforcements, generally made of geotextiles or geogrids, the most common way of varying the reinforcement density $T_{a} / S_{v}$ is to change the vertical spacing $S_{\mathrm{v}}$, especially if wrapped facing is used, because it easily accommodates spacing variations. The range if acceptable spacings is governed by consideration of placement and compaction of the backfill for the minimum value $\left(\mathrm{S}_{\mathrm{m}}\right.$

$\sim 15 \mathrm{~cm})$ and by local stability during construction for the maximum value $\left(\mathrm{S}_{\mathrm{m}} \sim 0.6\right.$ $\mathrm{m})$.

\subsubsection{Local stability}

\subsubsection{Facing connection strength}

The connection strength between the reinforcement and the facing units is equal to the lesser of:

$$
T_{a c}=\operatorname{Min} \cdot\left[\begin{array}{l}
\frac{T_{u l t} C R_{u}}{R F_{d} R F_{c r} F S_{u n c}} \\
\frac{T_{u l t} C R_{s}}{F S_{u n c}}
\end{array}\right]
$$


Where the connection strength is limited to the minimum of the ultimate value at rupture, or the capacity at $20 \mathrm{~mm}$ deformation. The connection capacity must be greater than or equal to the allowable tension in the reinforcement.

\subsubsection{Resistance to bulging}

The inter-unit shear capacity as obtained by testing (Test Method, SRWU-2, NCMA) at the appropriate normal load should exceed the horizontal earth pressure at the facing by a factor of safety of 2.0.

Test Method SRWU-2 refers to the inter-block shear capacity used in the bulging calculation. The interface shear capacity at the reinforcement elevations is to be greater than the destabilizing earth pressures above that point. The force on the units at the elevation considered is equal to the horizontal earth force at that level minus the tension in the reinforcement layers above.

$$
F S=2.0=\frac{\left(a_{u}+W_{u} \tan \left(\lambda_{u}\right)\right)<V_{\max }}{P_{a}}
$$

\subsection{Seismic design}

Design of reinforced soil walls for seismic loading should be based on dynamic analysis or on a pseudo-static analysis in which dynamic seismic effects are determined by an equivalent static force model. The pseudo-static analysis according to the Mononobe-Okabe procedure is typically used for reinforced soil walls. This pseudo-static analysis was developed for gravity retaining walls and assumes that the reinforced soil behind the wall behaves as rigid body.

The methods outlined in the NCMA and FHWA guidelines recommends are based on this procedure to compute dynamic forces in reinforced soil structure. (Reference 3,5) There are two dynamic forces induced by earthquake; horizontal inertia forces $\left(\mathrm{P}_{\mathrm{IA}}\right)$ and dynamic horizontal thrust $\left(\mathrm{P}_{\mathrm{AE}}\right)$. For external stability calculation, the horizontal inertia forces $\left(\mathrm{P}_{\mathrm{IA}}\right)$ is

$$
P_{I A}=\alpha_{m} \gamma_{r} H L
$$


where, $\gamma_{\mathrm{r}}$ is the unit weight of the reinforced zone and $\alpha_{\mathrm{m}}$ is the maximum acceleration developed in the wall:

$$
\alpha_{m}=\left(1.45-\alpha_{o}\right) a_{o}
$$

where, $\alpha_{0}$ is the peak ground acceleration based on the design earthquake. The seismic thrust $\left(\mathrm{P}_{\mathrm{AE}}\right)$ is evaluated based on the pseudo-static Mononobe-Okabe analysis,

$$
P_{A E}=0.375 \alpha_{m} \gamma_{b} H^{2}
$$

where, $\gamma_{\mathrm{b}}$ is the unit weight of the back-fill. The seismic thrust $\mathrm{P}_{\mathrm{AE}}$ and $50 \%$ of the $\mathrm{P}_{\mathrm{IA}}$ are added to the static force acting on the wall. The reduced $\mathrm{P}_{\mathrm{IA}}$ is used since these two forces are unlikely to peak simultaneously. The required factor of safety for seismic case are also reduced to $75 \%$ of the static values, i.e. 1.5 and 1.12 for sliding and overturning respectively.

Only the inertia force is considered for internal stability computation because this force acts in the active zone while the dynamic thrust acts in the backfill. The force led to the incremental dynamic increase in the maximum tensile forces in the reinforcements assuming that the location and the slope of the maximum force line does not change seismic loading. This assumption is conservative for tensile resistance but acceptable for pull-out resistance analysis. The dynamic force increment at a reinforcement layer is

$$
\left(T_{m 2}\right)_{i}=P_{I A}\left[\frac{\left(R_{c} L_{e}\right)_{i}}{\sum\left(R_{c} L_{e}\right)_{i}}\right]
$$

where, $R_{c}$ is the reinforcement coverage ratio, $L_{e}$, is effective length of reinforcement, and $\mathrm{P}_{\mathrm{IA}}$ is the inertia force increment due to seismic force:

$$
P_{I A}=\alpha_{m} M_{a}
$$


where, $M_{a}$ is the mass of active zone. The coverage ratio $\left(R_{c}\right)$ is the ratio between the width of reinforcement strip and the horizontal spacing. For planar reinforcement, the coverage ratio is equal to 1 .

The factor of safety against failure by outward sliding should be greater than or equal to 1.1. The potential for liquefaction or excessive subsidence of the foundation soils supporting the reinforced soil wall must be analyzed separately. Pseudo-static techniques might not be appropriate for areas subject to high seismic loadings on supporting critical structure.

\subsection{Design Software}

Several computer programs are available for performing stability analyses or design computations of reinforced soil retaining walls. However, few of these are both comprehensive in their analysis features and user-friendly. The NCMA has sponsored the development of the program, SRWall (Bathurst and Simac, 1995) that allows to perform design analysis according to the NCMA method.

Another program, MSEW (Leshchinsky, 1999) has been sponsored by the FHWA and has been made available to State DOT engineers in the country. This program has been tested, as part of the present study. Documentation on MSEW can be found in Appendix. This software was found very useful because of its applicability to a broad range of reinforced soil wall configurations and technologies, and its design oriented user interface. The design method used by the program MSEW is compatible with both the FHWA method and the NCMA method. 


\section{Performance of Reinforced Soil Segmental Retaining Walls}

\subsection{Wall in Algonquin, Illinois (Simac et al., 1990, Bathurst et al., 1993a)}

\subsubsection{Synopsis}

In the late 80 's, a full scale $6.1 \mathrm{~m}$ high by $15 \mathrm{~m}$ wide geogrid reinforced soil test wall was constructed using a continuous filament polyester geogrid and dry-stacked, 200mm, segmental facing units. The purpose of the test wall was to evaluate the applicability of existing design methods (e.g. FHWA) to this type of reinforced soil wall and to assess the wall performance. A comprehensive instrumentation included inclinometers to monitor lateral movement, extensometers and strain gages on the geogrid, and soil pressure cells in the fill. A $2.1 \mathrm{~m}$ high surcharge fill, sloped at $34^{\circ}$, was placed on the wall.

\subsubsection{Design and materials}

The design method was based on recommendations contained in AASHTO and FHWA guidelines in effect, consisting of a conventional limit-equilibrium approach with tied wedge back analysis.

In order to test the validity of the method, the wall was designed with a very low factor of safety (long term internal factor of safety less than 1.1 without surcharge loading).

Several types of segmental facing units were used in different sections of the wall, the two main types consisting of interlocking concrete modules. Both modules had open cores to permit filling with a coarse drainage aggregate and incorporated a pin or clip shear connection.

The reinforced fill as well as the retained fill were made of cohesionless well-graded sandy gravel with a peak friction angle of $40^{\circ}$, compacted to $95 \%$ of standard Proctor. A coarse gravel was used as drainage fill behind the facing and within the facing units.

The test wall cross-section and monitoring system are shown in Figure 7.1. 


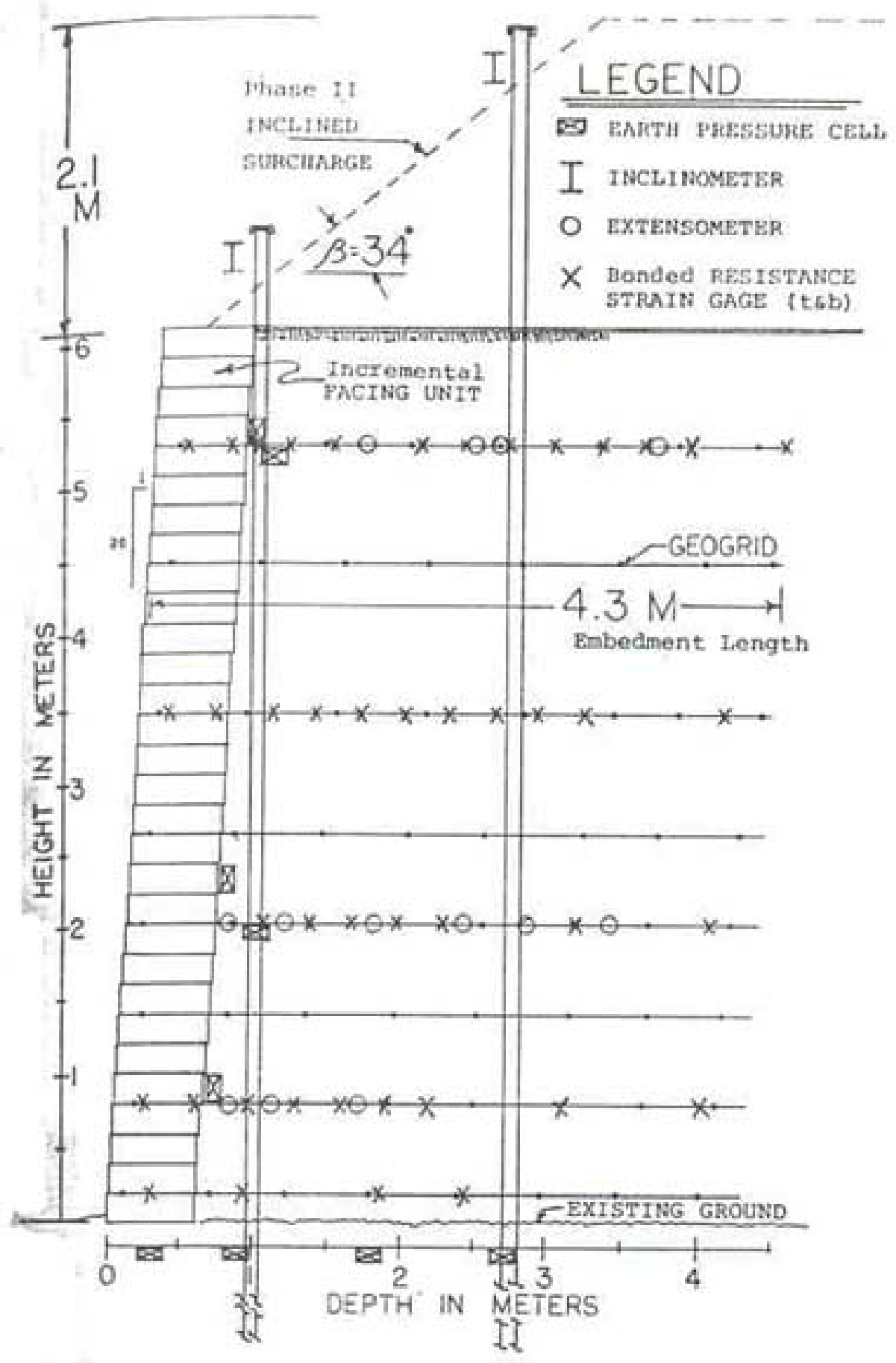

Figure 7.1. Algonquin Wall Instrumentation Layout 


\subsubsection{Performance}

An important aspect of the instrumentation program was to monitor the wall movement during construction. The construction phase induced the largest single phase of lateral movement, $1.2 \%$ and $1.0 \%$ of the wall height, measured at wall heights of 2.0 ad $5.3 \mathrm{~m}$, respectively. This movement is significant enough to create an active state of stress in the soil mass (it is generally considered that active yielding is achieved at horizontal strains greater than $0.5 \%$, Lambe, 1969). These measurements emphasize the importance of starting the monitoring during construction instead of waiting for the end of construction to make measurements.

The time-dependent properties of the reinforcement are generally a concern for this type of structure. The initial data indicate the geogrid performed without significant timedependent degradation, since there was relatively little difference in measurement during a period of 54 days after the surcharge was applied. The small $(15-20 \mathrm{~mm})$ global movement that occurred during a period of 104 days after construction constitutes a redistribution of soil shear stress as tension was mobilized in the reinforcement. This does not necessarily indicate deterioration of reinforcement properties with time. However, during the subsequent year, the deformation increased to $90 \mathrm{~mm}$, indicating significant time effect during this period.

The strain data from the extensometer showed that the maximum reinforcement strain in the reinforcement were not greater than $2 \%$. The maximum strain reading of $2 \%$ was well within the creep limit of the reinforcement. Despite being designed for strains as great as $10 \%$, the loads in the reinforcement did not approach the design loads. It should be noted that the polymer used as reinforcement material in this project, polyester, creeps very little as compared to, for instance, polyethylene which is more commonly used for geogrids.

The relatively low earth pressure measured just below and just behind the segmental facing units is unusual when compared to larger and more rigid precast elements. The flexibility of the segmental facing units which permit small rotations during construction and the possible cushioning effect of the geogrid reinforcement in the facing connection 
may account for some stress relief. However, once the facing system stiffened up and the surcharge was applied, the pressure increased dramatically beneath the facing units.

\subsubsection{Lessons learned}

The following conclusions may be drawn from Algonquin wall test.

- The internal stability may be analyzed using the limit equilibrium tied-back wedge concepts.

- Sufficient lateral deformation occurs, particularly during construction, for an active state of stress developed.

- The magnitude of horizontal strain was observed to be between 0.5 and 1.5 percent. To control that strain and wall movement during construction of incremental facing systems, the reinforcement should be tensioned prior to fill placement.

- Little creep in the reinforcement or other time dependent phenomenon deteriorating its performance was observed. However, significant wall deformation continued to develop over a period of at least one year after construction.

- The tensile load transfer mechanism of the geogrid to the soil has performed well and has not relaxed over the observation period.

- Both precast concrete segmental facing units and the friction facing connection performed adequately.

- The reinforcement loads observed in this test wall were lesser than anticipated by the design analysis.

- The maximum tensile loads in the reinforcement were developed close to the facing, and load transmission occurred within the facing connections. Therefore, the facing connections must be designed to carry these forces and the horizontal interface between facing units must be designed to transmit shear stresses. 


\subsection{Wall at University of Wisconsin-Platteville (Wetzel et al., 1995)}

\subsubsection{Synopsis}

A segmental retaining wall, 3.5m high, reinforced with geosynthetics was constructed on the campus of the University of Wisconsin-Platteville in 1993. It was instrumented to measure movements, earth pressures, forces acting between the segmental units, temperatures, and strains in one of the reinforcement materials. Temperature readings in the backfill indicated that the frost line extended approximately $1 \mathrm{~m}$ in from the wall face. Measured settlements varied from $5 \mathrm{~mm}$ at one end to $15 \mathrm{~mm}$ at the other. Horizontal displacements of the facing units varied from 0 to $7 \mathrm{~mm}$ with most of the movement occurring during construction. Load cell measurements of normal forces acting between layers of segmental wall units indicated that forces were significantly larger than the weight of the units located above the cell initially but decreased with time.

The wall and the monitoring system are shown in Figure 7.2.

\subsubsection{Design and materials}

The test wall was $3.5 \mathrm{~m}$ high, $36.6 \mathrm{~m}$ long and constructed using 23 courses of segmental facing units and 5 layers of geosynthetic reinforcement. The concrete units used for the wall facing were $410 \mathrm{~mm}$ wide by $150 \mathrm{~mm}$ high by $310 \mathrm{~mm}$ deep with a weight of $365 \mathrm{~N}$. Three types of geosynthetic reinforcement were used in different sections of the wall, including: a rigid geogrid, a flexible geogrid, and a woven geotextile. The granular footing and the reinforced fill were made of washed, crushed limestone with maximal size, $19 \mathrm{~mm}$, and peak friction angle of $38^{\circ}$.

The wall was designed in accordance with the guidelines of the National Concrete Masonry Association. 


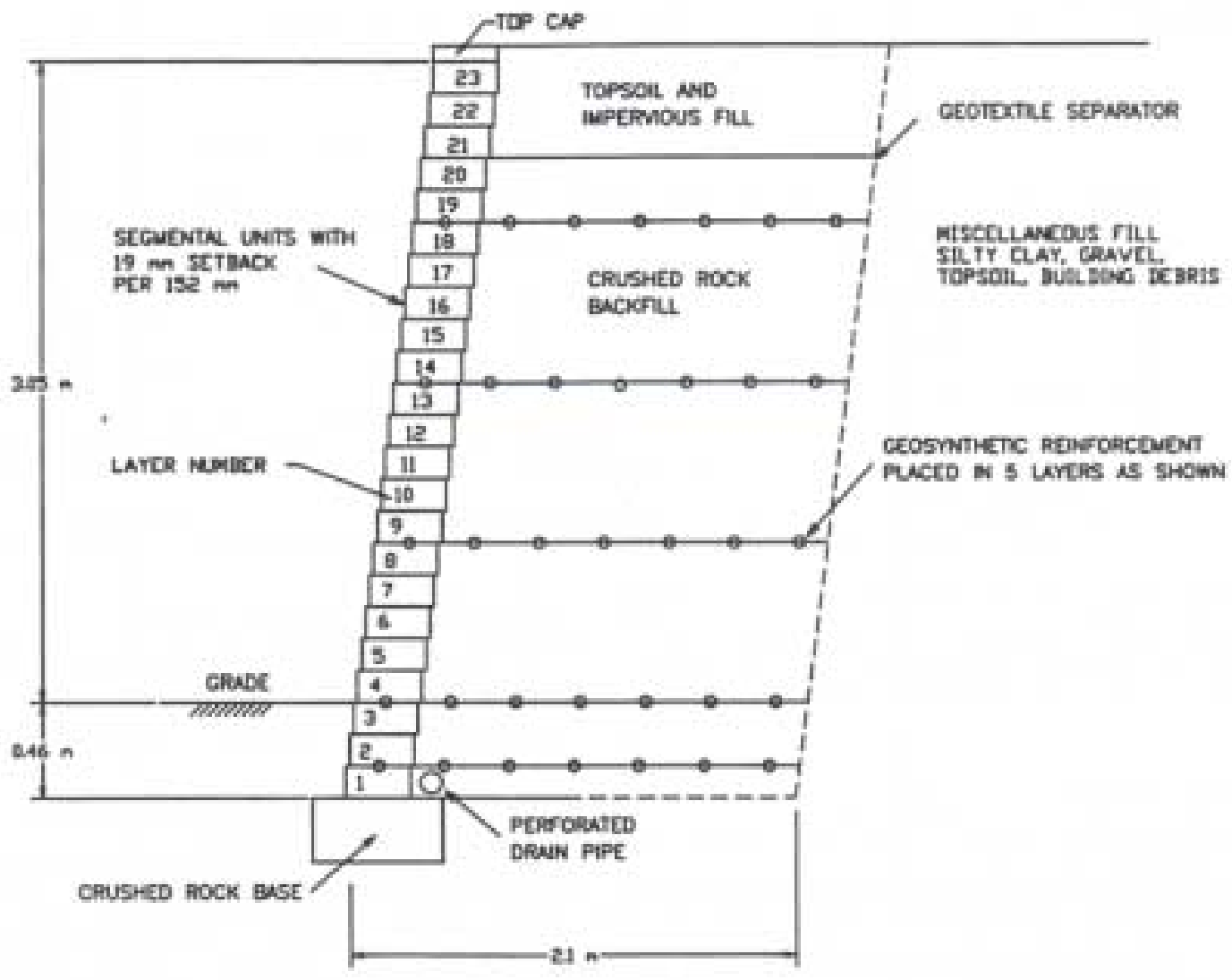

Figure 7.2. Wall at University of Wisconsin Instrumentation Layout 
Instrumentation was installed as the wall was being constructed. The instruments included: (1) targets to measure vertical and horizontal movement of the units, (2) thermistors to measure temperatures within the fill, (3) load cells placed between units to measure the vertical forces acting on the units, (4) earth pressure cells to measure the lateral earth pressures on the back face of the units, (5) strain gages bonded to the rigid geogrid, and (6) magnetic extensometers to measure movements within the reinforced backfill.

\subsubsection{Performance}

Temperature measurements indicated that the masonry facing units are better conductors of heat than the soil backfill. The concrete masonry units have higher thermal conductivity than soil, thus soil temperature changes were greater than would be expected for soil alone and could possibly affect the creep behavior of the geosynthetic reinforcement, the long term design strength, and the connection strength. Temperatures below freezing were observed to penetrate a zone about $60 \mathrm{~cm}$ thick from the facing.

Most of the settlement occurred during the wall construction. Measured settlements reached $15 \mathrm{~mm}$, but had no detrimental affect on the wall appearance. The horizontal movement was maximum at the top of the wall and reached, by the end of construction, $36 \mathrm{~mm}$. This corresponds to $1.2 \%$ of the wall height. This value remained approximately constant after construction.

Measured vertical normal forces between adjacent facing unit rows were initially about 90 percent larger than the weight of the segmental facing units stacked above the load cells. Load cell readings indicated a marked decrease in normal force between adjacent rows as thawing occurred and throughout the warm weather period. Finally, the measured normal forces tended to decrease with time and appear to be stabilizing at values approximately equal to the weight of all facing units above the load cell locations. 


\subsubsection{Lessons learned}

Interface normal (vertical) forces between facing units and on the facing foundation that develop by the end of construction are significantly underestimated if the soil-facing interface friction is neglected in the design. Two mechanisms may account for this. The first involves the friction force between the units and the fill soil, which acts downward on the units, assuming the fill settles relative to the facing units. The second possibility involves the geosynthetic reinforcement. As the fill settles, the reinforcement tend also to go down and apply a drag force to the facing units with a significant vertical component. The measured normal forces decreased as the ground thawed in the spring and continued to decrease until approaching the weight of the units above the load cells.

\subsection{Failure of Geogrid Reinforced Wall in Calgary, Alberta (Burwash and Frost, 1991)}

\subsubsection{Synopsis}

This case involves the failure of a $9 \mathrm{~m}$ high geogrid reinforced retaining wall with a horizontal backfill behind a separate soldier pile and lagging aesthetic facing. The case history and details of analyses have been described by Burwash and Frost (1991). The principal details of the case are summarized below.

Development of a 4 acre commercial site in Calgary, Alberta, Canada, to accommodate three single-story restaurants included the construction of several retaining walls to support asphalt paved parking areas. The pre-development topography consisted of a reasonably level are over the central and eastern portions of the site at an elevation of about $1060 \mathrm{~m}$. Local variations were of the order of $0.5 \mathrm{~m}$. In contrast, the western portion of the site sloped downwards, varying between $3 \mathrm{H}: 1 \mathrm{~V}$ and $7.5 \mathrm{H}: 1 \mathrm{~V}$, to the western property line where the elevation was approximately $1050 \mathrm{~m}$. In order to provide the required number of parking spaces for peak use of the restaurants, several retaining walls were proposed to bring the entire area of the site to elevation $1060 \mathrm{~m}$. 


\subsubsection{Design and materials}

The retaining walls were to be up to $9 \mathrm{~m}$ in height and were to consist of vertical steel soldier piles on $2.2 \mathrm{~m}$ centers, timber lagging and deadman anchors which were to be designed by the contractor. An alternative design using high strength Tensar SR2 geogrids to replace the deadman anchors but still using the soldier pile and timber lagging façade for aesthetic purposes was accepted by the owner on the basis of lowest price. In particular, the North wall, where the distress was subsequently observed, ranged between about 2 to $9 \mathrm{~m}$ in height. This wall was reinforced by up to 10 layers of SR2 geogrid with lengths up to $6.8 \mathrm{~m}$. The geogrids were incorporated into the wall design using the "wrap-around" method (Fig. 7.3).

As part of the alternative design it was decided to use low plastic silty clay till as backfill for the reinforced retaining wall. Drainage was to be provided by a $60 \mathrm{~cm}$ wide zone of coarse granular fill adjacent to the timber lagging. A slip-form was to be used during construction of the wall to provide a $7.5 \mathrm{~cm}$ void between the geogrids and the back of the soldier pile facing wall to allow for possible post-construction movement. Foundation soils consisted of a deep deposit of very stiff low plastic silty clay till. Unconfined compressive strengths for the foundation soils ranged between 360 and 440 $\mathrm{kPa}$. Liquid and plastic limits of about 30 and 15, respectively, were determined for the foundation and backfill soils. The groundwater table was well below the original ground surface.

\subsubsection{Performance}

The wall was constructed in the Spring of 1984 and appeared to perform satisfactorily until September 1985 when signs of settlement and distress were first observed on the paved surface. Conditions gradually deteriorated and in January 1986 a slope indicator was attached to the fact of the wall to monitor movements. Subsequent measurements showed that the wall facing was rotating about its base and by the time the wall was demolished in June 1987, the outward deflection at the top of the wall was 

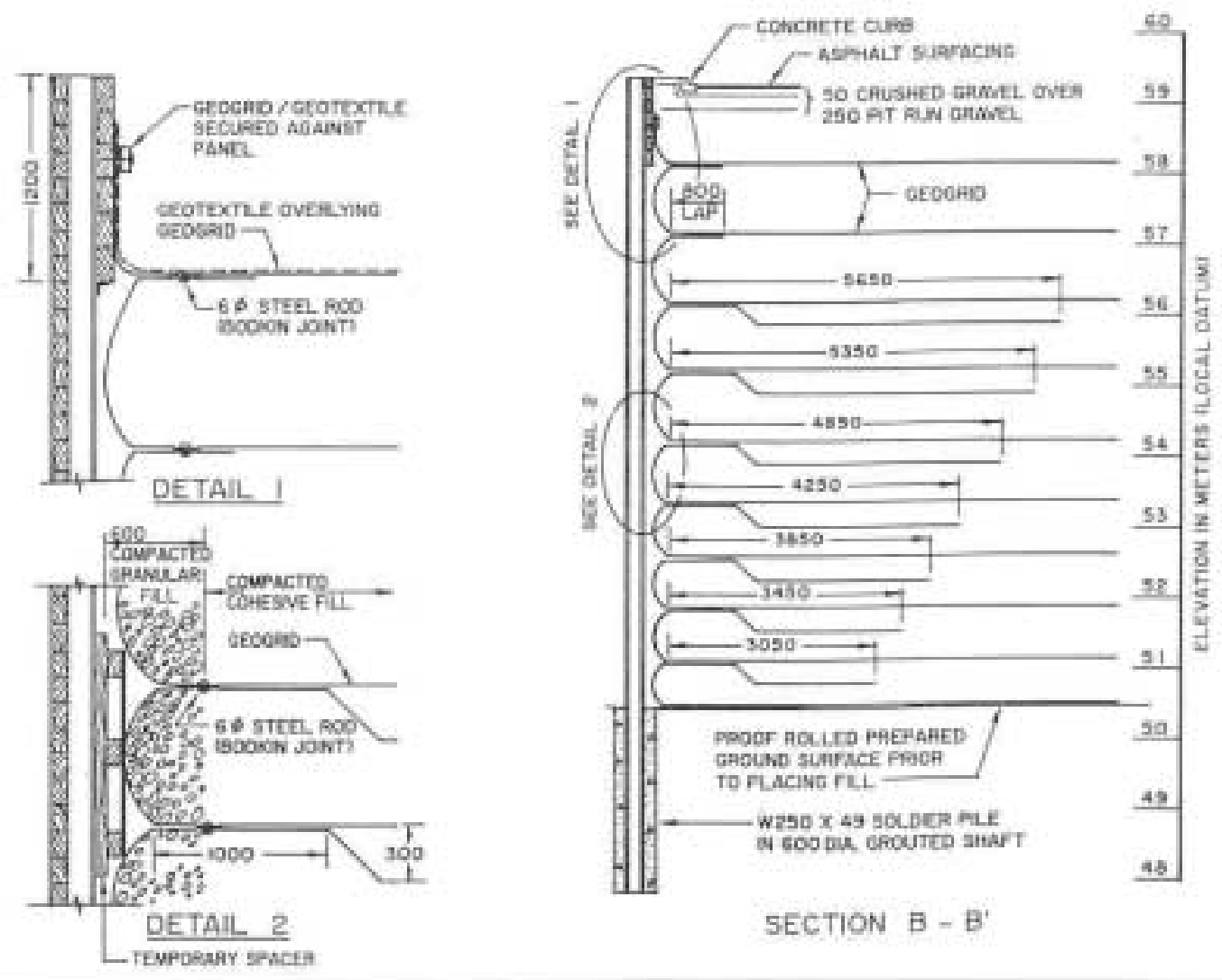

Figure 7.3. Calgary Wall - Typical Cross Section and Details 
about $30 \mathrm{~cm}$. Settlement of the parking lot behind the soldier pile was observed to continue over the same period.

In November 1986, three boreholes were drilled behind the retaining wall. Standard penetration tests showed that the clay backfill had softened to a depth of about 3 m. A subsequent review of construction records showed that the average placement moisture content of the clay backfill was $10.5 \%$ which was about $4 \%$ dry of the standard Proctor optimum value of $14.5 \%$. However, in contrast, the moisture contents determined for samples obtained from the post-failure boreholes above optimum, i.e. 5.5 to $7 \%$ above the as-placed moisture content. The increase in moisture content was less apparent with depth and at increasing distances from the wall. In June 1987, the upper 6 $\mathrm{m}$ of the wall was removed and replaced with a free standing $2 \mathrm{H}: 1 \mathrm{~V}$ slope. The lower 3 $\mathrm{m}$ of wall was left in place. A site survey conducted just before demolition of the wall showed maximum settlements of the order of $0.9 \mathrm{~m}$ or approximately $10 \%$ of the height of the fill. Maximum settlements at the back of the reinforced zone were about $0.5 \mathrm{~m}$.

\subsubsection{Lessons learned}

The distress at the North retaining wall resulted from in service saturation of the clay backfill which was placed about $4 \%$ dry of optimum. The saturation resulted from ponding of surface runoff water near the face of the wall. Laboratory tests have confirmed that saturation of the dry of optimum clay backfill would result in significant loss of strength and collapse type settlement. It is believed that interaction occurred between the geogrid reinforcement and the back of the facing wall soldier piles as the geogrids strained to compensate for the loss of strength in the backfill. This interaction resulted from the failure of the construction slip-form to provide the desired void between the geogrids and the back of the soldier piles. Accordingly, lateral restraint offered by the embedded soldier piles restricted the lateral deformations during the first 1.3 years of service. Once the strength loss in the soil exceeded the capacity of the non-structural soldier piles, the rate and magnitude of deformations increased rapidly. The other retaining walls at the site, constructed using the same techniques and materials, performed successfully because they were never subjected to the same increase in 
moisture content due to the imposed surface drainage details adjacent to these other walls. In addition, the soldier piles at these other locations had significantly greater embedment lengths and hence lateral restraint capacities which contributed to the overall strength of these walls.

\subsection{Failure of a Segmental Reinforced Wall in Glasgow, Kentucky (Leonards, et al., (1994)}

\subsubsection{Synopsis}

This case study is of a geogrid reinforced structure failure in Glasgow, Kentucky that used a cohesive soil backfill. The composite structure (Fig. 7.4) consisting of compacted clay slope above a Keystone/Tensar reinforced retaining wall, began showing distress in the backfill slope shortly after completion, deteriorating to a total wall collapse of a $70 \mathrm{ft}$ section a few months later. The wall was constructed to develop a shopping plaza while not encroaching on an adjacent city park. The pre-construction topography consisted of a gentle slope (20H:11V) from an elevation of $830 \mathrm{ft}$ to $780 \mathrm{ft}$. The bedrock is generally less than $40 \mathrm{ft}$ overlain by chert gravel and silty clay soil of medium to high plasticity ( $L L=50-60, P L=25-35)$. The natural moisture content above the ground water table is at or slightly below the plastic limit.

During construction the contractor excavated the entire cut before constructing the wall. Design required a steep cut of $35 \mathrm{ft}$ in some areas. A major slope failure occurred during. Construction photos confirm loose debris was either removed or compacted. Post failure compacted. Blasting of the bedrock was needed to allow the leveling pad to be placed in designed locations. Contract specification specified 95\% compaction (standard Proctor), no water contents were specified. Most of the wall was compacted dry of optimum under lax quality control. The contractor omitted the last layer of reinforcing strips that resulted in a $4 \mathrm{ft}$ cantilever in the Keystone wall. 


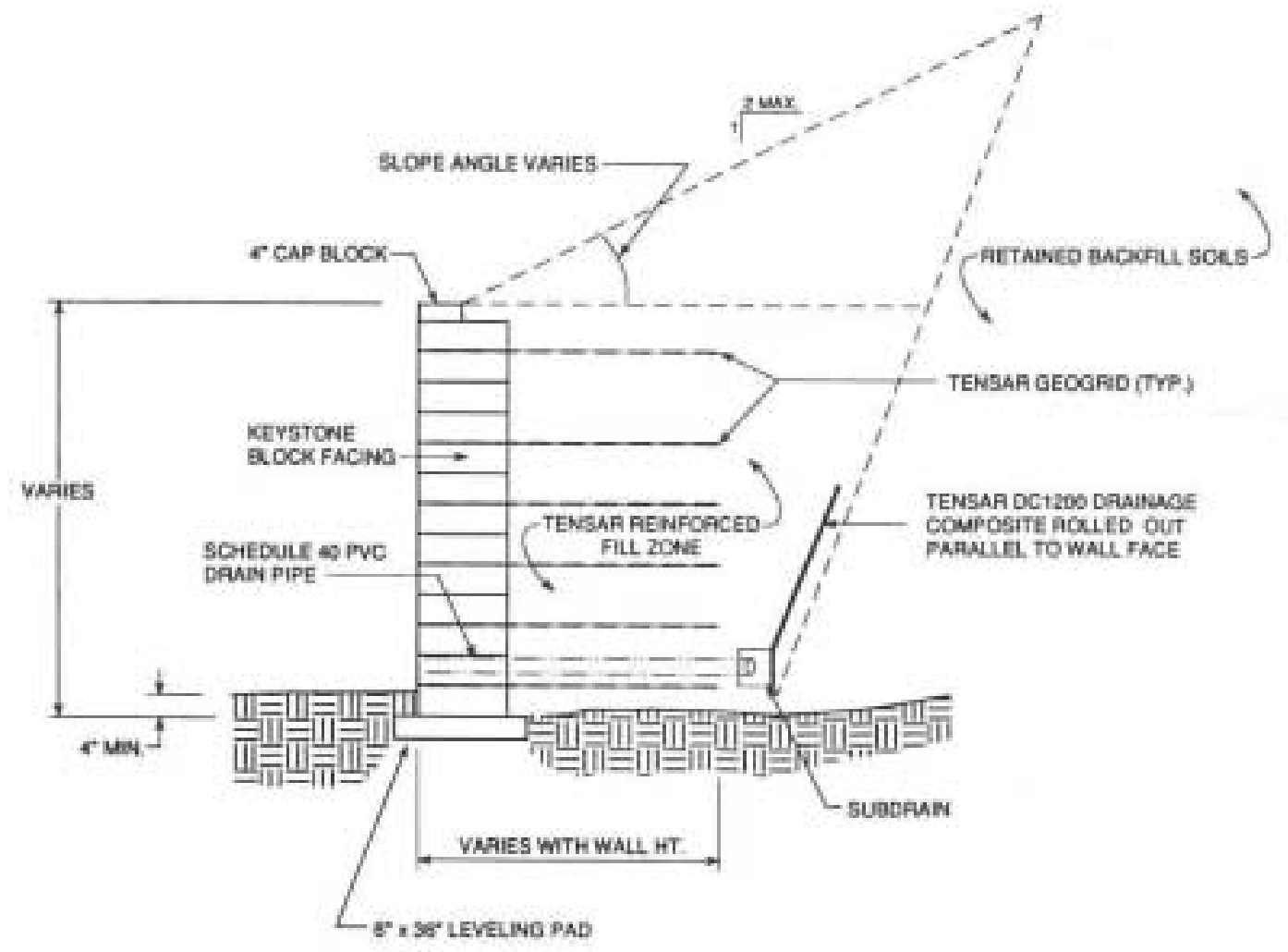

Figure 7.4. Glasgow, Kentucky Wall 


\subsubsection{Performance}

The first indication of failure, in November 1990, was shallow slumping of the backfill with the same main scarp as the construction failure. After heavy rainfall slumping increased resulting in a collapse of the Keystone wall at Station 14+70 on December 23, 1990. Surveys of wall movements initiated in January 1991 showed a relative outward movement at the top of the wall. Deformation of 2 in between Station $10+50$ and 11+50 was noticed. Other surveys illustrated outward lateral displacements of more than 10.5 in at Station $12+50$.

\subsubsection{Lessons learned}

Investigation of this failure led to attributing the failure to the following factors:

- Omission of the top geogrid reinforcement

- Large losses in strength upon imbibing water especially those compacted dry of optimum

- No specific site investigation for the wall (wall's design assumptions used cohesionless backfill, the bedrock was uneven, the wall was in ground water surface, $35 \mathrm{ft}$ cut slope was unsafe)

- Inadequate available space for geogrid and construction (slope failure encroaching on park)

- Not heeding the warnings of the landslide and improper processing of slide debris

- Compaction control inadequate (SPT values indicate none in areas and under specs in others, no cognizance for backfill soil variability). 


\section{Discussion and Recommendations}

Two main categories of low cost reinforced soil retaining walls have been identified: (1) geosynthetic-reinforced soil walls with segmental facing and (2) geosyntheticreinforced soil walls with wrap-around facing. The later category is used primarily for temporary structures. In the case of prolonged service the geosynthetic facing must be protected against sunlight degradation, erosion and vandalism by growing vegetation or by the addition of a non-structural architectural facing. The former category consists in dry stacked masonry units backfilled with geosynthetic-reinforced soil. The reinforcement layers are connected to the facing through the units interfaces. Segmental facing geosynthetic-reinforced soil walls were introduced in North America in the mid1980's and have been since increasingly used for temporary as well as permanent structures. They are an attractive cost-saving alternative to more traditional modular facing steel-reinforced soil walls.

In this chapter, important aspects of these technologies are discussed, and recommendations are offered, with respect to their possible application in Indiana Highway projects.

\subsection{Technological Differences between Low-Cost Reinforced Soil Walls and Traditional Reinforced Soil Walls}

\subsubsection{Facing}

Segmental facings are constructed by stacking dry masonry units, of small size, on each other. Because of the small size of the units, there is typically no possibility for a mechanical connection with the reinforcement to be placed within the unit. Thus the reinforcements have to be inserted within the interface between consecutive blocks. Not all the block rows are connected to a reinforcement. The vertical distance between consecutive reinforcement layers is generally larger than the individual segmental blocks height. This typically leaves intervals of several block rows unreinforced. Because of these characteristics, segmental facing units must transfer both compression and friction to each other and have a structural function in the system. 
In wrap-around facing walls, the facing is, by nature, made of the same flexible material as the geosynthetic reinforcement. There is no need, obviously, for connections. The facing does not need to transfer vertical compression and does not play a structural role in the system. Its function is to prevent erosion at the face and ensure local stability.

In traditional modular block systems, the facing elements are large size precast concrete panels that include connections for several rows of reinforcement layers. The reinforcement/facing mechanical connection is integrated to the facing unit. There is no connection between facing units and no need for it. By design, a gap is left between consecutive panel rows with only small compressible pads to provide contact. In such systems, the facing panels are able to experience relative vertical movements without the need for them to transfer important vertical loads. Their structural function is only to provide local reaction to the reinforcement horizontal forces at the connections.

\subsubsection{Reinforcement}

Traditional modular facing reinforced soil walls are reinforced using steel strips, steel meshes or high-performance plastic polymer geogrids. Low-cost reinforced soil walls, including segmental and wrap-around facing walls, are reinforced using geosynthetics (plastic polymer geogrids or reinforcement geotextiles).

\subsubsection{Structural fill material}

In traditional modular facing reinforced soil systems, because of the nature of the reinforcement (with low interface friction coefficient and small area of contact with the fill), the material used as engineered fill must have dilatant behavior under shear when compacted or/and good grain interlocking in the reinforcement patterns. These requirements exclude materials other than granular cohesionless soil with well graded particle size and high internal friction angle.

In systems reinforced with geotextiles and, to some extent, geogrids, there is less emphasis on the dilatant behavior of the fill. Successful stress transfer between soil and reinforcement can be achieved with a broader range of grain size including a significant fraction of fine particles, provided the angle of internal friction remains sufficient. This 
may allow to use native soil as structural fill in a number of situations. If this is the case, then the design must include provision for internal drainage of the fill (e.g. granular drainage zone behind the facing).

\subsection{Performance of Low-Cost Reinforced Soil Walls}

Because the technology is more recent than traditional modular reinforced soil walls (only about 15 years for segmental walls) long-term performance data (typically over 20 to 30 years) are still missing. Case histories or well-documented full-scale tests data are mainly short-term information. Given this limitation to our current knowledge, the data available to date show that, overall, the performance of segmental reinforced walls is satisfying in most of the cases. The failures experienced (e.g. case histories in this report) can be explained by gross design or construction errors that should have been avoided.

The following aspects of segmental walls performance seem to be of particular importance.

\subsubsection{Range of current experience with segmental facing reinforced soil walls}

- $\quad$ Experience in North America with segmental reinforced walls have been gained mainly with non-critical structures, less than $10 \mathrm{~m}$ high, subjected to small (or no) surcharge.

- In spite of potential use in such projects of native soil with significant fine-grain fraction, there is still in the profession strong reluctance to use such soils as structural fill. Almost all the walls built include coarse granular fill with no or little fines.

- Quantitative data on seismic performance is still lacking. Visual inspections of walls affected by the Loma Prieta earthquake in California in 1989 and the Northridge earthquake in the Los Angeles area in 1994 showed no significant damage for structures located within 20 to $100 \mathrm{~km}$ of the epicenter (Bathurst and 
Simac, 1994). Still, there is concern among the experts about the seismic performance of segmental walls because of their discrete nature.

- Under static conditions, the horizontal deformation measured at the facing is of the order of $1 \%$ to $2 \%$ of the wall height. This horizontal deformation is typically maximal at the top of the wall. Such deformation should be anticipated and must be acceptable for the wall serviceability.

- $\quad$ Tensile forces recorded in reinforcements are maximal at or near the facing. This emphasizes the need for connection resistance.

- The durability of the segmental facing units is still largely unknown. A particular problem in Indiana is the effect of freezing and thawing on the integrity of these masonry elements. It is noted that, for an ongoing project of Mesa ${ }^{\mathrm{TM}}$ type wall in Lafayette (INDOT contract R-24148) as part of the Lafayette Railroad Relocation Project, special requirements have been made with respect to the freeze/thaw testing (per ASTM 1262) of the facing blocks (Hall, 2001).

- The most serious concern is the effect of the segmental facing vertical stiffness can have on the integrity of the structure. As discussed earlier in this report, significant vertical compression occurs in the dry stacked column of wall facing. This is due, in addition to the self-weight of the masonry, to friction developed at the back of the facing units by the structural fill material. Such phenomenon is the consequence of the different vertical stiffnesses of the facing and the fill material. It should be expected that, during construction, as the fill material is placed and compacted, its vertical deformation is much greater than that of the rigid facing. In addition to inducing large load transfer to the facing, the differential deformation results also in downward deflection of the reinforcement and a downward component of the connection force be generated. This, in turn, contributes to further drag forces in the facing. Two detrimental effects may result for the structure:

(1) Overloading of the facing column and its foundation (as much as twice the value of the self-weight at the end of construction, according to Bathurst and Simac, 1994), possibly leading to 
bulking of the masonry or bearing capacity failure of the foundation at the wall toe.

(2) Overstressing and kinking of the reinforcements at the connection, leading to tensile or shear failure.

Based on observation of facing panel gap closure in Reinforced Earth ${ }^{\mathrm{TM}}$ walls (Findlay, 1978) the vertical strain of a reinforced fill can be of the order of $1 \%$. In a segmental facing wall, this would correspond to the differential vertical strain between the fill and the facing. A simple way to minimize these effects is, of course, to limit the use of segmental facing to structures of relatively small height, consistently with current practice.

\subsubsection{Cost Considerations}

According to Koerner (2000), the relative cost savings obtained by selecting a segmental, geosynthetic-reinforced soil, retaining wall instead of a modular steelreinforced soil wall, decreases with increasing wall height. For instance the relative savings would be almost $40 \%$ for a $2 \mathrm{~m}$ wall height, $25 \%$ for a $7 \mathrm{~m}$ wall, and only $4 \%$ for a $11 \mathrm{~m}$ wall. When this is considered together with the technical considerations in the above section, it seems that the optimal range for segmental walls is for height lesser than $10 \mathrm{~m}$.

\subsection{Additional Consideration on Structural Fill}

According to the National Concrete Masonry Association, soils with up to $35 \%$ fines, grain size distribution within the range indicated in Table 3.2 of this report, PI $<20$, and low to moderate frost susceptibility (as defined in Table 3.1) could be used as structural fill material. However, the potential savings brought by such a recommendation might be overcome by its practical shortcomings:

(a) When structural fill with as much fine contents is used, a vertical internal drainage layer is required. This drainage layer made of granular material is difficult to construct. Its placement requires significant manual work 
that generates additional cost. Further, the quality control process is made more complex by the presence of two different fill materials.

(b) Contractors preparing bids for INDOT projects would need to investigate and test new borrow sources because the NCMA fill characteristics do not correspond to materials currently used in Indiana highway construction. It is also noted that the NCMA fill characteristics refer to the USCS soil classification which is not used by INDOT (instead the AASHTO and INDOT Textural Systems are used). These elements would likely be sources of uncertainty in the bidding process and lead to errors in the cost estimates.

The above difficulties can be avoided if material currently identified by INDOT as B-Borrow is used as structural fill in segmental geosynthetic reinforced walls. This sand, sand and gravel, or crushed stone has less than $8 \%$ fines. It is very permeable and not frost sensitive. When walls are located below the 100-year flood elevation, an even more permeable backfill is used by INDOT, the No. 8 stone. If used as structural fill, these materials do not require internal drainage layers. Since contractors are familiar with their utilization in INDOT's projects, the borrow sources and costs are well known.

\subsection{Recommendations}

In view of using low-cost alternatives to traditional modular reinforced soil retaining walls for Indiana highways, the following guidelines are offered:

(1) Segmental facing, geosynthetic-reinforced soil, retaining walls may be used as non-critical structures with height less than $6 \mathrm{~m}$ and no traffic or structural load. This height limitation is essentially motivated by current uncertainty on the durability and structural performance of dry cast segmental concrete blocks used in facings of SGR walls.

(2) Structural fill should generally consist of B-Borrow materials. When walls are constructed below the 100-year flood elevation, No. 8 stone should be used.

(3) Internal drainage layers can be avoided when fill material as permeable as BBorrow is used. 
(4) Facing units should include active mechanical connections between blocks, and between blocks and reinforcement layers. Purely frictional connections are not recommended. It should be noted that the need for active mechanical connection makes the use of geotextiles as reinforcement inadequate for segmental facing walls. For this reason, geotextiles should be used only in wrap-around facing walls.

(5) When seismic performance is of consideration, the reinforcements should be distributed in such a way that each facing units interface layer is connected to a reinforcement. This will result in leaving no row of facing units unreinforced.

(6) The design methods of the FHWA and the NCMA are recommended. For numerical implementation of these methods, it is suggested to use the software program, MSEW (see Appendix C).

(7) Specification for segmental walls should follow the model presented in Appendix B.

(8) Preference should be given to those systems evaluated by the Highway Innovative Technology Evaluation Center (HITEC), a service center of the Civil Engineering Research Foundation (CERF).

(9) Geotechnical site investigations are of primary importance in order to assess the bearing capacity of the foundation soil and the final settlement of the structure.

(10) The present guidelines will need to be revised and updated as new data and experience become available. It would be highly beneficial to this process that, as part of a future Indiana highway project, a segmental facing reinforced soil wall be instrumented and its performance monitored during and after construction. 


\section{Appendix A. List of References}

AASHTO-AGC-ARTBA Task Force 27 Joint Committee (1990). "In-situ Soil Improvement Techniques: Guidelines for Use of Extensible Reinforcements (Geosynthetics) for Mechanically Stabilized Earth Walls in Permanent Applications", AASHTO, Washington, D.C.

Albers, R. (1996). "Widen a Highway and Save Space", Geotechnical Fabrics Report, $33-35$.

Allen, T. M. and Holtz, R. D., 1991. Design of retaining walls reinforced with geosynthetics. Geotechnical Engineering Congress 1991, ASCE GSP 27: 970-987.

Allen, T. M. (1993). "Issues Regarding Design and Specifications of Segmental BlockFaxed Geosynthetic Walls", Transportation Research Record, 1414, 6-11.

Alston, C. and Crowe, R. E. (1993). "Design and Construction of Two Low Retaining Wall Systems Retrained by Soil Nail Anchors", Transportation Research Record, 1414, 49-58.

Anderson, R. B. (1993). "Construction Considerations for Geogrid-Segmental Block Mechanically Stabilized Earth Retaining Walls", Transportation Research Record, 1414, $12-15$.

Anonymous (1994). “Segmental Retaining Wall Protects Slopes”, Public Works, 125(6), 46-47.

Anonymous (1996). "Hold it Together", Geotechnical Fabrics Report, 36-37. 
Ashmawy, A. K. and Bourdeau, P. L. (1997). "Testing and Analysis of GeotextileReinforced Soil Under Cyclic Loading", Proceedings, Geosynthetics '97 Conference, Long Beach, CA, Vol. 2, pp. 663-674.

Ashmawy, A. K., Bourdeau, P. L., Drnevich, V. P. and Dysli, M. (1999). "Cyclic Response of Geotextile-Reinforced Soil”, Soils and Foundations, Japanese Geotechnical Society, Vol. 39, No. 1, pp. 43-52.

Barrett, R. K. and Ruckman, A. (1996). "Geosynthetics in Jamaica", Geotechnical Fabrics Report, 28-31.

Bathurst, R. J., Simac, M. R. and Berg, R. R. (1993). "Review of NCMA Segmental Retaining Wall Design Manual for Geosynthetic Reinforced Structures", Transportation Research Record, 1414, 16-25.

Bathurst, R. J., Simac, M. R., Christopher, B. R. and Bonczbiewica, C. (1993a). “A Database of Results from a Geosynthetic Reinforced Modular Block Soil Retaining Wall", Proceedings, Conference on Soil Reinforcement: Full Scale Experiments of the 80's, ENPC, Paris, France, November 1993, pp. 341-365.

Bathurst, R. J. and Simac, M. R., 1994. Geosynthetic Reinforced Segmental Retaining Wall Structure in North America, Fifth International Conference on Geotextiles, Geomembranes and Related Products, Singapore, 5-9, Sept.:1275-1298.

Bathurst, R. J. and Simac, M. R. (1995). "Software for Segmental Retaining Walls", Geotechnical Fabrics Report, Vol. 13, No. 7, pp. 20-21.

Bathurst, R. J., Cai, Z. and Pelletier, M. (1996). "Seismic Design and the Performance of Reinforced Segmental Retaining Walls", Geotechnical Fabrics Report, 48-51. 
Bell, J. R. and Barrett, R. K. (1995). "Survivability and Durability of Geotextiles Buried in Glenwood Canyon Wall", Transportation Research Record, 1474, 55-63.

Bergado, D. T. and Chai, J. (1994). "Pillout Force/Displacement Relationship of Extensible Grid Reinforcements", Geotextiles and Geomembranes, 13(6-7), 403-420.

Bergado, D. T., Long, P. V., Lee, C. H., Loke, K. H. and Werner, G. (1994). "Performance of Reinforced Embankment on Soil Bangkok Clay with High Strength Geotextile Reinforcement", Geotextiles and Geomembranes, 13(6-7), 403-420.

Bright, D. J., Collins, J. G., Berg, R. R. (1994). "Durability of Geosynthetic Soil Reinforcement Elements in Tanque Verde Retaining Wall Structures", Transportation Research Record, 1439, 46-54.

Burwash, W. J. and Frost, J. D. (1991). "Case History of a 9m High Geogrid Reinforced Retaining Wall Backfilled with Cohesive Soil”, Proceedings, Geosynthetics '91 Conference, Atlanta, GA, Vol. 2, pp. 485-493.

Buttry, K. E., McCullough, E. S. and Wetzel, R. A. (1993). "Laboratory Evaluation of Connection Strength of Geogrid to Segmental Concrete Units", Transportation Research Record, 1414, 26-31.

Cai, Z. and Bathurst, R. J. (1995). "Seismic Response Analysis of Geosynthetic Reinforced Soil Segmental Retaining Walls by Finite Element Method", Computers and Geotechnics, 17, 523-546.

Chang, D. T., Sun, T. and Hung, F. (1995). "Pullout Mechanism of Geogrids Under Confinement by Sandy and Clayey Soils", Transportation Research Record, 1474, 64-72.

Chewning, R. J. and Collin, J. G. (1991). "Evaluation of Geogrid to Wall Facing Connection for Modular Block Earth Retaining Wall Systems”, Proceedings, Design and 
Construction with Geosynthetics, XXII the Ohio River Valley Soils Seminar, Lexington, KY, pp. 5.1-5.13.

Christopher, B.R., Gill, S. A., Giroud, J.-P., Juran, I., Mitchell, J. K., Schlosser, F. and Dunnicliff, J. (1990). "Reinforced Soil Structure: Vol. I, Design and Construction Guidelines", Report No. FHWA-RD-89-043, November 1990.

Claybourn, A. F. and Wu, J. T. H., 1993. "Geosynthetic-reinforced soil wall design", Geotextiles and Geomembranes, 12(8): 707-724.

Collin, J. G. and Berg, R. R. (1993). "Connection Strength Criteria for Mechanically Stabilized Earth Walls", Transportation Research Record, 1414, 32-37.

Collin, J. G. (1996). “Controlling Surficial Stability Problems on Reinforced Steepened Slopes", Geotechnical Fabrics Report, 26-29.

Collin, J.G. (Editor) (1996). Design Manual for Segmental Retaining Walls, $2^{\text {nd }}$ Edition, National Concrete Masonry Association (NCMA)

Ehlich, M. and Mitchell, J. K. (1994). "Working Stress Design Method for Reinforced Soil Walls", Journal of Geotechnical Engineering, 120(4), 625-645.

Findlay, T. W. (1978). "Performance of a Reinforced Earth Structure at Granton", Ground Engineering, Vol. 2, No. 7, pp. 42-44.

Fishman, K. L., Desai, C. S. and Sogge, R. L. (1993). "Field Behavior of Instrumented Geogrid Soil Reinforced Wall”, Journal of Geotechnical Engineering, 119(8), 12931307.

Fuller, C., Lowry, D. and Crowe, E. (1996). "Constructing a Geogrid-Reinforcement Rail Embankment", Geotechnial Fabrics Report, 24-31. 
Hall, K. (2001). "Lafayette Railroad Relocation Project - Modular Block Wall Testing INDOT Contract R-24148”, Unpublished Communication, HNTB, Indianapolis, March 6, 2001.

Hearn, G., Myers, S. and Barret, R. K. (1995). "Independent Facing Panels for Mechanically Stabilized Earth Walls", Transportation Research Record, 1474, 13-22.

Hill, J. J. and Berg, R. R. (1993). "Use of Segmental Wall System by Minnesota Department of Transportation", Transportation Research Record, 1414, 1-5.

Holtz, R. D. and Kovacs, W. D. (1981). “An Introduction to Geotechnical Engineering”, Prentice-Hall, Englewood Cliffs, NJ.

Ingold, T. S. (1981). "A laboratory simulation of reinforced clay walls", Geotechnique, Vol. 31, No. 3, pp. 399-412.

Ingold, T. (1982). "Analytical and laboratory investigations of reinforced clay", Proceedings of the second international conference on geotextiles, Industrial Fabrics Association International, Vol. 3, Aug. 1982, pp. 587-592.

Ingold, T. S. (1983). "Reinforced clay subject to undrained triaxial loading", ASCE Journal of Geotechnical Engineering, 109 (5), pp. 738-744.

Ismail, I and Raymond, G. P. (1995). "Influence of Geosynthetic Reinforcement on Granular Soils", Transportation Research Record, 1474, 96-101.

Karpurapu, R. and Bathurst, R. J. (1995). "Behavior of Geosynthetic Reinforced Soil Retaining Walls Using the Finite Element Method", Computers and Geotechnics, 17, 279-299. 
Keller, G. R. (1995). "Experiences with Mechanically Stabilized Structures and Native Soil Backfill", Transportation Research Record, 1474, 30-37.

Kharchafi, M. and Dysli, M. (1994). "Mechanical Performance of Two Experimental Full-Scale Embankments Reinforced by Geotextiles", Proceedings, $5^{\text {th }}$ International Conference on Geosynthetics, Singapore, Vol. 1, pp. 491-494.

Khing, K H., Das, B. J., Puir, V. K., Yen, S. C. and Cook, E. E. (1993). "Ultimate Bearing Capacity of Eccentrically Loaded Strip Foundation on Geogrid Reinforced Sand", Transportation Research Record, 1414, 65-70.

Koerner, R.M. (1998). Designing with Goesynthetics, Prentice-Hall, Englewood Cliffs, $\mathrm{NJ}, 4^{\text {th }}$ Edition.

Koerner, R. M. (2000). "Emerging and Future Developments of Selected Geosynthetic Applications - The $32^{\text {nd }}$ Terzaghi Lecture", ASCE Journal of Geotechnical and Geoenvironmental Engineering, April, pp. 291-306.

Lambe, P.C., Hansen, L.A. (1990). "Design and performance of earth retaining structures", ASCE

Lee, K., Jones, C.J.F.P., Sullivan, W. R. and Trolinger, W. (1994). "Failure and Deformation of Four Reinforced Soil Walls in Eastern Tennessee", Geotechnique, 4(3), 397-426.

Leonards, G. A., Frost, J. D. and Bray, J. D. (1994). "Collapse of Geogrid-Reinforced Retaining Structure", ASCE Journal of Performance of Constructed Facilities, 274-292.

Leshchinsky, D. and Smith, D. S., 1988. Mechanically stabilized walls over soft clay: Geosynthetic to prevent deep-seated failures. Geotextiles and Geomembranes, 7(4): 309323. 
Leshchinsky, D., Kaliakin, V., Boe, P. and Collin, J. (1994). "Failure Mechanism in Geogrid Reinforced Segmental Walls: Experimental Implications", Soils and Foundations, 34(4), 33-41.

Leshchinsky, D., Ling, H., and Hanks, G., 1995. Unified design approach to geosynthetic reinforced slopes and segmental walls. Geosynthetics International, 2(5): 845-881.

Leshchinsky, D. (1999). "Putting Technology to Work: MSEW and ReSlope for Reinforced-Soil-Structure Design”, Geotechnical Fabrics Report, Vol. 17, No. 3, pp. 3438.

Lopes, M. L., Cardoso, A. S. and Yeo, K. C. (1994). "Modeling Performance of a Sloped Reinforced Soil Wall Using Creep Function”, Geotextiles and Geomembranes, 13(3), 181-197.

Martin, J. S. and Simac, M. R. (1996). "Landfill's Slopes Pose Unusual Design Challenge", Geotechnical Fabrics Report, 28-32.

Munfakh, G. A. (1995). "Contracting for Mechanically Stabilized Backfill Walls", Transportation Research Record, 1474, 46-52.

Omar, M. T., Das, B. J., Puri, V. K., Yen, S. C. and Cook, E. E. (1993). "Shallow Foundations on Geogrid-Reinforced Sand", Transportation Research Record, 1414, 5964.

Peck, R. B., Hansen, W. E. and Thornburn, T. H. (1974). "Foundation Engineering", John Wiley \& Sons, New York, $2^{\text {nd }}$ Edition.

Runser, D.J. (1999). "Instrumentation and experimental evaluation of a $17 \mathrm{~m}$ tall reinforced earth retaining wall”, MS thesis, Purdue University 
Simac, M. R., Christopher, B. R. and Bonczkiewicz, C. (1990). "Instrumented Field Performance of a $6 \mathrm{~m}$ Geogrid Soil Wall", Proceedings, $4^{\text {th }}$ International Conference on Geotextiles, Geomembranes and Related Products, The Hague, Netherlands, Vol. 1, pp. 53-59.

Soong, T.Y. and Koerner, R. M. (1997). "On the required connection strength of geosynthetically reinforced walls". Geotextiles and Geomembranes, 15(4-6): 377-393.

Wang, Y. H. and Wang, M. C. (1993). "Internal Stability of Reinforced Soil Retaining Structures with Cohesive Backfills", Transportation Research Record, 1414, 38-48.

Wetzel, R. A., Buttry, K. E. and McCullough, E. S. (1995). "Preliminary Results from Instrumented Segmental Retaining Wall', Proceedings, Geosynthetics '95 Conference, Nashville, TN, Vol. 1, pp. 133-146.

Wilson-Fahmy, R. F., Koerner, R. J. and Sansome, L. J. (1994). "Experimental Behavior of Polymeric Geogrids in Pullout”, Journal of Geotechnical Engineering, 120(4), 661676.

Wong, K. S. and Broms, B. B. (1994). "Failure Modes at Model Tests of a Geotextile Reinforced Wall”, Geotextiles and Geomembranes, 13(6-7), 475-493.

Wu, J.T.H. (1994). "Design and construction of low cost retaining walls", Colorado Transportation Institute.

Yoder, E. J. and Witczak, M. W. (1975). "Principles of Pavement Design”, John Wiley $\&$ Sons, New York, $2^{\text {nd }}$ Edition. 


\section{Appendix B. Specification Model}

The following specification model is recommended by NCMA for segmental reinforced soil walls. It is suggested that a similar model be adopted by INDOT.

\section{A. General}

\section{Description}

Work shall consist of furnishing materials and placement of segmental retaining wall system in accordance with these specifications and in reasonably close conformity with the lines, grades, design and dimensions shown on the plans or as established by the Owner or Owner's Engineer.

\section{Related Work}

- Section __ : Site Preparation

- Section _ _ : Earthwork

\section{Reference Standards}

3.1 Engineering Design

- NCMA Design Manual for Segmental Retaining Walls

- FHWA Design and Construction Guidelines for Reinforced soil Structures

3.2 Segmental Retaining Wall Units

- $\quad$ ASTM C 140 : Sampling and Testing Concrete Masonry Units

- ASTM C 1262 : Evaluating the Freeze-Thaw Durability of Manufactured Concrete Masonry Units and Related Concrete Units. 
3.3 Geosynthetic Reinforcement

- ASTM D 4595 : Test Methods for Tensile Properties of Geotextiles by the WideWidth Strip Method

- ASTM D 5262 : Test Method for Evaluating the Unconfined Creep Behavior of Geosynthetics

- GRI GG-1 : Single Rib Geogrid Tensile Strength

- GRI GG-5 : Geogrid Pullout

- GRI GT-6 : Geotextile Pullout

3.4 Soils

- ASTM D 698 : Moisture Density Relationship for Soils, Standard Method

- ASTM D 422 : Gradation of Soils

- ASTM D 424 : Atterberg Limits of Soils

- ASTM D G51 : Soil pH

3.5 Drainage Pipe

- ASTM D 3034 : Specification for Polyvinyl Chloride (PVC) Plastic Pipe

- ASTM D 1248 : Specification for Corrugated Plastic Pipe

3.6 Where specifications and reference documents conflict, the Owner's Engineer shall make the final determination of applicable document.

\section{Approved Segmental Retaining Wall Systems}

4.1 Suppliers of segmental retaining wall system material components, engineering and construction shall have demonstrated experience in the construction of similar size and types of segmental retaining walls on previous projects, and shall be approved by the Owner's Engineer. The supplier must be approved two weeks prior to bid opening. Suppliers currently approved for this work are: 


\section{Submittals}

\subsection{Material Submittals}

The contractor shall submit notarized manufacturer's certifications, 30 days prior to the start of work, stating that the SRW units, the Geosynthetic reinforcement, and the drainage aggregate meet the requirement of this specification. The contractor shall provide a list of successful projects with references showing that the installer for the segmental retaining wall is qualified and has a record of successful performance.

\subsection{Design submittal}

The contractor shall submit 3 sets of detailed design calculations, construction drawings, and shop drawings for approval at least 30 days prior to the beginning of

reinforced segmental retaining wall construction. A detailed explanation of the design properties for the Geosynthetic reinforcements shall be submitted with the design. All computer generated calculations and drawings shall be prepared and sealed by a professional engineer, licensed in the State or Province where the wall is to be built.

\section{Delivery, Storage, and Handling}

6.1 The contractor shall inspect the materials upon delivery to assure that proper type and grade material has been received.

6.2 The contractor shall store and handle all materials in accordance with manufacturer's recommendations and in a manner to prevent deterioration or damage due to 
moisture, temperature changes, contaminants, corrosion, breaking, chipping or other causes.

6.3 The contractor shall protect the materials from damage. Damaged material shall not be incorporated into the segmental retaining wall.

\section{B. Material}

\section{Concrete Segmental Retaining Wall Units}

1.1 Concrete segmental units shall conform to the requirements of design manual (NCMA/FHWA) and have a minimum 28 days compressive strength of 3000 psi and a maximum absorption of $10 \mathrm{pcf}$ as determined in accordance with ASTM C 140. For areas subject to detrimental freeze-thaw cycles as determined by the Owner or Owner's Engineer the concrete shall have adequate freeze/thaw protection and meet the requirements of ASTM C1262.

1.2 All units shall be sound and free of cracks or other defects that would interfere with the proper placing of the unit or significantly impair the strength or permanence of the construction.

1.3 SRW units dimensions shall not differ more than $\pm 1 / 8$ inch except height, which shall not differ more than, $\pm 1 / 16$ inch, as measured in accordance with ASTM C140

1.4 SRW units shall match the color, surface finish and dimension for height, width, depth and batter as shown on the plans.

1.5 If connectors are used by the retaining wall supplier to interconnect SRW units, they shall meet the requirements of the manufacturer. 
1.6 Cap adhesive shall meet the requirements of the SRW units manufacturer.

\section{Geosynthetic Reinforcements}

2.1 Geosynthetic Reinforcements shall consist of Geogrids or Geotextiles manufactured for soil reinforcement applications. The type, strength and placement location of the Geosynthetic reinforcement shall be determined by the Engineer providing the wall design. The design properties of the reinforcement shall be determined according to the procedures outlines in this specification and the design manual (NCMA/FHWA). Detailed test data shall be submitted to the Owner's Engineer for approval at least 30 days prior to construction and shall include tensile strength, creep site damage and durability and pullout and connection test data.

\section{Drainage Pipe}

3.1 The drainage collection pipe shall be a perforated or slotted, PVC or corrugated HDPE pipe. The pipe may be covered with a geotextile sock what will function as a filter.

3.2 Drainage pipe shall be manufactured in accordance with ASTM D 3034 and/or ASTM 1248.

\section{Drainage Aggregate}

4.1 Drainage aggregate shall be a clean crushed stone or granular fill meeting the gradation determined in accordance with ASTM D 422. 


\section{Reinforced Backfill}

5.1 The reinforced backfill shall be free of debris and consist of one of the following inorganic USCS soil types: GP, GW, SW, SP, SM meeting the gradation determined in accordance with ASTM D422.

The maximum size should be limited to $3 / 4$ inch for reinforced soil SRWs unless tests have been performed to evaluate potential strength reduction in the geosynthetic due to installation damage.

The plasticity of the fine fraction of the reinforced soil shall be less than 20

5.2 The $\mathrm{pH}$ of the backfill material shall be between 3 and 9 when tested in accordance with ASTM G51.

\section{Geotextile Filter}

6.1 Drainage geotextile shall have the following minimum properties or shall meet the criteria recommended by the Wall Design Engineer.

$\begin{array}{ll}\text { AOS } & \text { ASTM D4751 } \\ \text { Grab Tensile } & \text { ASTM D4632 } \\ \text { Trap Tear } & \text { ASTM D4533 } \\ \text { Water Flow Rate } & \text { ASTM D4491 } \\ \text { Puncture } & \text { ASTM D4833 }\end{array}$

\section{Wall Design Criteria}

The design by the wall system supplier shall consider the internal stability of the reinforced soil mass and shall be in accordance with acceptable engineering practice and these specifications. External stability including global stability and total and differential 
settlement is the responsibility of the Owner or the Owner's Geotechnical Engineering Consultant. The design life of the structure shall be 75 years unless otherwise specified by the Owner.

\section{Design Height}

The structures' design height, $\mathrm{H}$, shall be measured from the top of the leveling pad to the top of the wall where the ground surface intercepts the wall facing.

\section{Soil Reinforcement Length}

The minimum soil reinforcement length shall be as required to achieve a minimum width of structure, B, measured from the front face of wall to the end of the soil reinforcements, greater than or equal to 50 70 percent of the design height, H. The length of the reinforcements at the top of the wall may be increased beyond the minimum length required to increase pullout resistance.

\section{Inclination of Failure Surface}

3.1 A Coulomb failure surface through the base of the wall behind the facing units up to the ground surface at or above the top of wall shall be assumed in design of walls. (NCMA)

3.2 Two different failure surfaces through the base of the wall behind the facing units up to the ground surface at or above the top of wall shall be assumed in design wall. (FHWA)

\section{Soil}

Design parameters: The following soil parameters shall be assumed for the design unless otherwise shown on the plans or specified by the Engineer. 

Reinforced fill:
unit weight $=$ tcm, $\phi=$ , $\mathrm{C}=0$
Reinforced backfill:
unit weight $=$ tcm, $\phi=$ $\mathrm{C}=0$
Foundation soils: unit weight $=$ tcm, $\phi=$ $\mathrm{C}=0$

\section{Minimum Factors of Safety for Internal Stability:}

Reinforcement yield (rupture): $\mathrm{FS}_{\mathrm{UNC}}=1.5 @$ end of service life.

Reinforcement pullout: FS=1.5 against ultimate pullout (GRI GG-5 or GRI GT-6)

\section{Allowable Reinforcement Tension:}

The allowable reinforcement tension, $\mathrm{T}_{\mathrm{a}}$, at the end of the service life shall consider the time-temperature creep characteristics of the reinforcement, environmental degradation, construction induced damage and an overall factor of safety.

\section{Minimum Factors of Safety for external stability:}

Sliding of the mass:

Overturning of the mass:

Bearing capacity:

Eccentricity:
$\mathrm{FS}=1.5$

$\mathrm{FS}=2.0$

$\mathrm{FS}=2.0$

L-2e shall fail within the rear two thirds of the structure.

\section{Connection Strength}

The allowable connection strength of reinforcements to facing units, $\mathrm{T}_{\mathrm{ac}}$ shall be the lesser of:

$$
\begin{aligned}
& \mathrm{T}_{\mathrm{cl}}=\mathrm{T}_{\mathrm{ultconn}} / \mathrm{FS}_{\mathrm{c}}<\mathrm{T}_{\mathrm{a}} \\
& \mathrm{T}_{\mathrm{cs}}=\mathrm{T}_{\text {conn }} @ 3 / 4<\mathrm{T}_{\mathrm{a}}
\end{aligned}
$$

where: 


$\begin{array}{lll}\mathrm{T}_{\mathrm{ultconn}} & = & \text { ultimate connection strength } \\ \mathrm{T}_{\mathrm{cl}} & = & \text { long-term allowable connection strength } \\ \mathrm{T}_{\mathrm{cs}} & = & \text { long-term connection strength with serviceability } \\ \mathrm{T}_{\mathrm{conn}} @ 2 & = & \text { the connection strength at } 2 \mathrm{~cm}(3 / 4 \text { inch)deformation } \\ \mathrm{FS}_{\mathrm{c}} & = & \text { Factor of safety against connection failure }(1.5)\end{array}$

\section{State of Stress:}

9.1 The lateral earth pressure to be resisted by the reinforcements at each reinforcement layer shall be calculated using the Coulomb coefficient of earth pressure, $\mathrm{K}_{\mathrm{a}}$, times the vertical stress at each reinforcement layer.

9.2 The vertical soil stress at each reinforcement layer shall be taken equal to the unit weight of soil times the depth to the reinforcement layer below the finished grade behind the facing units. A coefficient of active earth pressure, $\mathrm{K}_{\mathrm{a}}$, shall be used from top to bottom of wall. The coefficient of active earth pressure, $K_{a}$, shall be assumed independent of all external loads except sloping fills. For sloping fills, the coefficient of active earth pressure, $\mathrm{K}_{\mathrm{a}}$, appropriate for the sloping condition, using Coulomb earth pressure, shall be used in the analysis.

\section{Minimum embedment}

The minimum wall embedment shall be the greater of $0.5 \mathrm{~m}$ or the following:

$\begin{array}{ll}\text { Level Slope in Front } & \mathrm{H}^{\prime} / 20 \\ \text { Level Slope (abutments) } & \mathrm{H}^{\prime} / 10 \\ \text { 3H:1V Slope in Front } & \mathrm{H}^{\prime} / 10 \\ \text { 2H:1V Slope in Front } & \mathrm{H}^{\prime} / 7 \\ \text { 3H:2V Slope in Front } & \mathrm{H}^{\prime} / 5\end{array}$

where $\mathrm{H}^{\prime}$ is the exposed height of the wall 


\section{Settlement control}

It is the responsibility of the Owner or the Owner's Geotechnical Engineering Consultants to determine if the foundation soils will require special treatment to control total and differential settlement.

\section{Construction}

\section{Inspection}

1.1 The Owner or Owner's Engineer is responsible for certifying that the contractor meets all the requirements of the specification. This includes all submittals for materials and design, qualifications and proper installation of the system.

1.2 As requested by the Owner's Engineer or Contractor, the segmental retaining wall system supplier shall provide a qualified and experienced representative on site for up to 3 days to assist the Contractor regarding proper wall installation.

1.3 The contractor's field construction supervisor shall have demonstrated experience and be qualified to direct all work at the site.

\section{Excavation}

2.1 The contractor shall excavate to the lines and grades shown on the project grading plans. The contractor shall take precautions to minimize over-excavation. Excavation support, if required, shall be designed by the contractor.

\section{Foundation Preparation}

3.1 Following excavation for the leveling pad and the reinforced soil zone foundation soil shall be examined by the Owner's Engineer to assure the actual foundation soil 
strength meets or exceeds the assumed design bearing strength. Soils not meeting the required strength shall be removed and replaced with soil meeting the design criteria, as directed by the Owner's Engineer.

\section{Leveling Pad Preparation}

4.1 A minimum $15 \mathrm{~cm}$ ( 6 inch) thick layer of compacted granular material shall be placed for use as a leveling pad up to the grades and locations as shown on the construction drawings. The granular base shall be compacted to provide a firm, level bearing pad on which to place the first course of concrete segmental retaining wall units. Compaction should be performed using a lightweight compactor, such as a mechanical plate compactor to obtain a minimum of $95 \%$ of the maximum standard Proctor density (ASTM D 698).

\section{SRW and Geosynthetic Reinforcement Placement}

5.1 All materials shall be installed at the proper elevation and orientation as shown in the wall details on the construction plans or as directed by the Owner's Engineer. The concrete segmental wall units and geosythetic reinforcement shall be installed in general accordance with the manufacturer's recommendations. The drawings shall govern in any conflict between the two requirements.

5.2 Overlap of the geosynthetic in the design strength direction shall not be permitted. The design strength direction is that length of Geosynthetic reinforcement perpendicular to the wall face and shall consist of one continuous piece of material. Adjacent sections of Geosynthetic shall be placed in a manner to assure that the horizontal coverage shown on the plans is provided. 
5.3 Geosynthetic reinforcement should be installed under tension. A nominal tension shall be applied to the reinforcement and maintained by staples, stakes, or hand tensioning until the reinforcement has been covered by at least $15 \mathrm{~cm}$ of soil fill.

5.4 The overall tolerance relative to the wall design verticality or batter shall not exceed $\pm 3.0 \mathrm{~cm}$ maximum over a $3.1 \mathrm{~m}$ distance; $8 \mathrm{~cm}$ maximum.

5.5 Broken, chipped, stained or otherwise damaged units shall not be placed in the wall unless they are repaired and the repair method and results are approved by the Engineer.

\section{Backfill Placement}

6.1 The reinforcement backfill shall be placed as shown in construction plans in maximum compacted lift thickness' of $25 \mathrm{~cm}$ and shall be compacted to a minimum 95\% of standard Proctor density (ASTM D698) at a moisture content within 2\% of optimum. Backfill shall be placed, spread and compacted in such a manner that eliminates the development of wrinkles or movement of the geosynthetic reinforcement and the wall facing units.

6.2 Only hand-operated compaction equipment shall be allowed within $1 \mathrm{~m}$ of the front of the wall face. Compaction within $1 \mathrm{~m}$ of the back face of the facing units shall be achieved by at least three passes of a lightweight mechanical tamper, plate or roller. No soil density tests should be taken in this area.

6.3 Tracked construction equipment shall not be operated directly on the Geosynthetic reinforcement. A minimum backfill thickness of $15 \mathrm{~cm}$ is required prior to operation of tracked vehicles over the geosynthetic reinforcement. Turning of tracked vehicles should be kept to a minimum to prevent displacing the fill and damaging or moving the geosynthetic reinforcement. 
6.4 Rubber-tired equipment may pass over the geosynthetic reinforcement, if in accordance with the manufacturer's recommendation, at slow speeds less that 10 mph. Sudden braking and sharp turning should be avoided.

6.5 At the end of each day's operation, the contractor shall slope the last level of backfill away from the wall facing to direct runoff of rainwater away from the wall face. In addition, the contractor shall not allow surface from adjacent areas to enter the wall construction site.

\section{Drainage Fill Placement}

7.1 Drainage aggregate shall be placed to the minimum finished thickness and widths shown on the construction plans or as modified by the Owner's Engineer.

7.2 Drainage collection pipes shall be installed to maintain gravity flow of water outside of the reinforced soil zone. The drainage collection pipe should daylight into a storm sewer manhole or along a slope at an elevation lower than the lowest point of the pipe within the aggregate drain.

7.3 The main collection drain pipe, just behind the block facing, shall be a minimum of 8 $\mathrm{cm}$ in diameter. The secondary collection drain pipe should be sloped a minimum of $2 \%$ to provide gravity flow into the main collection drain pipe. Drainage laterals shall be spaced at a maximum $15 \mathrm{~m}$ spacing along the wall face.

\section{Cap Block Placement}

7.1 The cap block and/or top SRW unit shall be bonded to the SRW units below using cap adhesive. 
Appendix C. Documentation on Computer Program, MSEW 

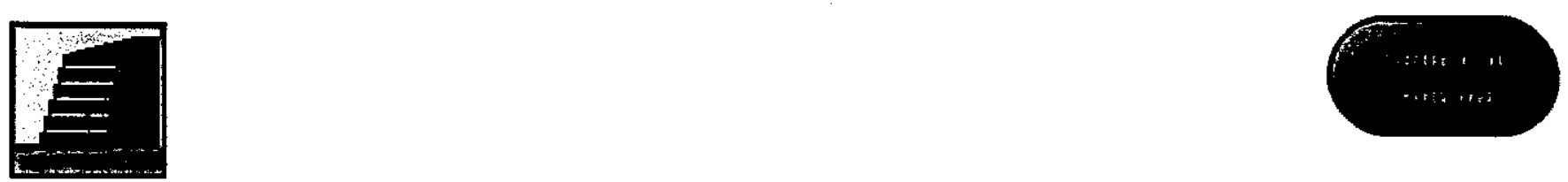

\title{
Introduction
}

The development of MSEW (Mechanically Stabilized Earth Walls) software was sponsored in part by the US Federal Highway Administration (FHWA). MSEW had been subjected to rigorous reviews. Version 1.0 has been designated exclusively for use by US Federal Agencies and US State Highway agencies. ADAMA Engineering, Inc. makes MSEW (1.1) available to the public. Version 1.1 includes an enhancement in which the user can retrieve quantities of reinforcement to estimate its cost. It also allows for live strip load.

MSEW software follows the design guidelines stated in Demonstration Project 82 (Publication No. FHWA-SA-96-071: Mechanically Stabilized Earth Walls and Reinforced Soil Slopes, Design and Construction Guidelines). Most of this manual is available as part of the Help menu in MSEW. MSEW also complies with AASHTO Standard Specifications for Highway Bridges, Interim 98.

You can purchase a copy of FHWA report via the Internet by entering the National Technical Information Service (NTIS) website. Once in this website click on Search and then type "Mechanically Stabilized Earth Walls and Reinforced Soil Slopes Design and Construction Guidelines. FHWA Demonstration Project 82." To place an order, follow instructions. Link to NTIS now.

\author{
ADAMA Engineering, Inc. \\ 33 The Horseshoe \\ Covered Bridge Farms \\ Newark, Delaware 19711, USA \\ Tel. (302) 368-3197 \\ Fax (302) 731-1001
}

E-mail: adama@msew.com 


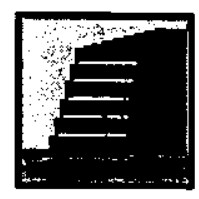

\section{Features}

- MSEW can analyze wall reinforced with geogrids, geotextiles, wire mesh, or metal strips. It allows for reduction factors associated with polymeric reinforcement. Corrosion of metallic reinforcement can be easily assessed.

- Up to five types of reinforcement can be specified for a single wall. The reinforcement type can be characterized by strength, reduction factors, coverage ratio, and cross sectional area (metals).

- MSEW has two modes of operation: Design and Analysis. In the Design mode, the program computes the required layout (i.e., length and vertical spacing) for prescribed factors of safety. In the Analysis mode, the program computes the factors of safety corresponding to a prescribed layout. In either mode, the program produces 'ideal' reinforcement values for strength or coverage ratios so that maximum utilization of reinforcement could be attained. These values can serve as guidance for the refinement of design.

- The user may run MSEW first in its Design mode to obtain a 'computer-based' initial layout. This layout can, for example, correspond to the optimal vertical spacing of reinforcement layers, constrained by a prescribed feasible minimum and maximum spacing. Upon clicking on Analysis, all results obtained in Design are preserved as input data. The user can then modify the layout or properties of some reinforcement layers to insure maximum adaptation to local conditions. MSEW will produce then the factors of safety corresponding to the users modified data.

- Walls with batter of up to 20 degrees and with inclined backfill can be designed and analyzed. Two tiered walls, trapezoidal walls, bridge abutment walls and back to back walls can also be designed and analyzed.

- If needed, MSEW conveniently considers uniform load (dead and live), strip footing (dead as well as live loads to simulate traffic load away from the back of the wall), isolated footing, point load, and horizontal load.

- Seismicity can be invoked either in Design (with factors of safety that are different than the static ones) or in Analysis (producing both the static and seismic factors of safety).

- Different facing units, such as blocks (i.e., connection is based on friction), precast panels, full height precast panels, or wrap-around can be specified. In case of block walls, the frictional connection strength is checked at all reinforcement elevations to assess the potential for reinforcement pullout or break. The confining pressure in between stacked blocks is estimated using the hinge height method. For mechanical connection the required versus available strength is checked at each elevation.

- Bearing capacity is calculated assuming an 'equivalent' homogeneous foundation soil. 
MSEW accounts for factors such as sloping soil at the toe or ground water table at the base.

- MSEW evaluates the mobilization of strength and pullout of each layer, the mobilization of connection strength, the resistance to direct sliding and the eccentricity at each reinforcement layer, and the bearing capacity considering ultimate bearing load as well as eccentricity.

- The natural soil profile composed of up to five different soils, as well as the phreatic surface, can be input for global/compound (slope) stability computations.

- Slope stability analysis (Bishop's method using circular slip surfaces) can be invoked to assess the potential for compound and deep-seated failures. The analysis automatically considers the reinforcement layout and available strength (including the connection strength), the profile of the various soil layers (including retained and reinforced soil), the soil surface geometry, the external loadings, and seismicity. Re-runs of specific circles can be done at a click of a button. For judgement the user can view each analyzed circle and its corresponding calculated driving and resisting moments. The user can also view the intersection of the failure circle with reinforcement layers, the actual force mobilized at each layer for stability, and the inclination of the force.

- In case of unsatisfactory deep-seated stability, the user can specify basal reinforcement of sufficient length and strength. MSEW can produce the resulted stability due to this basal reinforcement assuming circular slip surface.

- MSEW checks for conflicting input data.

- Units can be SI or English.

- The user can override default values to conduct instructive parametric studies or to allow for preliminary adaptation to specific locations. This combined with analysis makes the program useful in forsenic studies.

- MSEW Help is online. It includes all relevant chapters from Demo 82, including photos and figures. The user can print sections of the manual. Information can be accessed by selecting a particular chapter or through selection of a specific keyword. Help is accessible from all screens either through the Toolbar or by pressing F1. Some input screens include specific Help to clarify their usefulness in the context of design or analysis.

- MSEW contains extensive graphics for both input and output data. Some of the graphic displays force resultants thus making the evaluation of results easier. Other graphic provide an instant visualization whether prescribed safety factors have been attained (green) or not (red). Some graphic is instructive in the process of assessing the results (e.g., the horizontal stress distribution along the slip surface, resulting from self-weight of soil as well as external loads, used to calculate the force reaction in the reinforcement).

- Output data is tabulated. In Design, the minimum required length for each mode of stability, considering the prescribed factor of safety, can be viewed (i.e., intermediate results are accessible thus helping to rationalize design decisions).

- Results can be sent to the printer as a formal report. Three different version of report are 
Features Page

http://www.msew.com/features.htr.

available: abstract (2-3 pages), medium length (about 10 pages), and full report (15-20 pages).

- Results can be saved as a text file. Such a file can be retrieved by most word-processors (as well as Notepad) for editing and integration into the user report.

- Layout and circular slip surfaces can be captured as bitmap files. Most graphic programs (e.g., Paint) can retrieve this file, allowing the user to modify and print it out. Most word-processors can retrieve these bitmap files.

- MSEW allows the user to retrieve and display up to four bitmap files. This feature is handy if one is to compare the layout of up to four cross sections by placing their drawing side by side. Furthermore, the user can capture all four cross sections as another bitmap file.

- MSEW calculates the quantities of reinforcement per unit length of wall. Upon entering the unit cost of each reinforcement type, MSEW instantly produces the total cost. This information can be printed or saved as a text file.

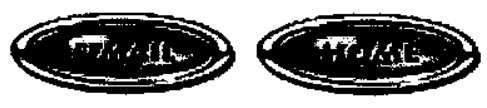

$2 \sim f x$

115

5/3/01 6:43 PN 

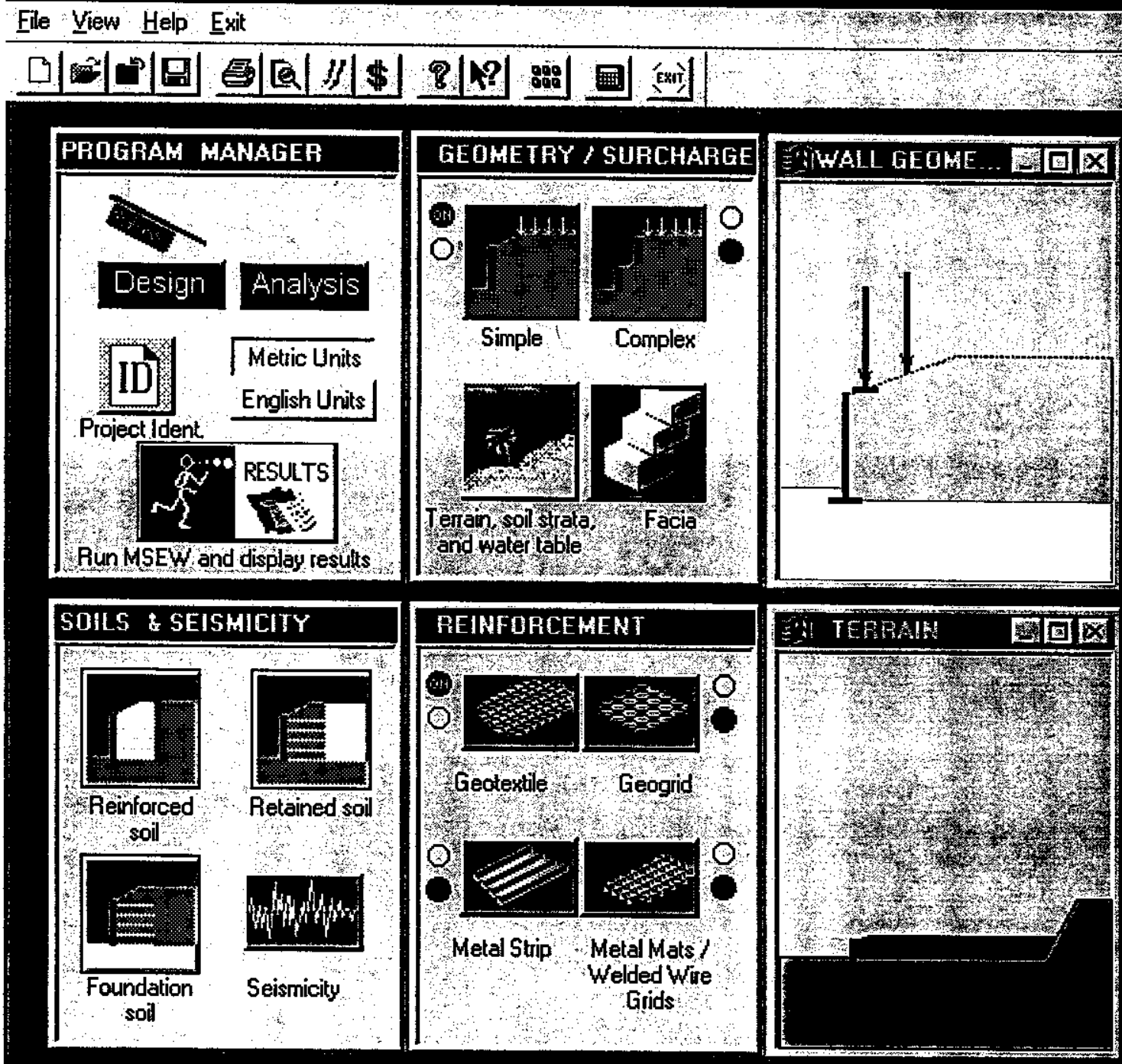

For Help, press F1 

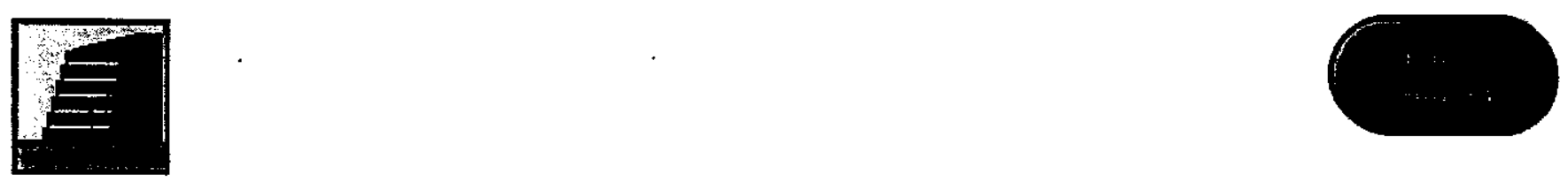

\section{Input Data}

The main menu for input data is grouped into four major windows: Program Manger, Geometry/Surcharge, Soils \& Seismicity and Reinforcement. Figure 1 depicts the layout of these windows, including the buttons that provide the access to data. The window titled Wall Geometry display a close view of the specified wall geometry and surcharge loads. The sixth window, Terrain, provides a global view of the wall over the specified foundation soil strata

Input data screen for simple geometry of wall is shown in Figure 2. Surcharge loads input data is convenient as illustrated in Figure 3 for strip footing. Complex wall structures can be input. Figure 4 captures the input data screen for tiered wall with an offset specified by the user. Figure $\underline{5}$ depicts the input data screen abutment. Figure 6 shows the specified abutment footing.

Input of existing soil strata and phreatic surface is conducted through sequential screens. The user can move back and forth between screens and modify data without reentering the whole sequence from start. Input can be inserted by typing coordinates in the table or by using the 'sliding bars.' For convenience, the profile is plotted simultaneously with the input of numbers. Figure 7 illustrates the input data screen for the phreatic surface.

The variety of facing options is shown in Figure 8. If one selects blocks facing, for example, the blocks dimensions are needed (Figure 9) to estimate the confining pressures in between stacked blocks using the hinge height approach. The user can specify the ratio between the calculated maximum tensile force in the reinforcement and the connection force as a function of depth or just use the default value of 1.00 (Figure 10). Figure 11 shows that the user can specify reduction and safety factors at the connection that are different from their in-soil values. Finally, for block type facing, experimental data relating the connection break or pullout resistance to the strength of the reinforcement, can be input (Figure 12) for interpolation in analysis when assessing the connection at various elevations.

In case seismicity is invoked in design, the user can specify the adjustment required for all design criteria under such conditions (Figure 13).

Figure 14 shows an overview of options available for prescribing the reinforcement in the Design mode. For example, the user can let the program select the optimal vertical spacing by specifying the maximum and minimum constraints (Figure 15). If the user selects to input the ultimate strength of the polymeric reinforcement, for example, the various reduction factors, including coverage ratio, can be conveniently specified (Figure 16). The default values of the empirical $\mathrm{K} / \mathrm{Ka}$ can be override by the user, a feature useful in parametric studies or unique projects (Figure 17).

The options available when prescribing metallic reinforcement are similar to the polymeric ones. However, special features of metallic reinforcement are incorporated. Figure 18 illustrates typical input data for strip reinforcement. Figure 19 shows that horizontal and vertical spacing of strips can be input using a spreadsheet-like table. Figure 20 displays the default values for the interaction coefficients for ribbed strips (based on the uniformity coefficient of the reinforced soil). 
SIHPLE WALL - Geometry / Surcharge

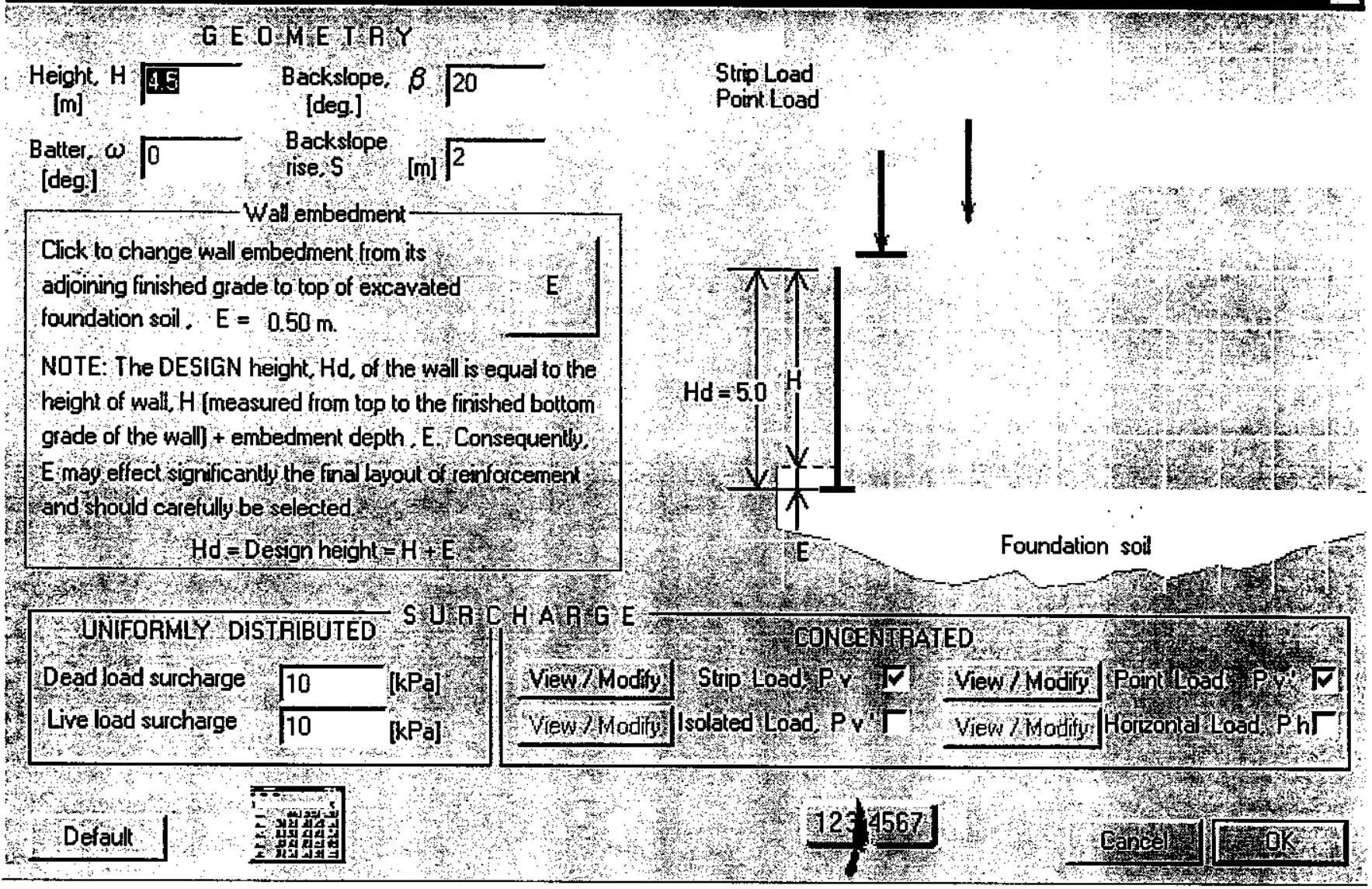




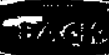

Terrain - Water

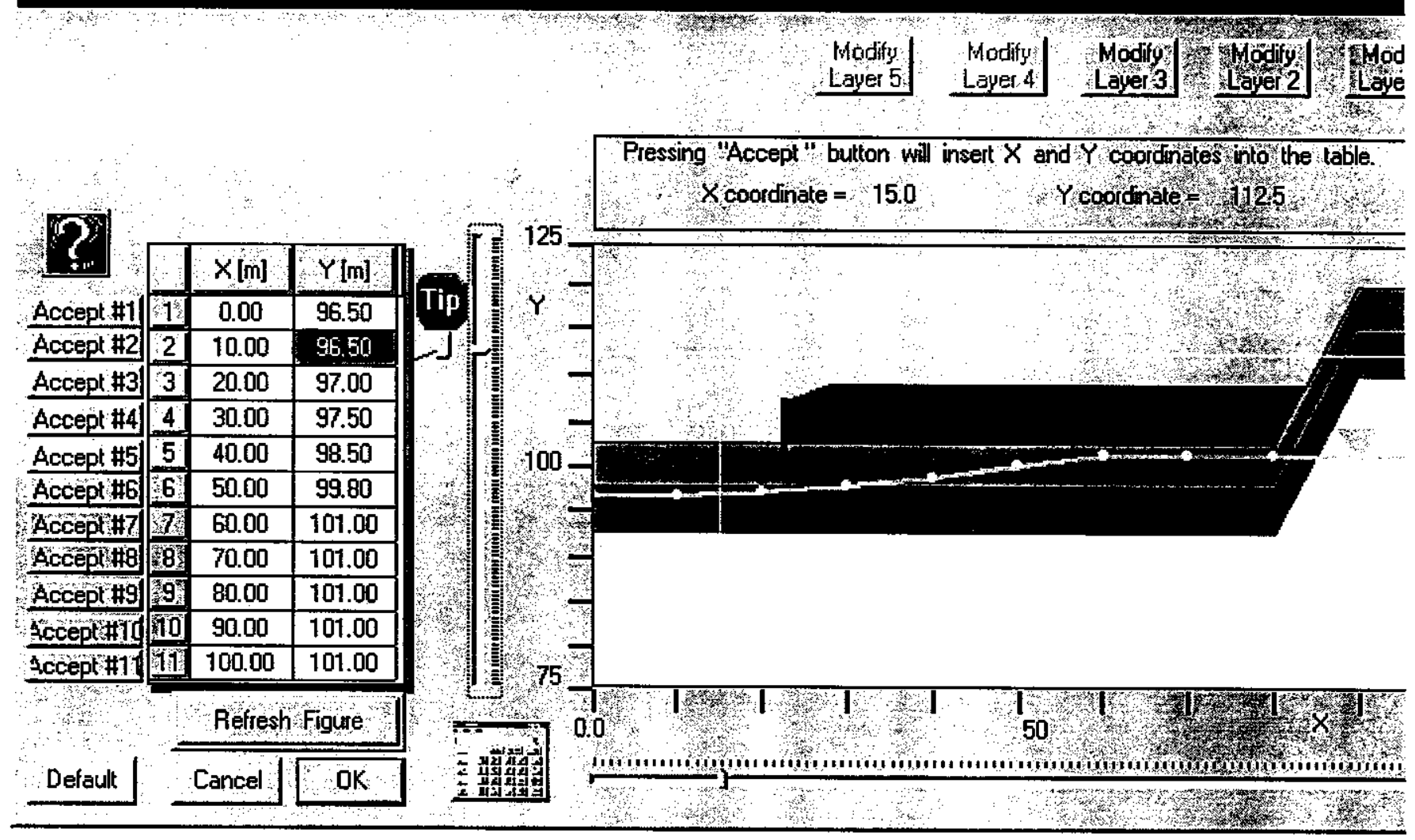



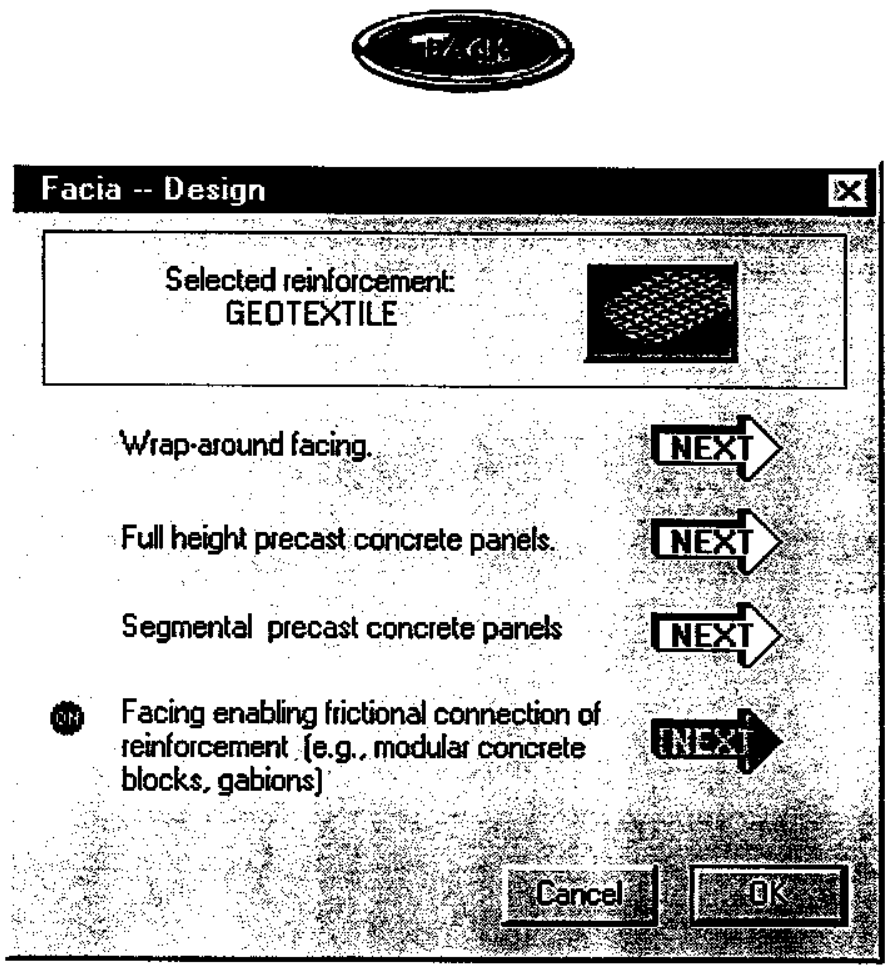


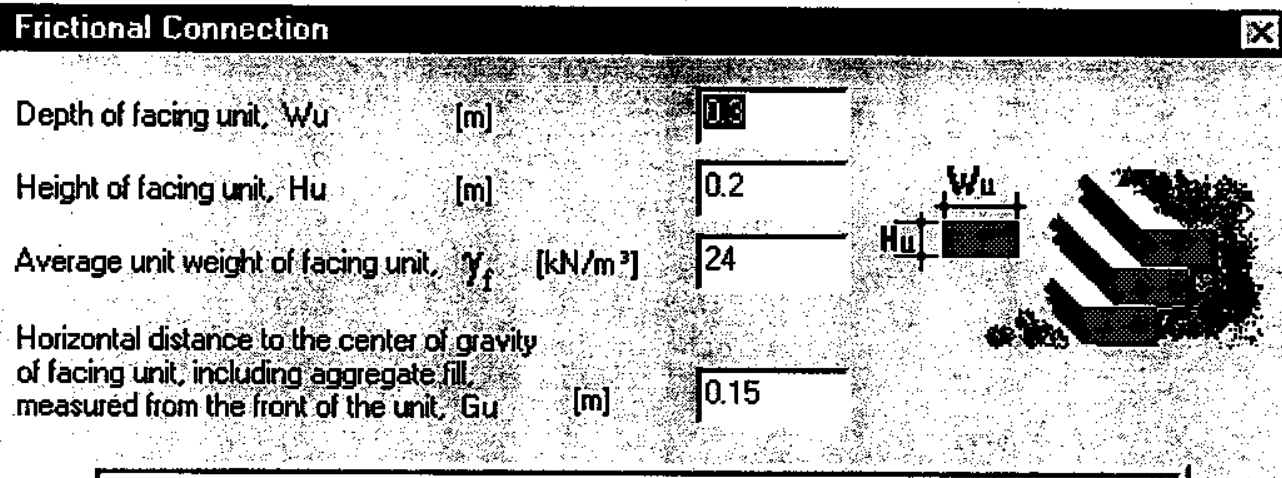

The shear strength of the facing system is conservatively neglected in calculations. Click for note on effects of facing in external stab ty calculations. 

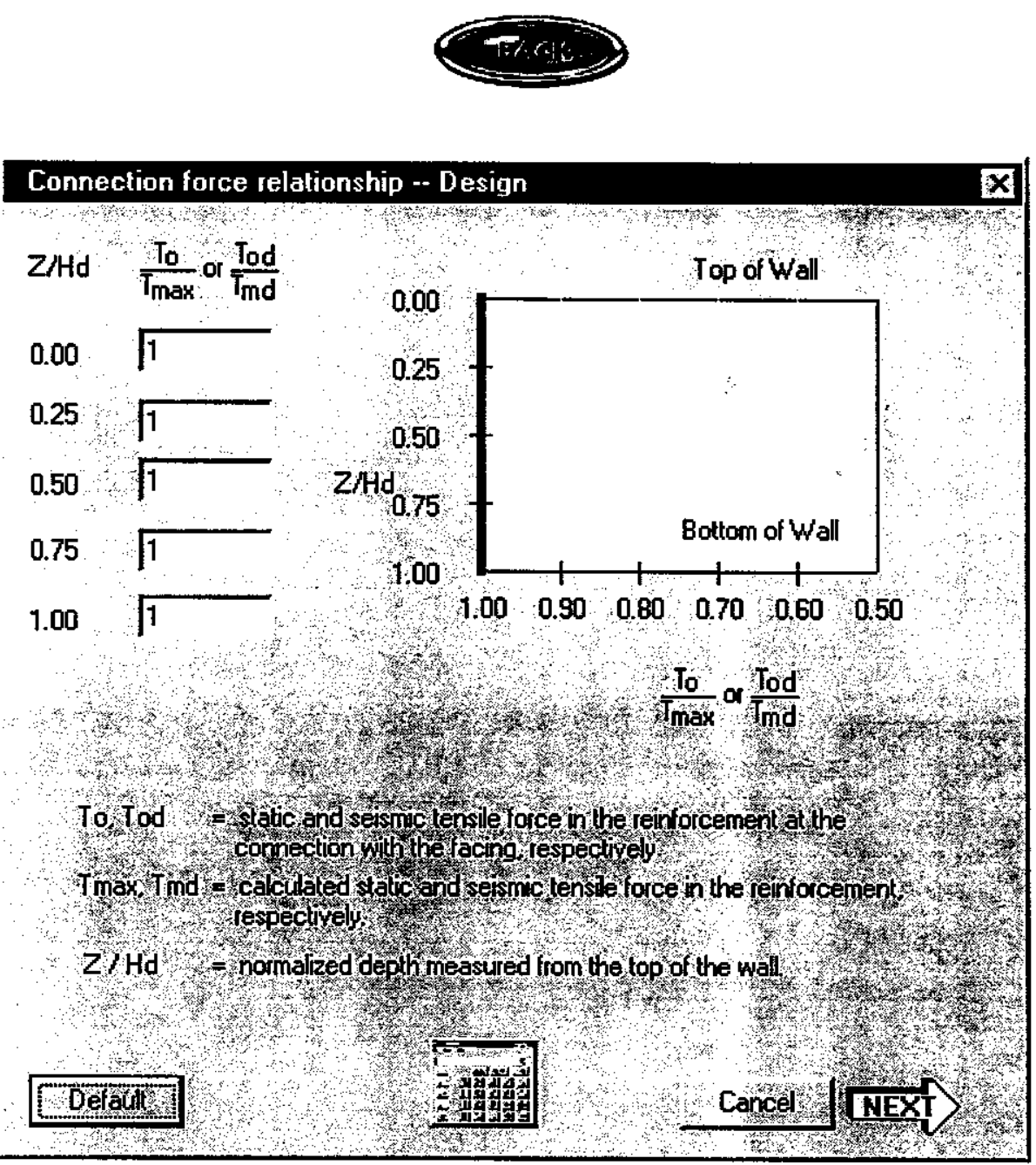


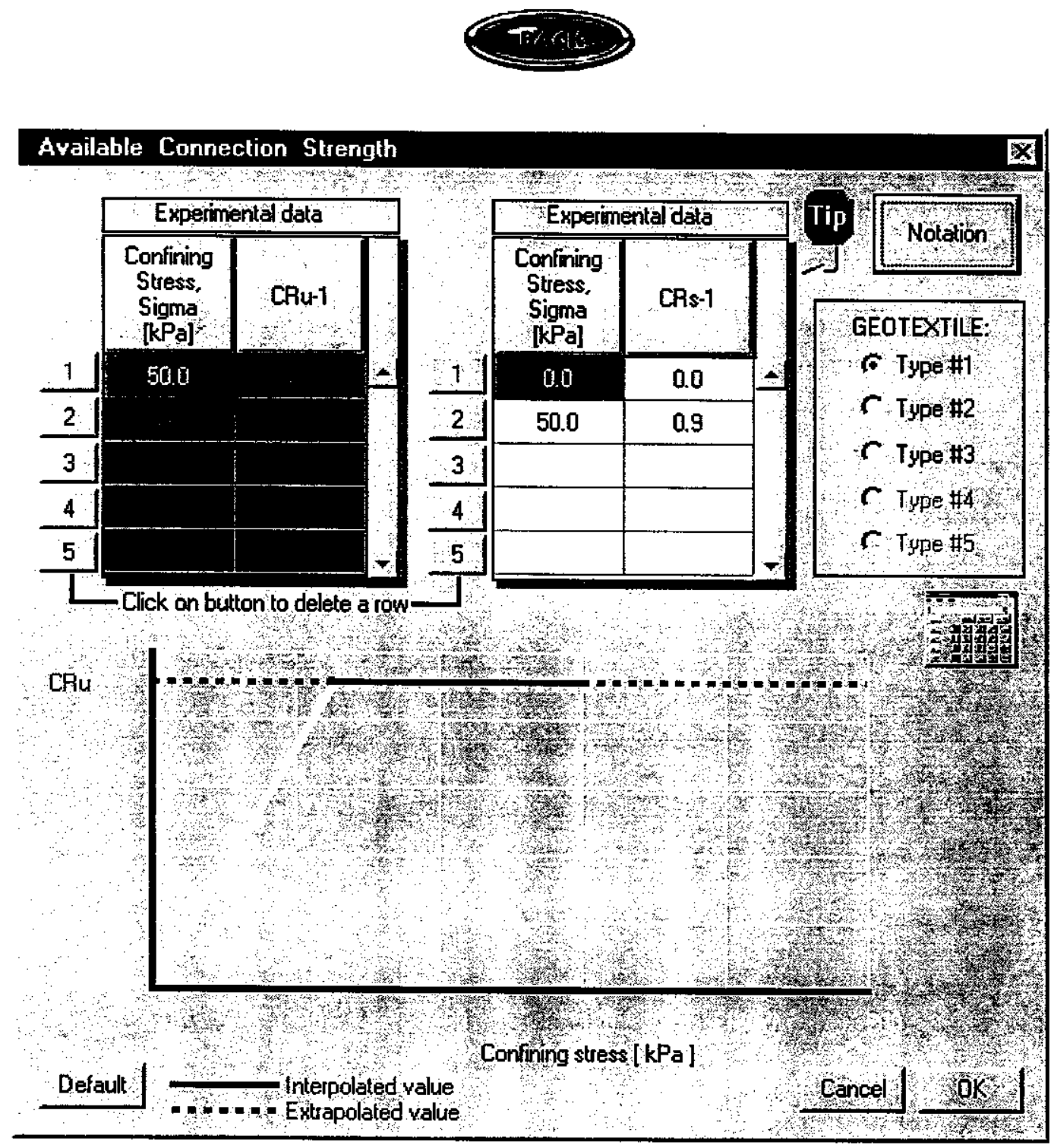



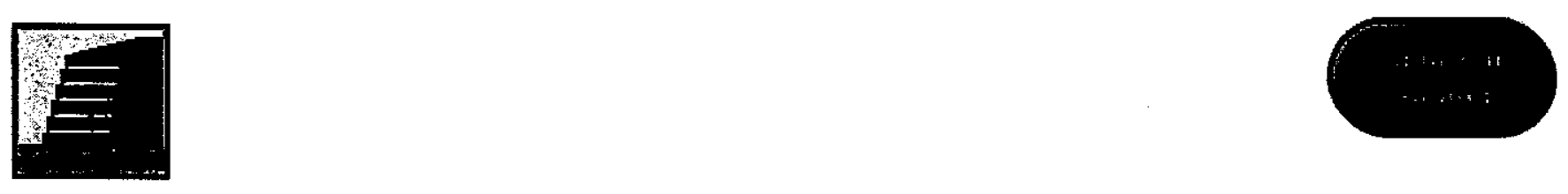

\section{Results (design)}

Upon running MSEW, the user arrives at the results menu screen (Figure 21). Either the intermediate results corresponding only to requirements of individual stability analysis can be examined for engineering judgement or the results corresponding to the synergy of all analyses can be reviewed. Figure 22 shows the synergistic results, indicating with check marks whether design targets (i.e., specified safety factors) were achieved. The user can then review each design aspect individually. Figure 23 shows the calculated factors of safety with regard to reinforcement strength. Clicking on the numeral of each layer, the user can view the distribution of lateral earth pressure used to calculate the reinforcement strength (Figure 24). Note that this distribution accounts for surcharge loads and that it might be different for tiered walls as well as for metallic reinforcement (it depends, among others, on the trace of the slip surface and the stiffness of the reinforcement). Figure 25 provides the status of the connection strength for each reinforcement layer. Figure 26 shows the calculated factors of safety for pullout resistance. The bearing capacity screen (Figure 27) illustrates details such as factors of safety and eccentricity. It also shows the assumed stress distributions along the base as well as the resultant forces acting on the reinforced mass. Figure 28 summarizes the factors of safety against direct sliding at each reinforcement elevation. Similarly, Figure 29 presents the eccentricity at each reinforcement level. Upon clicking on the desired layer, all resultant forces on the reinforced mass as well as the equivalent factor of safety for overturning are displayed (Figure 30).

The designed layout can be analyzed using Bishop slope stability method. In case the circle intersects a reinforcement layer, it considers its available strength at the point of intersection (e.g., if the intersection is at the face, the connection strength is used; if it is near the opposite end of the reinforcement, its pullout resistance may control the available strength.) Slip circles emerging at the face and through the foundation can be specified. Figure 31 shows user specified search grid for locating the minimum factor of safety. Figure 32 presents the summary of stability analysis results. In case of unreasonable result or if the minimum Fs was located on the edge of the search grid, a remark is indicated in the table. The user may then rerun each single case for a different search grid. Upon clicking on the numeral button of each layer, a color display of all calculated factors of safety within the specified search grid appears (Figure 33). Such a presentation may help in assessing the reasonableness of the calculated minimum factor of safety. Further assessment can be achieved by reviewing the actual critical slip circle (Figure 34). For comparison with 'hand calculations,' the user can retrieve the driving and resisting moments for the analyzed circle. Finally, all the analyzed critical slip surfaces can viewed; any 'stray' slip circle should be apparent in such representation.

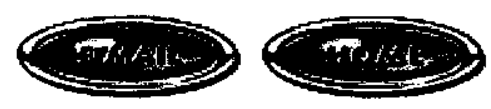



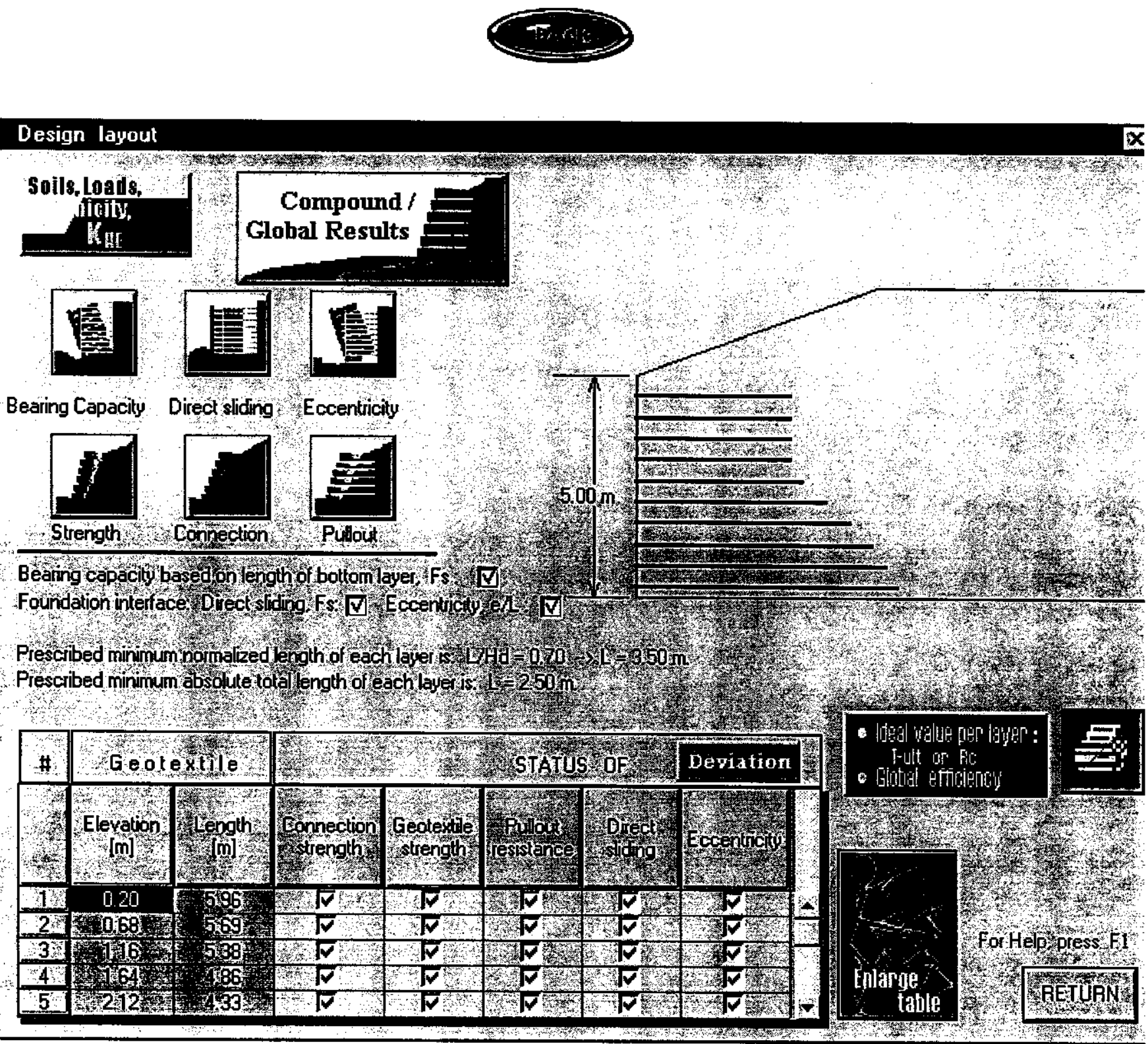


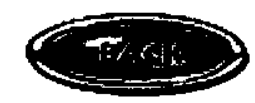

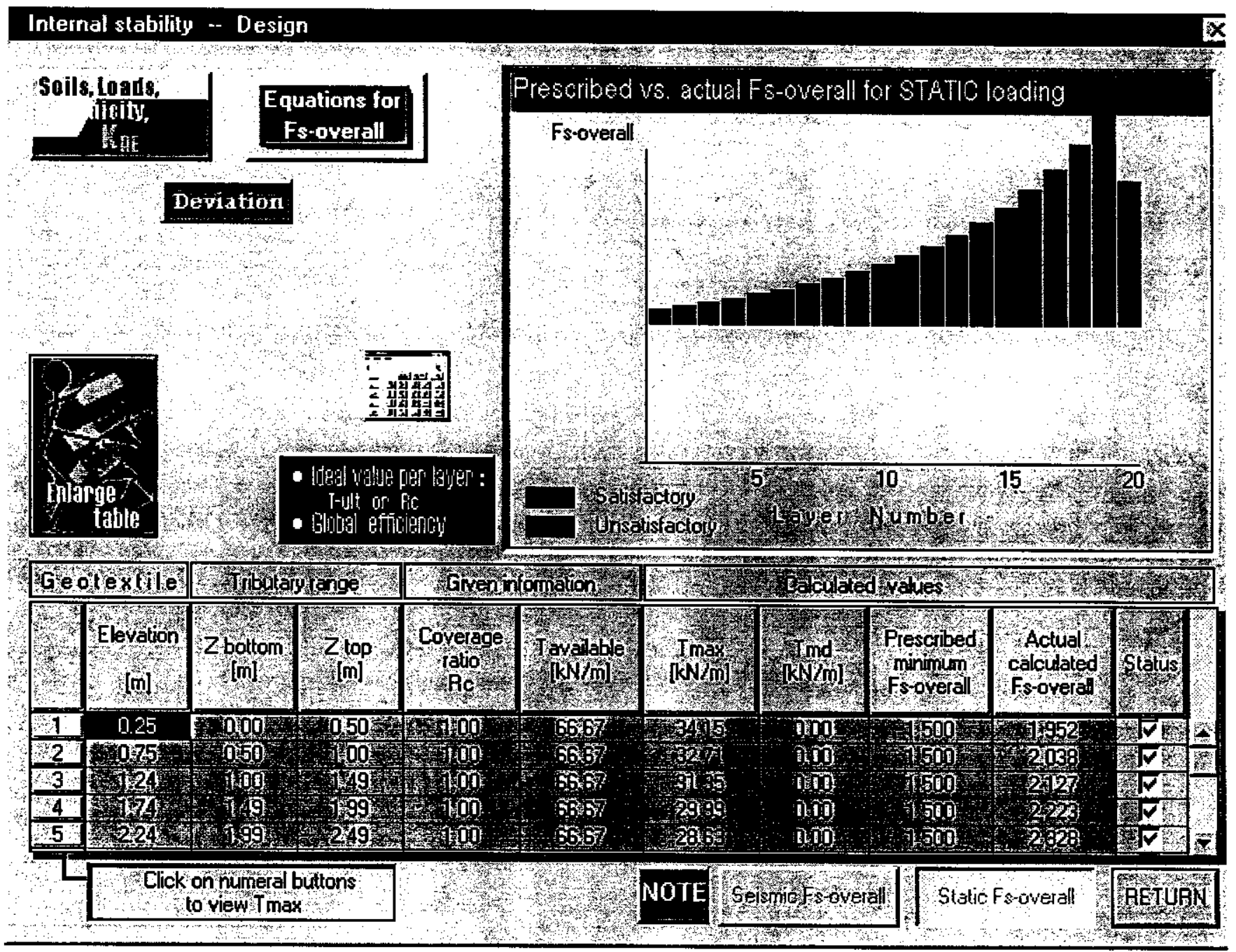




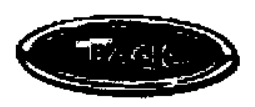

Pullout and total lengths

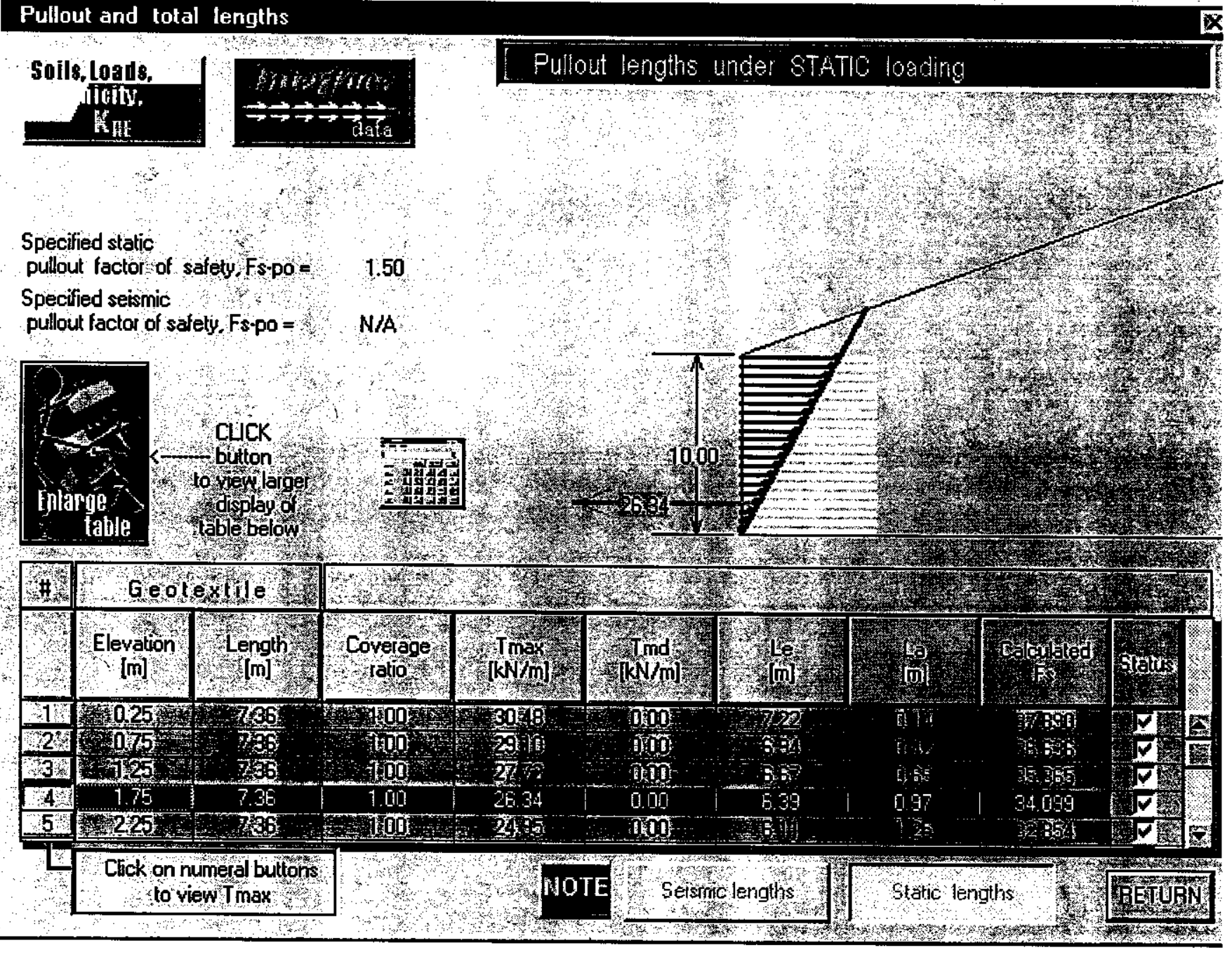




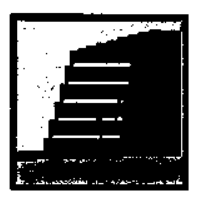

\section{Results (analysis)}

The layout of screens in this mode is similar to that in the Design mode. Please note that the explanations for the presentation of results in the Design mode in this web site are more detailed.

Figure 35 shows the summary of results. Upon clicking on the individual analysis button, detailed information can be retrieved. For example, clicking on Bearing Capacity and then on the Meyerhof button will present a screen similar to Figure 36. Note that all resultant forces acting on the reinforced mass are also displayed. Figure 37 shows the resultant forces used in direct sliding analysis; such a window is retrieved by clicking on the desired reinforcement layer. Similarly, Figure 38 depicts two nestled screens for eccentricity. The calculated factors of safety for the reinforcement strength are shown on Figure 39. Clicking on a particular layer will produce the horizontal stress distribution along the slip surface used to calculate the reinforcement force (Figure 40). Figure 41 shows the safety factors related to the connection strength. The calculated factors of safety for pullout resistance are represented in Figure 42.

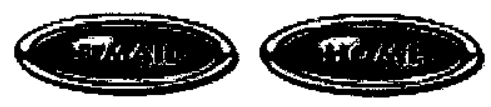



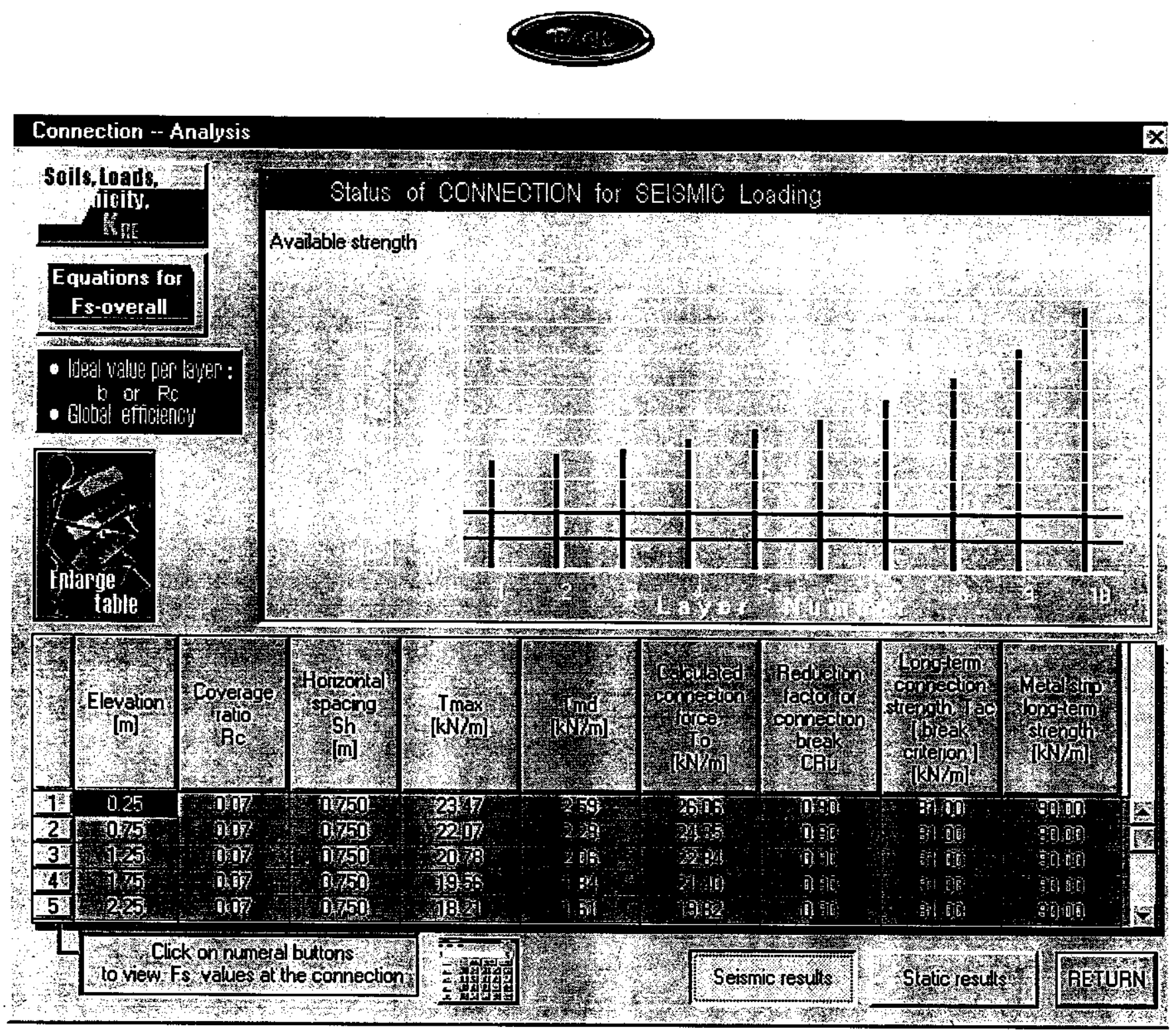

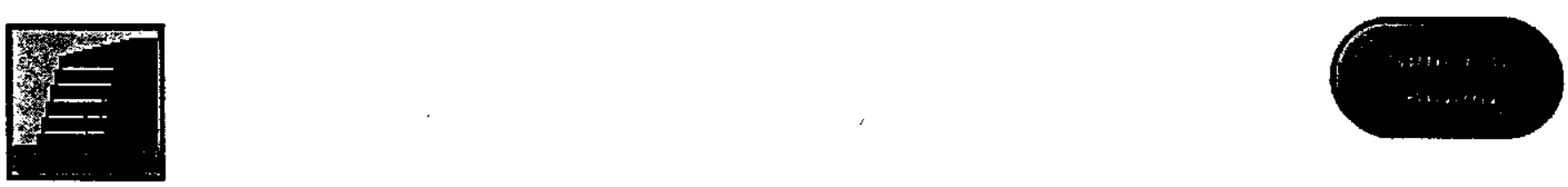

\section{Output}

Detailed output results can be saved as a text file by clicking on a button while in the results screen (e.g., Figure 21). Such text file can be retrieved by most word-processors (or by Notepad) for further modifications and integration into a custom-made report. Furthermore, the layout of reinforcement can be captured as a bitmap file while in the results screen (e.g., Figure 21). Most graphic programs, including some word-processors can retrieve this bitmap file. This can be used for further refinement of drawing and, possibly, be integrated into a report.

MSEW has a built-in three level of standard report: abstract, intermediate, and full report (Figure $\underline{43}$ ). These pre-organized reports can be sent directly to the printer. Figure 44 shows 4 bitmap files produced in 4 different runs. These side-by-side cross sections allow for convenient comparisons of layouts. MSEW enables the user to obtain quantities of reinforcement per unit length of the wall (Figure 45). Upon input of unit cost, the total cost of reinforcing material is immediately calculated. This useful information can be printed or saved as a text file. 
Calculate quantities and cost

DESIGN mode Quantites or 10 layers of Geotextile.

Remarks: Design wall 'A' section @ 50+00

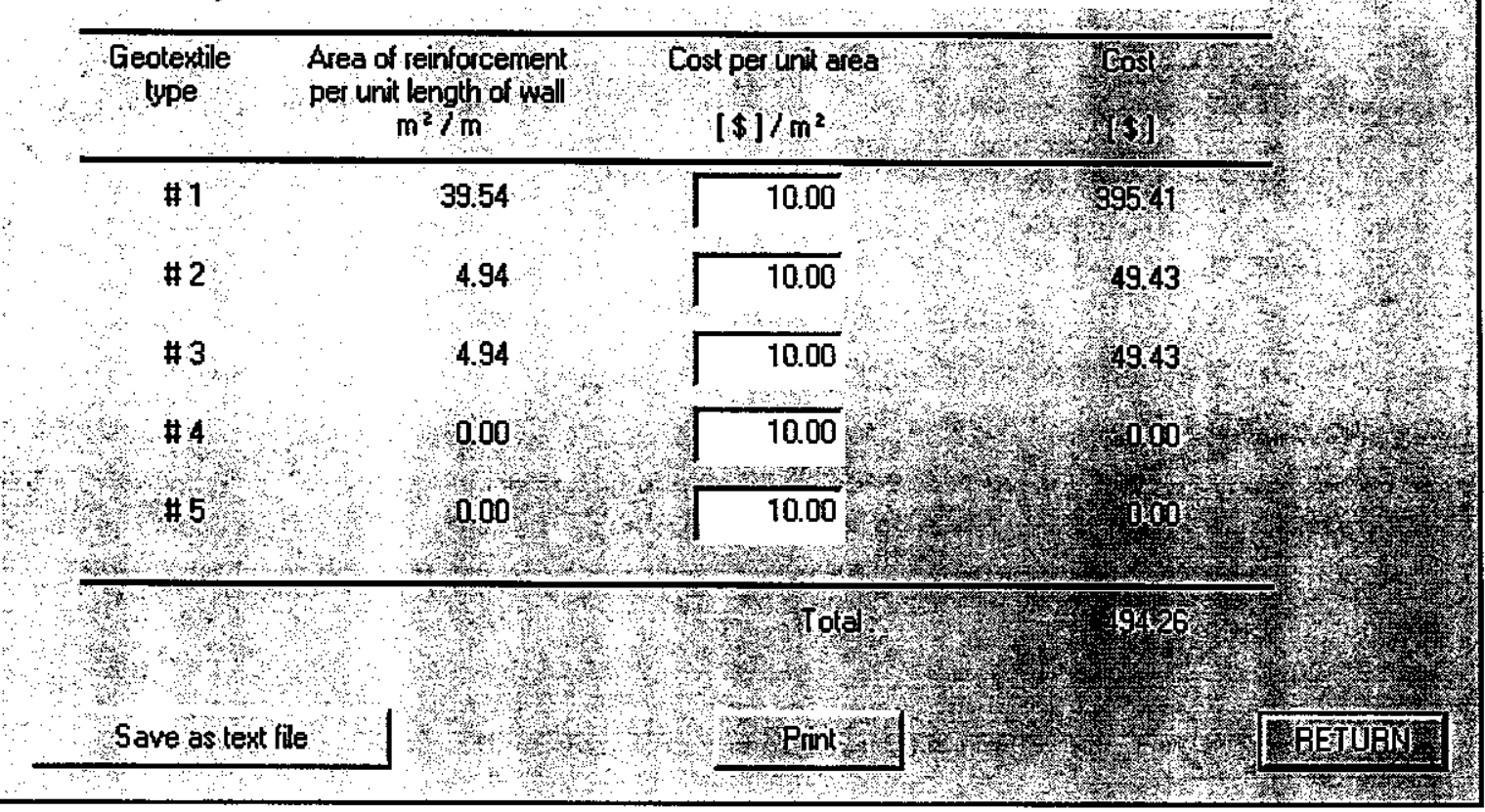


Appendix D. Performance Evaluation of a Reinforced Earth ${ }^{\mathrm{T}}$ Modular Block Retaining Wall (US24 Crossing of Minnow Creek, Near Logansport, Cass County, Indiana) 


\section{Introduction}

Development of mechanically stabilized earth (MSE) retaining wall systems has been rapid due to the substantial cost savings of these systems in comparison to conventional retaining walls. Initial work conducted in France involved inextensible reinforcements (Vidal 1966, 1969a), ultimately leading to a system of ribbed steel strips, precast concrete facing panels, and granular backfill soil. Although Vidal's early theoretical concepts emphasized the restraint of lateral deformation in the reinforced granular fill, for practical purposes current design methods consist of limit state analyses. These methods were developed using scale model and full-size tests and the classical Rankine and Coulomb earth pressure theories (Vidal 1969b, Lee et al. 1973). Results from full-scale instrumentations showed inconsistencies between reinforced soil and classical theory (Schlosser and Long 1974) and led to the semi-empirical coherent gravity method that is currently used today for the design of steel strip MSE structures (McKittrick 1978). With the emergence of geosynthetics, the tie-back wedge method (an active wedge limit equilibrium analysis applicable to extensible reinforcement) was developed by the $U . K$. Department of Transport (1978). As part of an effort supported by the U. S. Federal Highway Administration, Christopher (1993) proposed design concepts for reinforced soil structures that were based on the relative stiffness of the soil and reinforcement in an attempt to unify the coherent gravity procedure with the tie-back wedge analysis for a wide range of reinforcement materials. Commercial and governmental organizations have also developed their own specifications and limitations on design minimums and methods (AASHTO 1996, NCMA 1996). In all cases, due to the complexity of stress and strain fields in a reinforced soil mass, full-scale field performance data has been critical to the development and refinement of MSE design methodologies (Chang et al. 1977, Simac et al. 1990, Christopher et al. 1992).

The objective of this paper is to present data and interpretations from a comprehensive field study of the performance of a tall $(16.9 \mathrm{~m})$ steel strip MSE retaining wall. The instrumentation plan was devised such that predictions of the design model could be compared to measured field values with no assumptions required. Comparisons between design model predictions and measured field data are presented for external lateral earth pressure, bearing pressure on the foundation, internal coefficient of lateral earth pressure, lateral stress on the facing panels, 
tension in the reinforcement, location of the potential failure plane, and pullout capacity of the reinforcement. Conclusions are drawn regarding the applicability of the current design method for tall steel strip MSE walls.

\section{Project Description/Background}

The Indiana Department of Transportation (INDOT) is currently constructing the Hoosier Heartland Highway linking Fort Wayne to Lafayette, Indiana. A portion of the project consists of a US 24 bypass around Logansport, Indiana, which crosses Minnow Creek in Cass County. In lieu of constructing a large embankment with box culverts or a three-span bridge, a one-span bridge supported by steel H-piles with MSE abutment walls was constructed. The walls were designed by the Reinforced Earth Company (Vienna, Virginia, USA) and constructed during the period August 1998 to April 1999. The abutment walls consist of cruciform reinforced concrete facing panels, ribbed steel reinforcing strips, and poorly graded sand with gravel as the backfill soil. The instrumented section of the south abutment wall is $16.9 \mathrm{~m}$ tall and consists of 11 panels with 22 layers of reinforcement (Figure 1). As this was the tallest MSE wall yet constructed for INDOT, funds were provided for detailed field monitoring and analysis of the results (Runser 1999).

\section{Design Model}

The Minnow Creek south abutment wall was designed using the coherent gravity method, which has two primary design requirements: external stability and internal stability. External stability considers the retaining wall and reinforced soil mass as a rigid body subject to active earth pressure from the retained fill and traffic live loads. Reinforcement length is determined such that friction developed at the base of the structure is large enough to resist sliding. The reinforcement must also be sufficiently long such that the wall will not overturn or exceed the bearing capacity of the foundation soil.

Internal stability considers the position and strength of reinforcement within the reinforced soil mass. Figure 2 shows the assumed distributions of lateral earth pressure coefficient $\left(K=\sigma_{h}^{\prime} / \sigma_{v}^{\prime}\right)$, soil-reinforcement friction coefficient $\left(f^{*}\right)$, and strip tension $(T)$ for wall height $H$. 
The backfill is assumed to be cohesionless with angle of internal friction $\phi$. For an MSE wall with inextensible reinforcements, an at-rest $\left(K_{o}\right)$ lateral stress condition is assumed at the top of the reinforced mass, transitioning to an active $\left(K_{a}\right)$ stress condition at a depth of $6 \mathrm{~m}$ and below. At any given elevation, a horizontal earth pressure $\left(\sigma_{h}\right)$ is computed from the appropriate $K$ value and the vertical effective stress for an eccentrically loaded surface given by the Meyerhof method. The maximum tension in a reinforcing strip $\left(T_{\max }\right)$ is calculated as,

$$
T_{\max }=\frac{\sigma_{h} A}{n}
$$

where $A$ is the tributary area of the corresponding panel and $n$ is the number of strips connected to the panel. Points of maximum reinforcement tension define the potential failure surface within the reinforced soil mass. This surface is assumed to be bilinear, consisting of a line from the toe to the point $(0.3 \mathrm{H}, 0.5 \mathrm{H})$ and then extending vertically to the surface. Tension in each reinforcing strip is assumed to vary linearly from zero at the free end to $T_{\max }$ at the potential failure surface, and then linearly from $T_{\max }$ to $T_{c o n}$ at the facing. Lateral stress at the facing is taken as $\sigma_{h}$ for points below mid-height and $0.85 \sigma_{h}$ for points above mid-height. Thus, $T_{c o n}$ is equal to $T_{\max }$ for the lower half of the wall and $0.85 T_{\max }$ for the upper half of the wall. Values of $T_{c o n}$ for all strips connected to any given panel are assumed to be uniform. Reinforced soil in front of and behind the potential failure surface constitutes the active and passive zones, respectively. The reinforcement must extend into the passive zone such that adequate anchorage length of the reinforcement $\left(L_{e}\right)$ is achieved and pullout of the reinforcement is prevented. To compute the necessary $L_{e}$ values, $f^{*}$ is assumed to decrease from 2.0 at the surface to $\tan \phi$ at $6 \mathrm{~m}$ and below, which reflects a decreasing tendency for the soil to dilate with depth.

The design of the Minnow Creek wall (Figures 3 and 4) specified 22 rows of reinforcement with a vertical spacing of $0.75 \mathrm{~m}$ and a variable horizontal spacing ranging from $0.3 \mathrm{~m}$ at the bottom to $1.0 \mathrm{~m}$ at the top. The length of the reinforcement was $11.9 \mathrm{~m}(0.7 H)$. INDOT was concerned with the bearing capacity of the foundation soils and lengthened the lower 5 layers of reinforcement to $15.5 \mathrm{~m}$ in an attempt to reduce the applied bearing pressure (Figure 4). 


\section{Materials}

The reinforced soil was a poorly-graded sand with gravel (SP, A-1-a) with an average dry unit weight of $20.8 \mathrm{kN} / \mathrm{m}^{3}$ and an average moisture content of $4.8 \%$. The retained fill was a wellgraded sand with silt (SW-SM, A-1-b) with an average dry unit weight of $19.7 \mathrm{kN} / \mathrm{m}^{3}$ and an average moisture content of $5.8 \%$. Twelve large-scale consolidated-drained triaxial compression tests were performed on six specimens of the retained soil and six specimens of the reinforced soil having a diameter of $150 \mathrm{~mm}$ and a height of $300 \mathrm{~mm}$. Measured values of $\phi$ for the reinforced and retained soils were $38.0^{\circ}$ and $35.3^{\circ}$, respectively. Both soils had a zero cohesion intercept for the effective stress range applicable to the project. The tributary areas for full panels and half panels were $2.25 \mathrm{~m}^{2}$ and $1.14 \mathrm{~m}^{2}$, respectively. Average weights for full and half panels (9 measurements) were $8.06 \mathrm{kN}$ and $3.21 \mathrm{kN}$, respectively. Laboratory tension tests on 3 reinforcing strips gave average yield and ultimate strengths of $107 \mathrm{kN}$ and $143 \mathrm{kN}$, respectively.

\section{Instrumentation}

The instrumentation plan for the Minnow Creek wall, shown in Figures 3 and 4, was devised such that design model predictions could be compared to measured field values with no assumptions required (Runser 1999).

\section{Instrumented Reinforcing Strips}

A total of 134 T-rosette strain gages were applied to selected reinforcing strips to measure the distribution of strip tension in the reinforced mass, including tensions at the connections to the facing panels. Gages were applied directly to the steel of the reinforcing strip after the zinc galvanization was removed. Each measurement point consisted of two strain gage rosettes attached to the top and bottom of a strip and wired in a full wheatstone bridge. The gages were covered with a vulcanized rubber coating to protect against mechanical damage and water. Each strip was load tested prior to installation to ensure the attached gages were working properly and to determine the load calibration curve for each measurement point. Five reinforcing strips were fully instrumented, with 9 points or 10 measurement points, to measure the distribution of tension along their length (Figure 4). An additional 21 strips were instrumented with 1 point 
placed $175 \mathrm{~mm}$ away from the facing connection (Figure 3). Strain gage readings were zeroed after one lift of soil was placed and compacted to minimize effects of nonuniform bedding.

\section{Earth Pressure Cells}

Twenty-six earth pressure cells were distributed along the foundation and within the reinforced mass to measure bearing pressure, external lateral earth pressure, facing pressure, and internal lateral and vertical stresses. A $25 \mathrm{~mm}$ layer of sand was placed above and below the pressure cells to reduce the effects of gravel particle point loading. Once the cells were covered with sand, backfilling proceeded without modification. The cells against the facing panels were placed in a plexiglass frame to reduce stress concentrations at the edges of the cells (see Figure 10.12 of Dunnicliff (1988)). Measurements from each vertical pressure cell were calibrated to the in situ vertical stress for conditions shortly after cell placement (e.g., 1 to $3 \mathrm{~m}$ of fill). Most vertical pressure cells overestimated the calculated vertical stress, which is likely due to a greater stiffness of the pressure cells relative to the surrounding soil. The resulting average calibration factor of 0.84 was applied to all horizontal and vertical stress measurements to account for this effect.

\section{Load Cells}

Two hydraulic load cells were placed beneath the bottom half panel (type B4R7) and two beneath the bottom full panel (type A9R7) of the instrumented section to measure the vertical force on the leveling pad. Each pair of cells was constructed to match the contact area of the respective panel. For each cell, two $6.4 \mathrm{~mm}$ thick steel plates were welded together to form a $0.8 \mathrm{~mm}$ thick interior chamber that was later saturated with hydraulic oil. The edges were milled to increase cell flexibility following recommendations of Dunnicliff (1988). Prior to installation, the cells were load-calibrated in the laboratory at the estimated future ground temperature of the leveling $\operatorname{pad}\left(10^{\circ} \mathrm{C}\right)$.

\section{Pullout Tests}

Holes were cored in seven facing panels to provide access for pullout tests conducted after construction. Each pullout test was performed on a short reinforcing strip that was fitted with 
strain gages. To avoid the effect of lower compactive effort near the panels, the pullout strips were placed in a $100 \mathrm{~mm}$ diameter PVC pipe that provided $1.5 \mathrm{~m}$ of separation between the facing and the effective length. The two lower pullout strips had an effective length of $1.8 \mathrm{~m}$ and the upper five pullout strips had an effective length of $2.4 \mathrm{~m}$. The strips were pulled using a hydraulic jack with load, displacement, and strip tensile forces recorded every $1 \mathrm{~mm}$ of displacement until $40 \mathrm{~mm}$ of displacement was achieved or the strip yielded.

\section{Other Instrumentation}

Three vertical inclinometers/piezometers were installed, one behind the facing and two within the reinforced section, and extended to bedrock to provide measurements of lateral wall movement and groundwater levels. Additional piezometers were installed behind the reinforced zone and in front of the wall. The elevation of the leveling pad was surveyed regularly to provide an estimate of wall settlement.

\section{External Stability: Design Model vs. Measurements}

\section{External Horizontal Stress}

The design model for a steel strip MSE retaining wall assumes the wall behaves as a gravity structure, rotating about its toe due to active earth pressure behind the reinforced mass. Figure 5 compares the external earth pressure from the model (Rankine theory) using measured soil properties, an equivalent triangular Coulomb active lateral stress distribution, and three earth pressure cell measurements. The Coulomb stress distribution was calculated such that the resultant is equal to the horizontal component of the resultant Coulomb wedge force on the back of the reinforced mass. The Coulomb wedge force was calculated on a vertical plane $11.9 \mathrm{~m}$ behind the facing (i.e., ignoring the additional reinforcement length for the lower 5 reinforcement layers) and using the friction angle of the retained soil as the inclination of the resultant force from the horizontal.

Pressure cell measurements at elevations $197.0 \mathrm{~m}$ and $204.4 \mathrm{~m}$ indicate less horizontal stress than predicted by the design model. Close agreement was obtained with the equivalent Coulomb lateral stress distribution, which is consistent with the interface friction between the reinforced 
and retained fills. The pressure cell at elevation $200.0 \mathrm{~m}$ recorded a horizontal stress 3.5 times greater than the model prediction and is clearly anomalous.

\section{Force Under the Facing Panels}

Figure 6 compares the vertical force measured by the load cells with the weight of overlying facing panels during construction. Load cell $\mathrm{C}$ failed three months into construction and, thereafter, its value was taken equal to that for load cell D. Despite the different contact areas of the two panels, each pair of load cells should nominally measure the same total force. Figure 6 shows that the force measured by load cells A and B was consistently less than that measured by cells $\mathrm{C}$ and $\mathrm{D}$. In addition, the average force on the leveling pad was twice as large as the weight of overlying facing panels. This discrepancy is attributed to shear stress on the back of the panels and vertical loads transferred to the facing panels through the strip connection clips. Less compactive effort was used for backfill placed just behind the panels, which likely increased fill settlement and load transfer to the panels. Although the design model did not predict the stress concentration under the facing panels, no adverse effects on the wall have been observed as a result. Two survey points on the leveling pad indicated a total average settlement of $32 \mathrm{~mm}$ for the instrumented section at the end of construction.

\section{Foundation Bearing Stress}

The lower plot in Figure 7 shows the vertical stress distribution on the foundation soils as obtained from earth pressure cell and load cell measurements. Vertical stress was greatest under the panels and least just behind the panels. Again, load transfer from the backfill to the panels is likely responsible for this non-uniform stress distribution. Foundation pressure increases toward the front of the wall (except behind the facing), which is attributed to the overturning moment on the reinforced mass. Figure 7 also shows the foundation stress distribution calculated using depth $(z)$ and average unit weight $(\gamma)$ and that obtained using the design model and a reinforcement length of $11.9 \mathrm{~m}$ (Meyerhof method). Except near the facing, the measured foundation pressure is in good agreement with both methods. 


\section{Internal Stability: Design Model vs. Measurements}

Internal Vertical Stress

Values of vertical stress measured at three elevations within the reinforced mass using earth pressure cells are also shown in Figure 7, along with values of vertical stress calculated from the design model and $\gamma z$. Similar to the plot for bearing stress on the foundation, very small values of vertical stress were measured just behind the panels, which further supports the concept of high vertical load transfer from the backfill to the panels. Away from the panels, good agreement was found between measured and predicted values of vertical stress using either method.

\section{Horizontal Stress at the Facing}

Figure 8 shows horizontal stress measurements at the facing from earth pressure cells and strain gages at the panel/strip connections, and calculated values of total horizontal stress from the Rankine coefficient of active earth pressure $\left(K_{a}\right)$, the Jaky coefficient of earth pressure at rest $\left(K_{o}\right)$, Coulomb active earth pressure theory (equivalent stress triangle), and the design model. Strain gage measurements were computed by treating each instrumented panel as a free body such that the average lateral earth pressure was the sum of strip forces at the connections divided by the tributary area of the panel. Based on data obtained during pullout testing after construction (see Figure 15), the strain gage measurements are probably more reliable than the earth pressure cells measurements in Figure 8.

With the exception of one pressure cell data point at El. $204.7 \mathrm{~m}$, measured values of lateral stress at the facing were less than all the predictive models. Closest agreement was obtained with the equivalent triangular Coulomb distribution. On average, the design model overestimated the measured lateral stress at the facing (strain gage points) by $90 \%$. This important finding occurs because the reinforcement in the active zone (i.e., between the facing and the potential failure surface) has shear stress directed away from the facing, thus reducing the earth pressure on the facing. This basic concept of reinforced soil behavior, supported by the data herein, is discussed by Lee et al. (1973), Schlosser and Long (1974), Ingold (1982), and others. 
Coefficient of Lateral Earth Pressure

Values of the coefficient of lateral earth pressure $K$ measured at 11 locations within the reinforced mass using earth pressure cells are shown in Figure 9. Measurements taken under the groundwater table were corrected for hydrostatic pressure. Measured $K$ values at the back of the reinforced mass were close to $K_{a}$ using $\phi$ for the retained fill, suggesting active earth pressure conditions. At $5.5 \mathrm{~m}$ from the facing, three measured $K$ values closely match those from the design model. Measured $K$ values behind the facing ranged from 0.77 to 3.0 and were much larger than those given by the design model. Considering that the Rankine passive earth pressure coefficient $\left(K_{p}\right)$ for the reinforced fill is 4.2 , passive failure conditions were approached at El. $204.7 \mathrm{~m}$. These unexpectedly high values of $K$ behind the facing were due to low values of vertical stress (Figure 7), which were due to the stiffness of the reinforcing strips at the panel connections.

\section{Reinforcement Tension}

Figure 10 shows the distribution of tensile force in the five fully instrumented reinforcing strips. Strip tensions predicted by the design model are also shown, along with the assumed failure surface. Similar to the design model, tension in each strip increases from a small value $\left(T_{c o n}\right)$ at the panel connection to a maximum value $\left(T_{\max }\right)$ within the reinforced mass, and then decreases to zero at the end of the strip. The surface of maximum strip tension (i.e., potential failure surface) shows some deviation from that specified by the design model. To account for variability in the strain gage measurements, a potential failure zone (hatched area) is defined by the two largest measurements of tension in each strip. This potential failure zone is in good agreement with the assumed failure surface, which also suggests that the available reinforcement anchorage lengths $\left(L_{e}\right)$ are close to those assumed in the design.

A comparison of measured and predicted values of $T_{c o n}$ and $T_{\max }$ is show in Figure 11. Values of design model strip tension are staggered with depth because an average reinforcement density was assumed at the design stage rather than the actual reinforcement connected to each panel. Measured values of both $T_{\max }$ and $T_{\text {con }}$ show different trends than those calculated by the design model. The largest value of $T_{\max }$ occurs near the mid-height and $\mathrm{T}_{\text {con }}$ does not vary greatly with 
depth. On average, the design model underestimates the maximum strip tension by $17 \%$ and overestimates the connection tension by $127 \%$. Higher values of maximum strip tension translate into lower factors of safety with respect to strip rupture and strip pullout than computed at the design stage. Figure 11 also indicates strip connection tension at any given elevation can vary by $50 \%$ or more. As an example, Figure 12 shows the development of tension in the four reinforcing strips connected to a facing panel of type A4R4 during construction. Strip loads increased rapidly after panel placement and were constant after the end of construction. Although the connection tensions should nominally be equal, final values varied from 7.5 to 17.5 $\mathrm{kN}$.

\section{Soil-Reinforcement Friction Coefficient}

The distribution of reinforcement tension for the fully instrumented strips can be used to calculate values of mobilized apparent soil-reinforcement friction coefficient $\left(f_{m o b}^{*}\right)$, defined as,

$$
f_{m o b}^{*}=\frac{\Delta T}{2 b \cdot \Delta L \cdot h \gamma}
$$

where: $\Delta \mathrm{T}=$ difference in reinforcement tension for two adjacent strain gage measurement points

$\mathrm{b}=$ width of reinforcement

$\Delta \mathrm{L}=$ length of reinforcement between two adjacent strain gage measurement points

$\mathrm{h}=$ height of overburden soil

$\gamma=$ unit weight of overburden soil

Figure 13 presents values of $f_{\text {mob }}^{*}$ within the reinforced mass at the end of construction. Design model values, shown for comparison, are greater than the measured values in the passive zone and less than the measured values in the active zone. The average value of $f_{\text {mob }}^{*}$ for each strip decreases with increasing depth of the strip, indicating that soil-reinforcement friction is more fully mobilized at the top of the wall. 
Values of apparent soil-reinforcement friction coefficient $\left(f^{*}\right)$, shown in Figure 14, were determined from seven pullout tests performed after construction. For two tests (P4, P7) the soil yielded, giving peak values of $f$. For the remaining five tests, the strips yielded and only maximum $f^{*}$ values (less than peak) could be obtained. Design values of $f^{*}$, corresponding to a displacement $\delta$ of $12.7 \mathrm{~mm}$, were measured for all tests. Each value of $f^{*}$ was calculated as (Schlosser and Elias 1978),

$$
f^{*}=\frac{T}{2 b L h \gamma}
$$

where: $\quad T=$ tensile force applied to pullout strip

$$
\mathrm{L}=\text { effective length of reinforcement }
$$

Measured values of maximum/peak $f^{*}$ generally decreased with depth and ranged from 1.6 to 6.8 . On average, measured design values of $f^{*}(\delta=12.7 \mathrm{~mm}$ ) exceeded those given by the design model by $132 \%$ and exceeded the mobilized values $f_{\text {mob }}^{*}$ by $652 \%$.

The distribution of tension within pullout strip P7 is shown as a function of displacement measured at the jack in Figure 15. Load cell force measurements closely matched corresponding force measurements given by the first strain gage, thus providing independent verification of the accuracy of strain gage force measurements in this study. Figure 15 shows that tension did not decrease linearly in strip $\mathrm{P} 7$ during pullout testing, which suggests that $f^{*}$ was not mobilized uniformly along the strip. This is attributed to non-uniform soil conditions and the slight extensibility of the steel. The last data point recorded before the strain gages began to fail ( $\delta=$ $7.92 \mathrm{~mm}$ ) indicates larger values of $f^{*}$ were beginning to be mobilized near the end of the strip.

\section{Equivalent Coefficient of Wall Friction}

Coulomb earth pressure theory considers the horizontal thrust caused by an active wedge of soil that displaces relative to a retaining wall, resulting in friction between the soil and the structure. The coefficient of friction between a wall and soil is commonly taken as $\tan \left(C_{i} \phi\right)$, where $C_{i}=2 / 3$ 
(Bowles 1996). The equivalent coefficient of friction (including both shear stress on the panels and vertical loads transferred to the panels through the connections) was calculated as,

$$
C_{i}=\frac{\tan ^{-1}\left(\frac{\text { vertical force on panels }}{\text { horizontal force on panels }}\right)}{\phi}
$$

The vertical force on the panels was found by subtracting the weight of the panels from the total vertical force measured at the leveling pad. The total horizontal force on the panels was calculated from the measured lateral pressure distribution (strain gage measurements). The average value of $C_{i}$ for the Minnow Creek wall was 0.38 , as compared to $2 / 3$ typically assumed for rigid structures. The value of $C_{i}$ may have been reduced in part because each panel rests on a high-density neoprene pad that allows vertical compression to occur between the panels, reducing the shear that develops on the back of the panels.

\section{Wall Deformations}

Of the three inclinometers installed within the reinforced mass, only the one behind the facing survived construction. Figure 16 shows lateral movement of the facing panels during construction. As sections of the inclinometer tubes were added as the wall was erected, each data point indicates movement that occurred after the corresponding facing panel was placed. Lateral movement increased from essentially zero at the leveling pad to a maximum of $33.3 \mathrm{~mm}$ at $\mathrm{El}$. $197.5 \mathrm{~m}$. Movement then decreased to small values at the top of the wall. These findings are consistent with the design model, which prescribes active earth pressures for the lower portion of the wall and at-rest conditions near the surface. 


\section{Conclusions}

A field performance study of a tall $(17 \mathrm{~m})$ mechanically stabilized earth (MSE) retaining wall with steel strip reinforcements has led to the following conclusions:

1. External lateral stress measured at the back of the reinforced mass was in close agreement with the equivalent triangular active earth pressure distribution given by Coulomb theory.

2. A vertical force approximately equal to twice the weight of the facing panels was measured at the leveling pad. This force is attributed to soil shear stress on the back of the panels and vertical loads transferred from the soil to the facing panels through the strip connection clips.

3. Except near the facing panels, where vertical stresses were low, measured values of vertical stress were in good agreement with the design model (Meyerhof method).

4. Measurements of lateral stress at the facing were less than values based on at-rest conditions, Rankine coefficient of active earth pressure, Coulomb active earth pressure theory (equivalent stress triangle), and the design model. Closest agreement was obtained with Coulomb theory. On average, the design model overestimated the facing stress by $90 \%$.

5. Except for points behind the facing, measured values of the coefficient of lateral earth pressure within the reinforced mass were in good agreement with the design model.

6. The distribution of tension in the reinforcing strips was in good agreement with the design model. Tension in each strip increased from a lesser value $\left(T_{\text {con }}\right)$ at the facing to a maximum value $\left(T_{\max }\right)$ within the reinforced mass, and then decreased to zero at the free end. The location of the surface of maximum tension was in good agreement with the assumed failure surface of the design model. On average, the design model underestimated $T_{\max }$ by $17 \%$ and overestimated $T_{\text {con }}$ by $127 \%$. Measured values of $T_{\max }$ were largest at mid-height and measured values of $T_{c o n}$ did not show a clear correlation with depth.

7. Design values of apparent soil-reinforcement friction coefficient $\left(f^{*}\right)$, measured at a pullout displacement of $12.7 \mathrm{~mm}$, exceeded those specified by the design model, on average, by $132 \%$.

8. Lateral movement of the wall was generally consistent with the design model, with the largest movements measured for lower panels and small movements measured at the top. 


\section{Acknowledgments}

This full-scale instrumentation was financially supported by the Indiana Department of Transportation and the pullout testing was funded by the Reinforced Earth Company. This support is gratefully acknowledged. The writers thank Chad Rietmeyer and Jim Mutz of Crider and Crider, Inc. and Steve Dommer of V.S. Engineering, Inc. who assisted in coordinating the instrumentation effort. David Schlick of the Schlick Crane Co. and Aaron Humphrey assisted with the pullout testing. The views expressed in this paper are solely those of the writers and no endorsement by the sponsors is implied. 


\section{References}

AASHTO (1996). Standard Specification for Highway Bridges, AASHTO, Washington, D. C.

Bowles, J. E. (1996). Foundation Analysis and Design, $5^{\text {th }}$ Ed., McGraw Hill Companies, Inc., New York, 1175 p.

Chang, J. C. and Forsyth, R. A. (1977). "Design and Field Behavior of Reinforced Earth Wall," Journal of the Geotechnical Division, ASCE, Vol. 103, No. GT7, 677-692.

Christopher, B. R., Holtz, R. D., and Allen, T. M. (1992). "Performance of a $12.6 \mathrm{~m}$ High Wall in Seattle, Washington," Proceedings of the International Symposium on Mechanically Stabilized Backfill, Denver, 81-100.

Christopher, B. R. (1993). "Deformation Response and Wall Stiffness in Relation to Reinforced Soil Wall Design," Ph.D. Thesis, School of Civil Engineering, Purdue University, West Lafayette, Ind., $354 \mathrm{p}$.

Dunnicliff, J. (1988). Geotechnical Instrumentation for Monitoring Field Performance, J. Wiley and Sons, New York, $577 \mathrm{p}$.

Ingold T. S. (1979). "Retaining Wall Performance During Backfilling," Journal of Geotechnical Engineering, ASCE, Vol. 105, No. GT5, 613-626.

Ingold, T. S. (1982). Reinforced Earth, Thomas Telford Ltd., London, 141 p.

Lee, K. L., Adams, B. D., and Vagneron, J. J. (1973) "Reinforced Earth Retaining Walls," Journal of the Soil Mechanics and Foundation Division, ASCE, Vol. 99, No. SM10, 745764.

McKittrick, D. P. (1978). "Reinforced Earth: Application of Theory and Research to Practice," Reinforced Earth Technical Series, Report 79-1.

NCMA (1996). Design Manual for Segmental Retaining Walls, Collin, J. G., Ed., National Concrete Masonry Association, 289 p.

Runser, D. J. (1999). Instrumentation and Experimental Evaluation of a $17 \mathrm{~m}$ Tall Reinforced Earth Retaining Wall, M.S. Thesis, School of Civil Engineering, Purdue University, West Lafayette, Ind., 289 p.

Schlosser, F. and Long, N. (1974). "Recent Results in French Research on Reinforced Earth," Journal of the Construction Division, ASCE, Vol. 100, No. CO3, 223-237. 
Schlosser, F. and Elias, V. (1978). "Friction in Reinforced Earth," Proceedings of the ASCE Symposium on Earth Reinforcement, Pittsburgh, 735-763.

Simac, M. R., Christopher, B. R., and Bonczkiewicz, C. (1990). "Instrumented Field Performance of a $6 \mathrm{~m}$ Geogrid Soil Wall," Proceedings, $4^{\text {th }}$ International Conference on Geotextiles, Geomembranes, and Related Products, The Hague, Netherlands, 53-59.

U. K. Department of Transport (1978). "Reinforced Earth Retaining Walls and Bridge Abutments for Embankments," Technical Memorandum BE 3/78.

Vidal, H. (1966). "La Terre Armée," Annales de l'Institut Technique du Batiment et des Travaux Publics, Vol. 19, Nos. 223 (July) - 224 (Aug.), Paris, France.

Vidal, H. (1969a). “La Terre Armée - Réalisations Récentes," Annales de l'Institut Technique du Batiment et des Travaux Publics, Vol. 21, Nos. 259 (July) - 260 (Aug.), Paris, France.

Vidal, H. (1969b). "The Principle of Reinforced Earth," Transportation Research Record, Vol. 282, 1-16. 


\section{FIGURES}




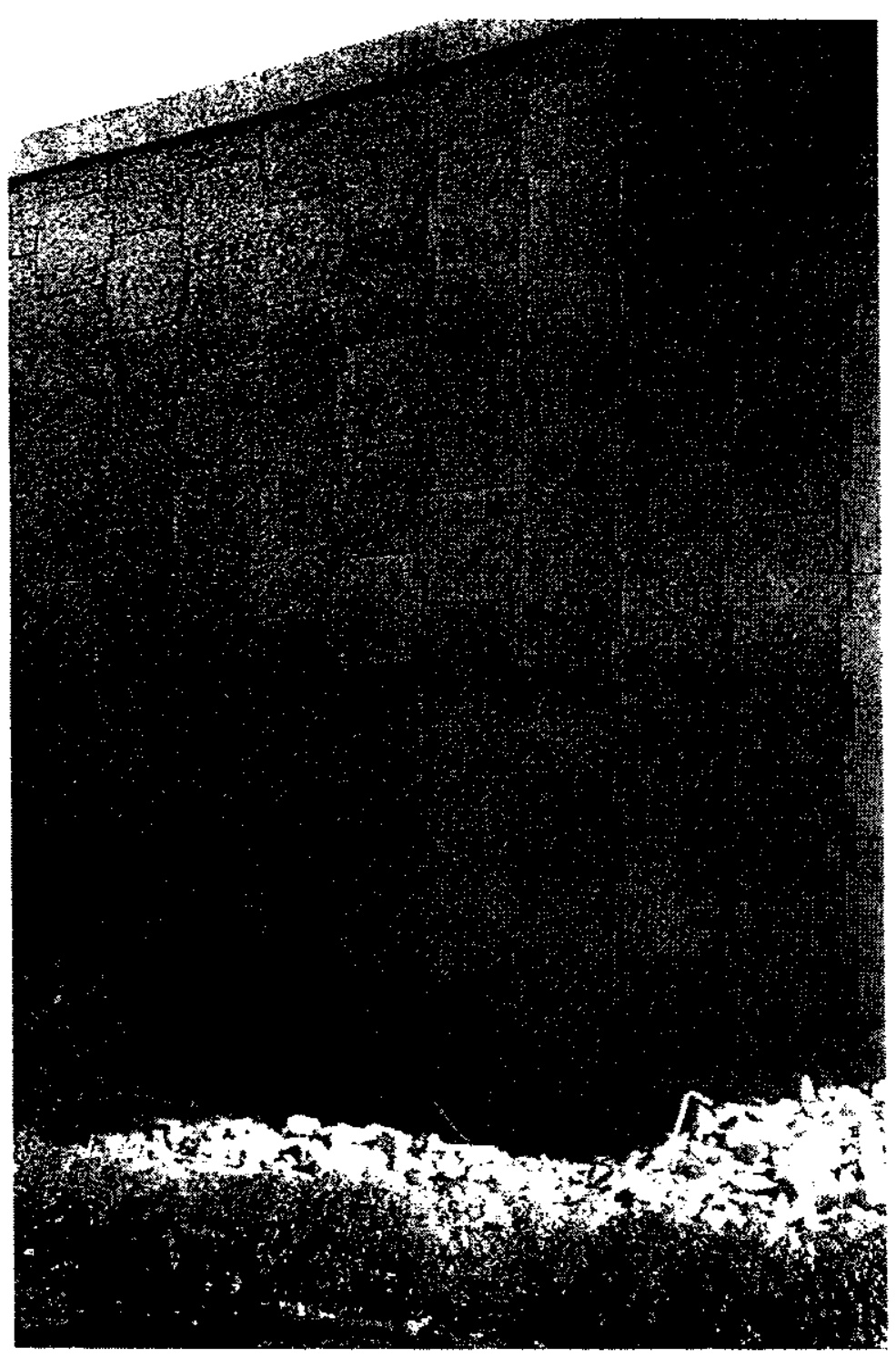

Figure 1

Minnow Creek wall 

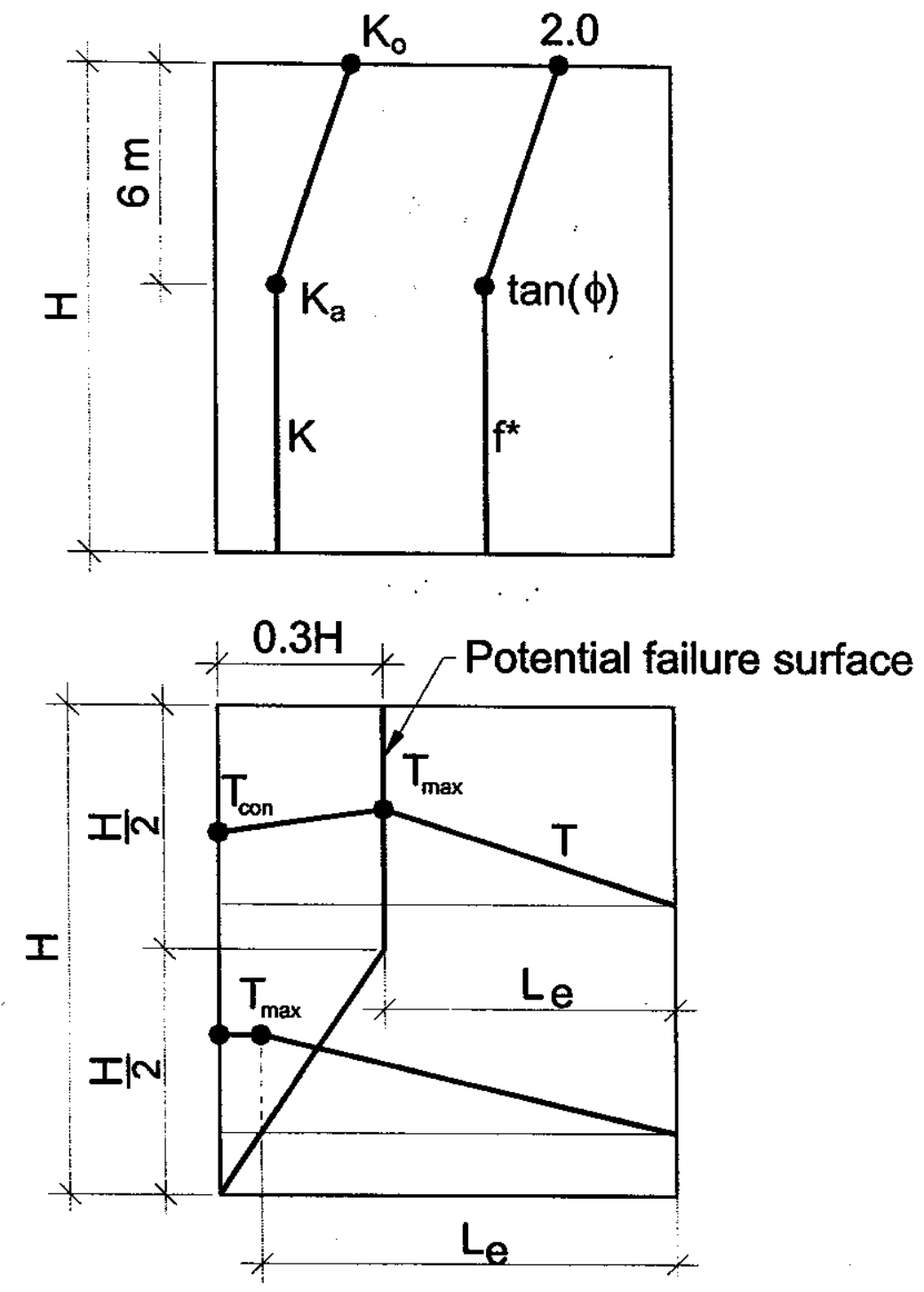

\section{$\mathrm{T}_{\max }$ - Maximum reinforcement tension \\ $T_{c o n}$ - Reinforcement tension at the connection}

Figure 2

Internal design assumptions: distribution of internal earth pressure, apparent friction coefficient, distribution of strip tension, and location of failure plane. 


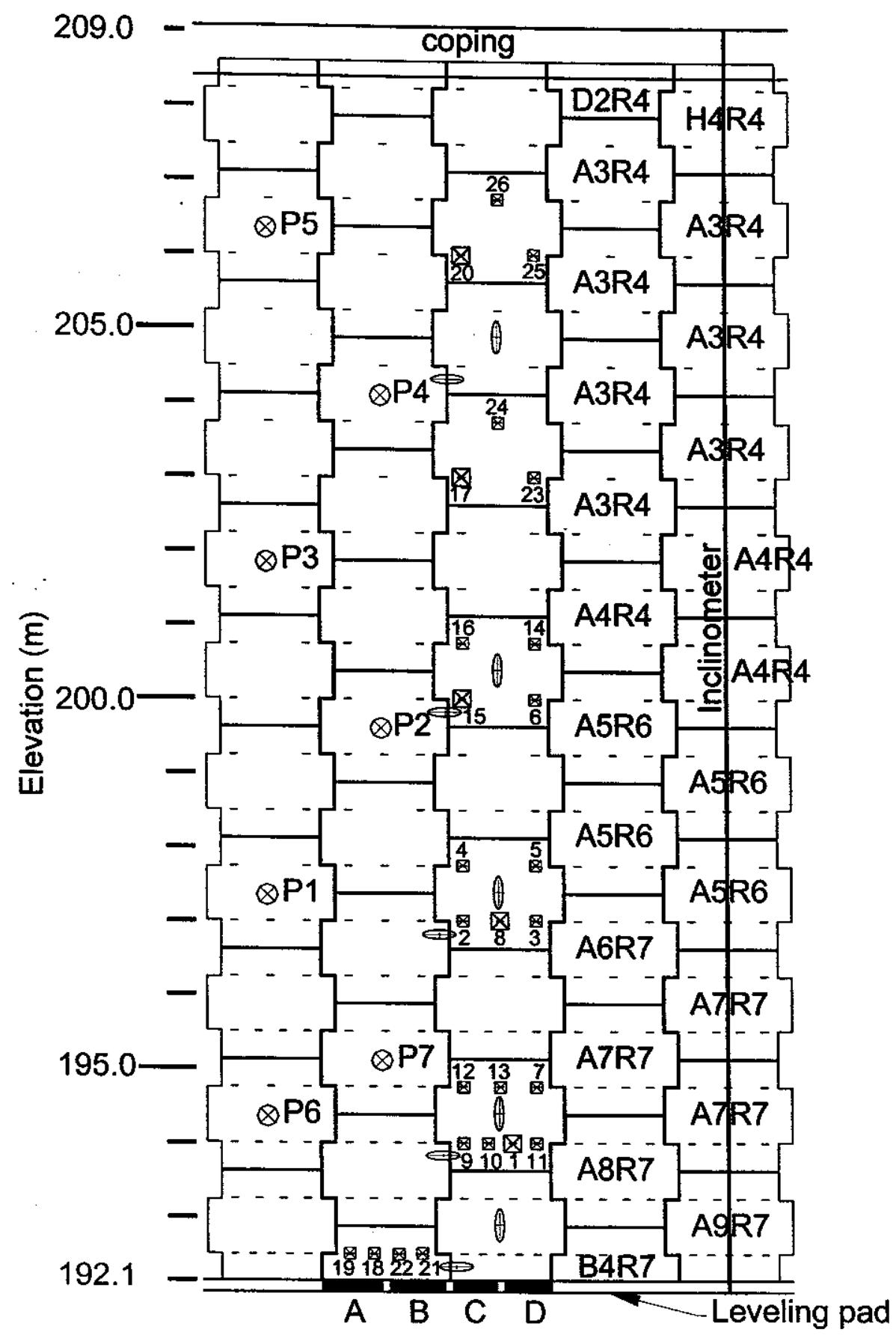

$\otimes$ pullout strip $\Leftrightarrow \sigma_{v}$ pressure cell $\theta \sigma_{h}$ pressure cell $\rightarrow$ load cell $\otimes$ single strain gage reinforcing strip $\otimes$ fully instrumented reinforcing strip

Figure 3

Instrumented section showing instrumentation locations (face view) 


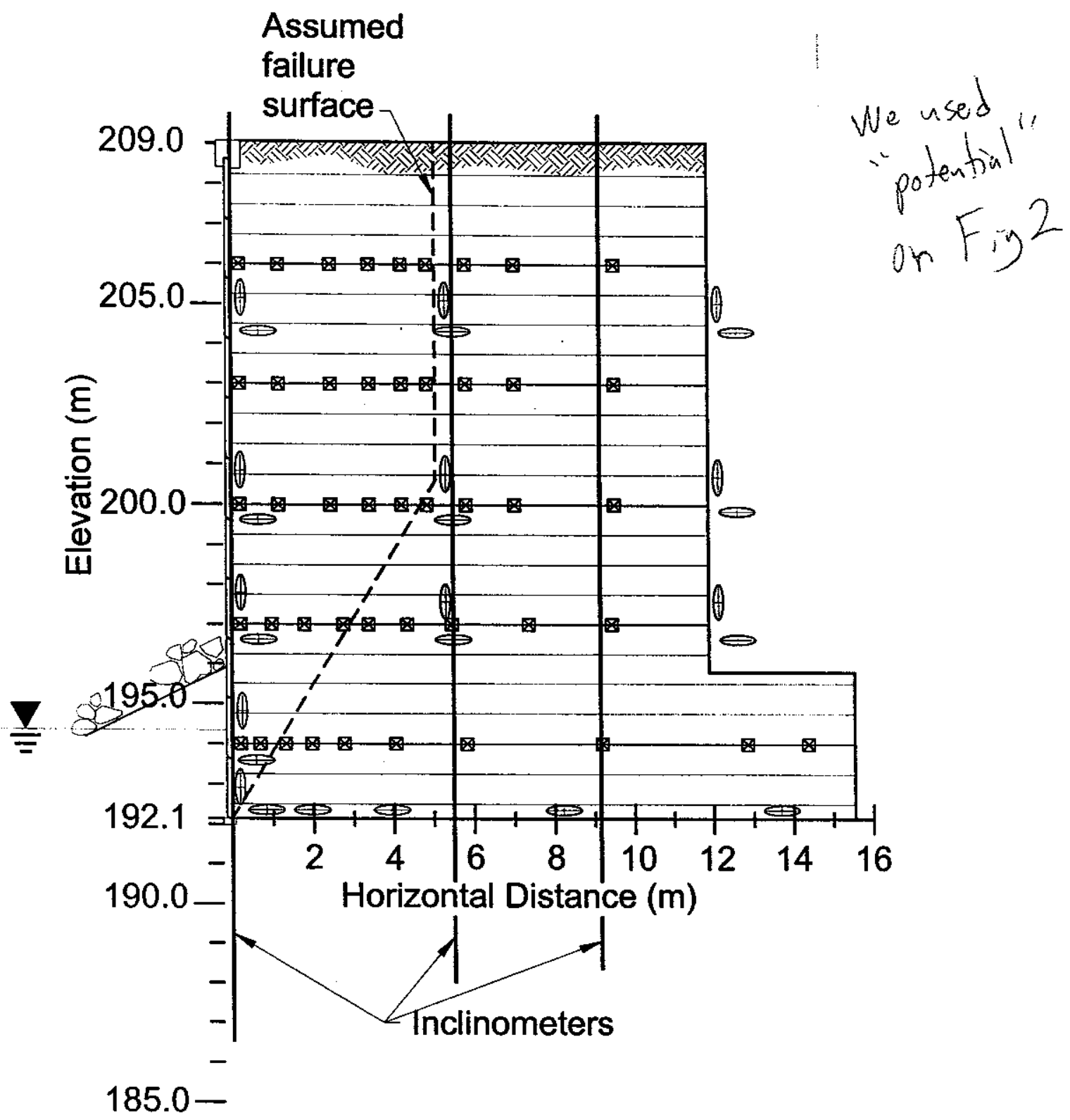

$\otimes$ strain gage $\Leftrightarrow \sigma_{\mathrm{v}}$ pressure cell $\theta \sigma_{\mathrm{h}}$ pressure cell

Figure 4

Instrumented section showing instrumentation locations (profile view). 


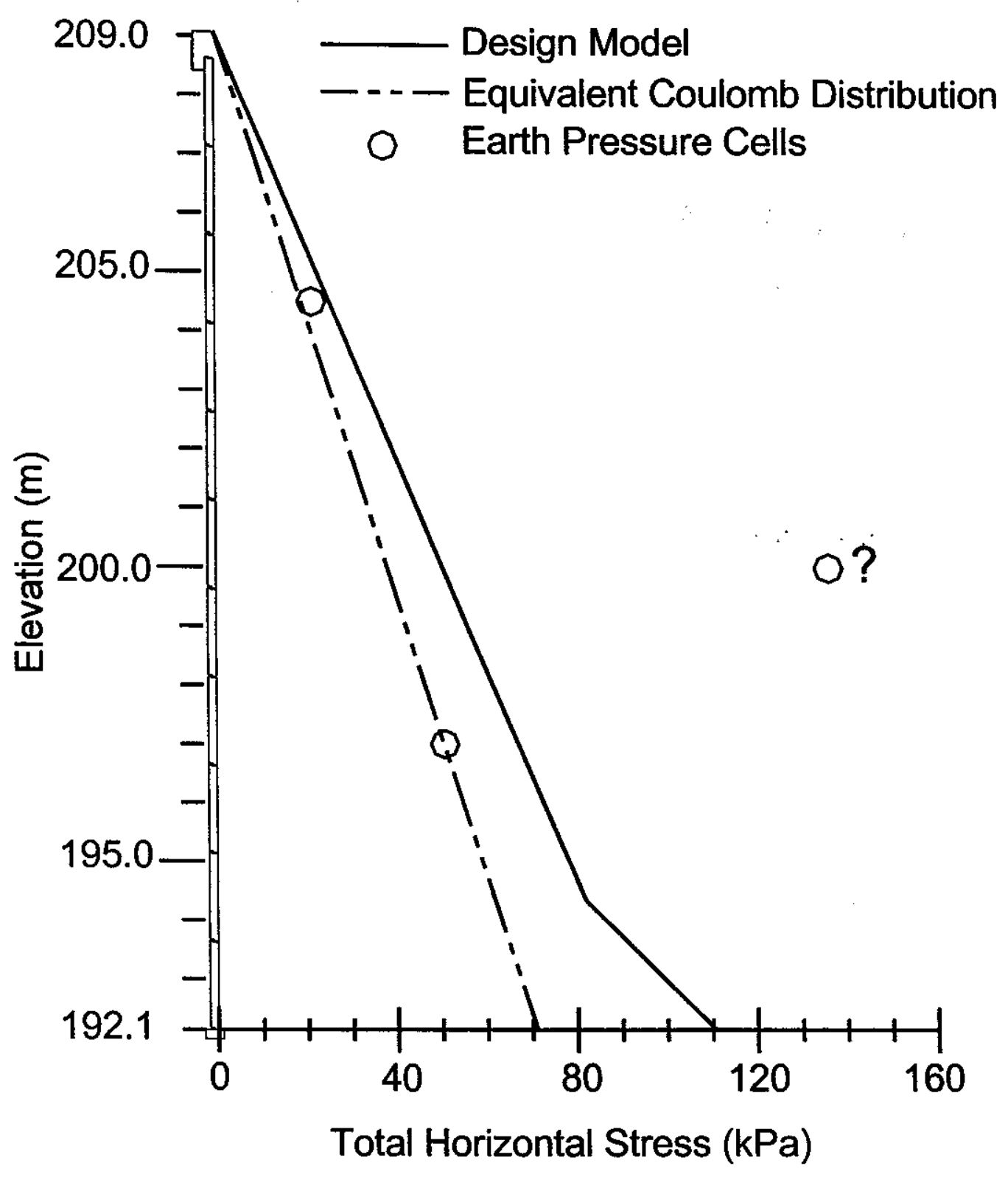

Figure 5

Distribution of total horizontal stress on the back of the reinforced soil mass. 


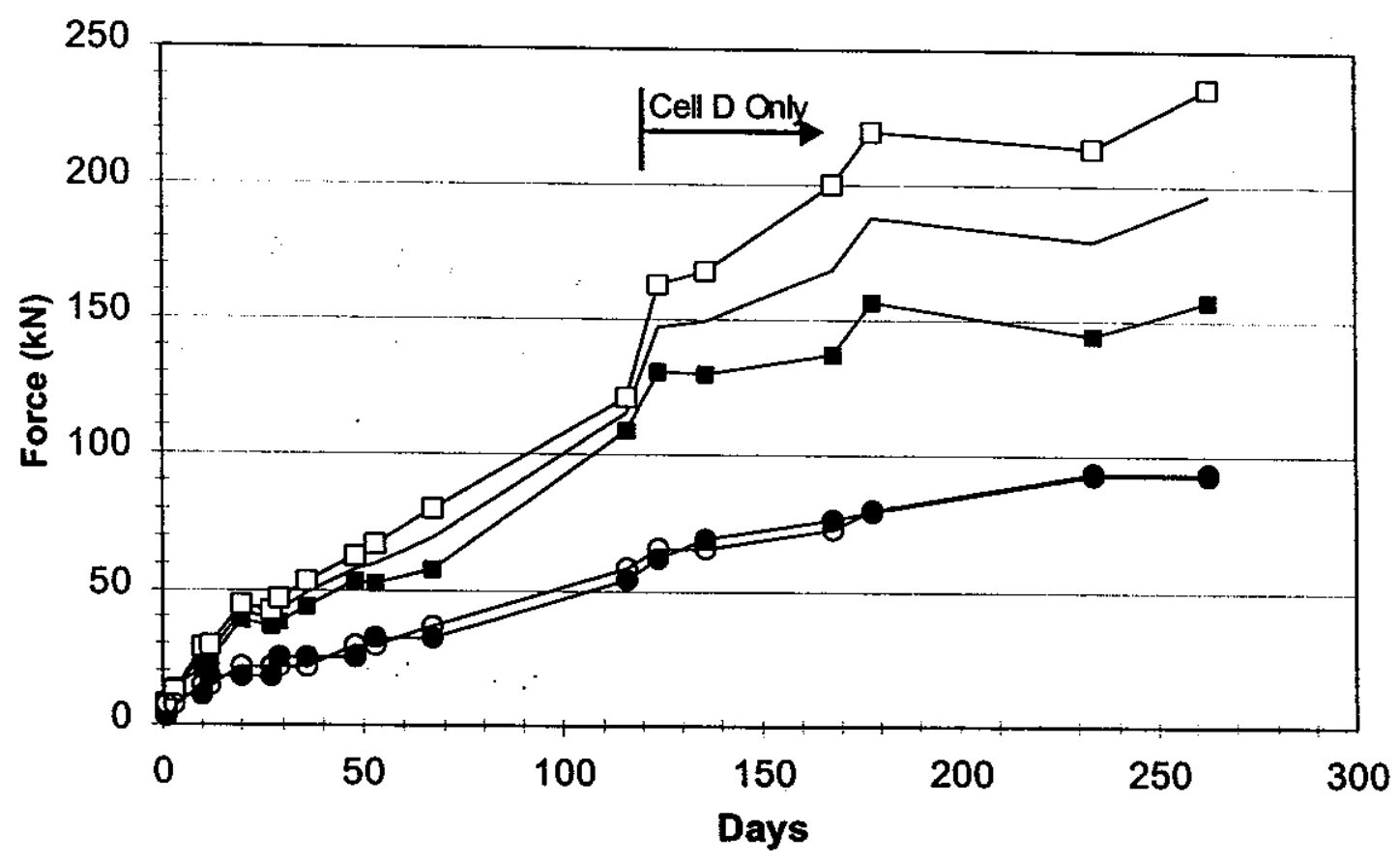

$\rightarrow-$ Load Cells $A+B \rightarrow$ Panels over A+B $\quad-\square$ Load Cells $C+D$ - Panels over $C+D \quad$ L Load Cell Average

Figure 6

Development of vertical force under bottom facing panels during construction. 


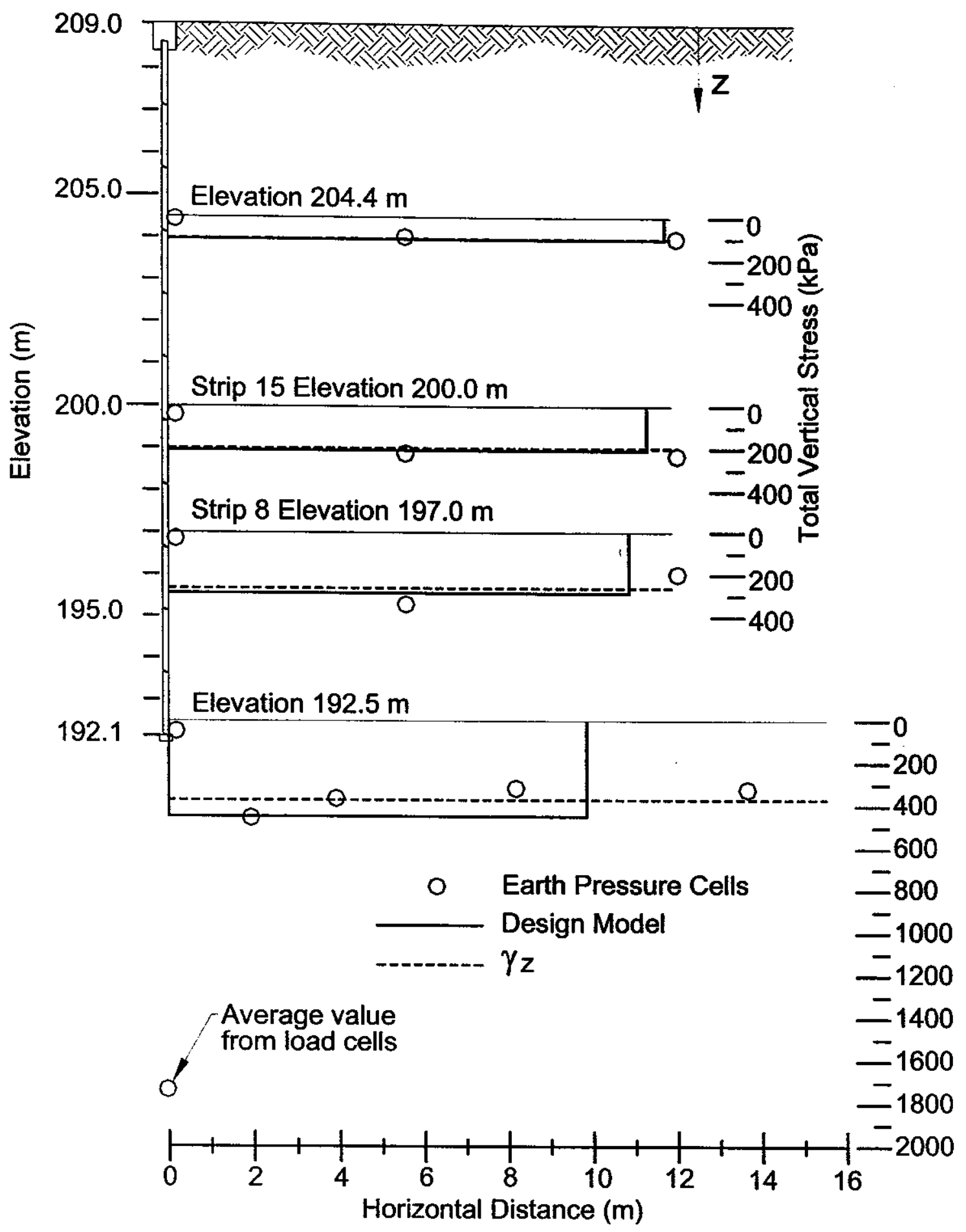

Figure 7

Distribution of total vertical stress at four elevations within the reinforced soil mass. 


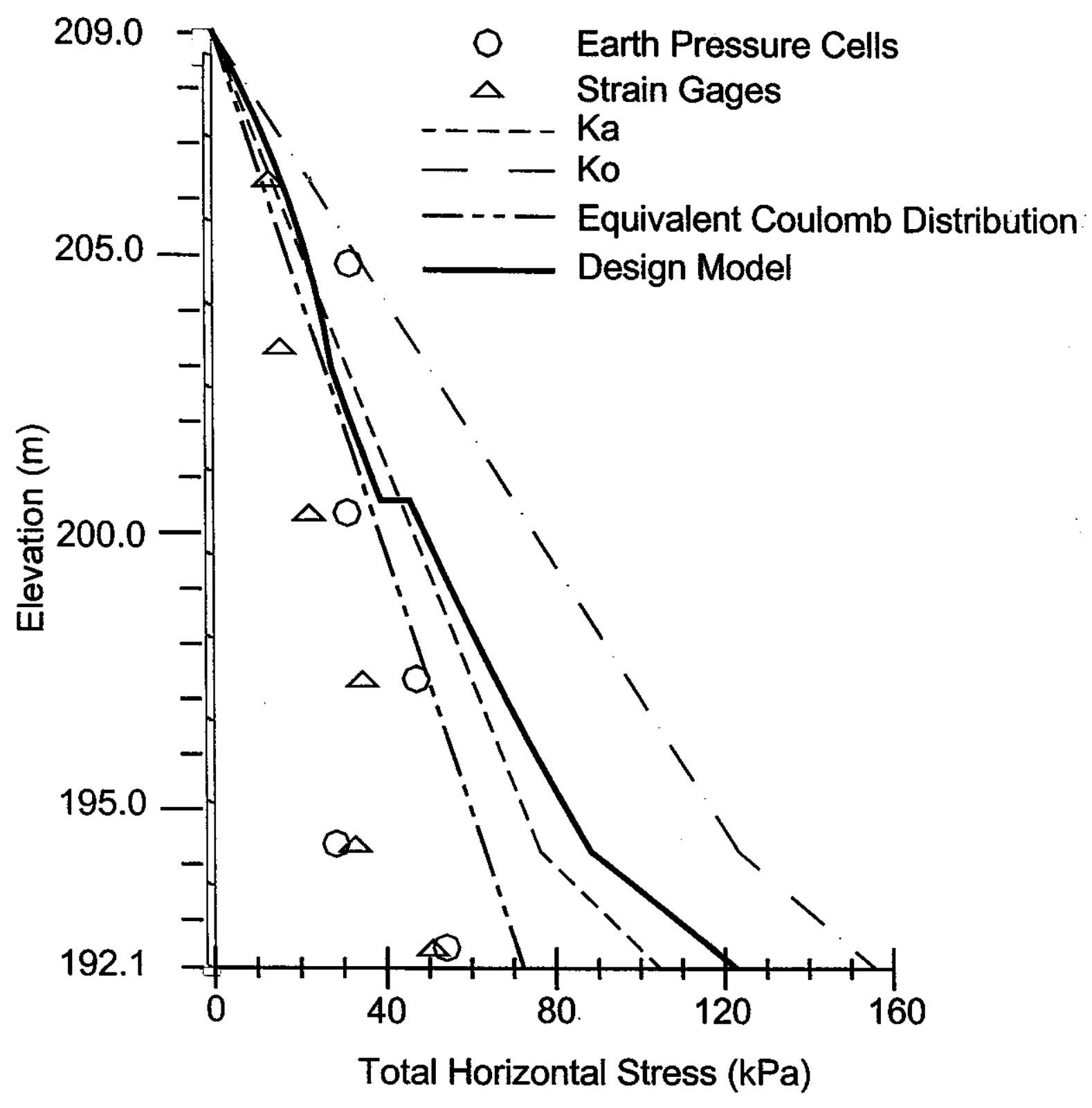

Figure 8

Distribution of total horizontal stress at the facing panels. 


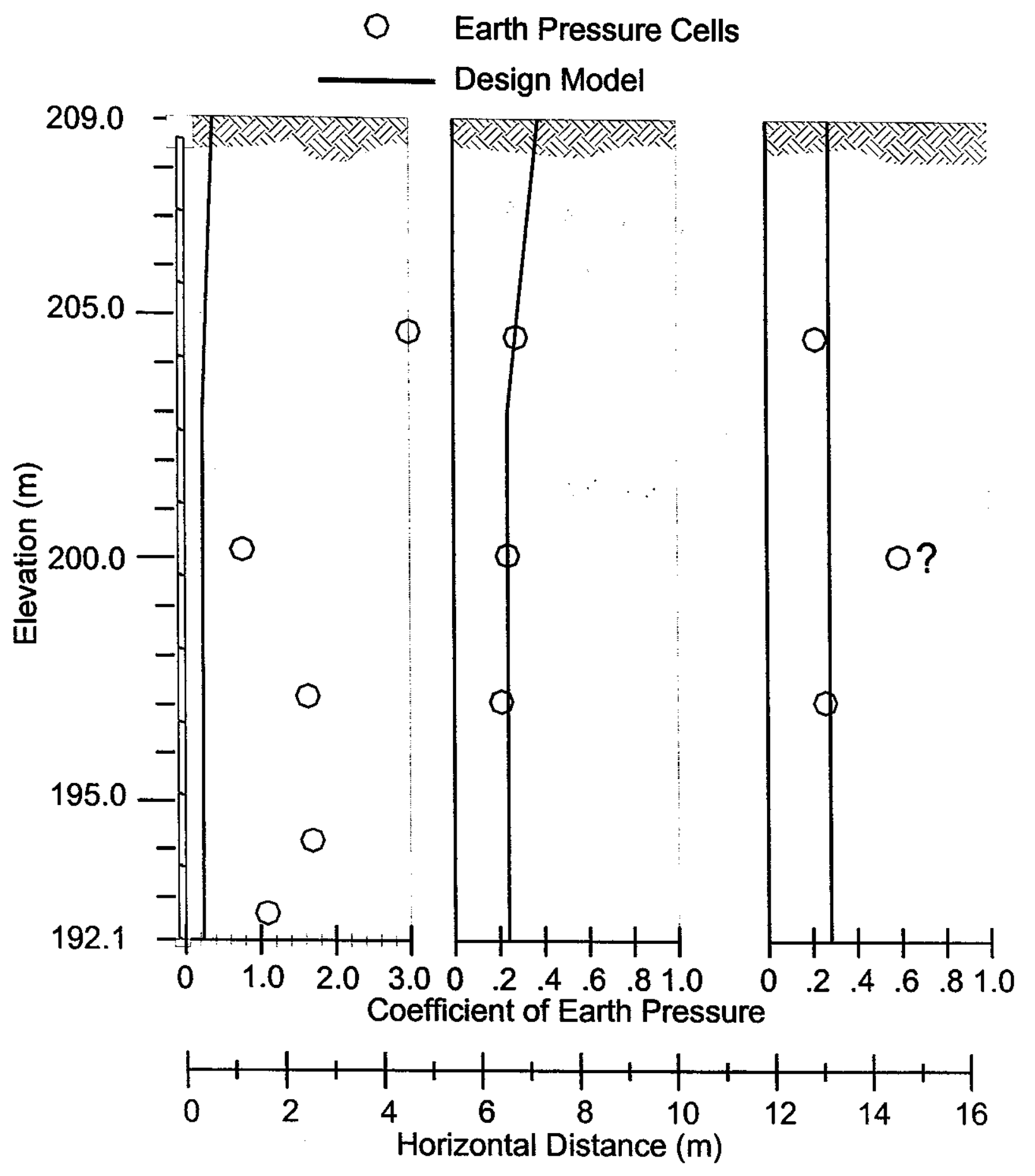

Figure 9

Coefficient of lateral earth pressure within reinforced soil mass. 


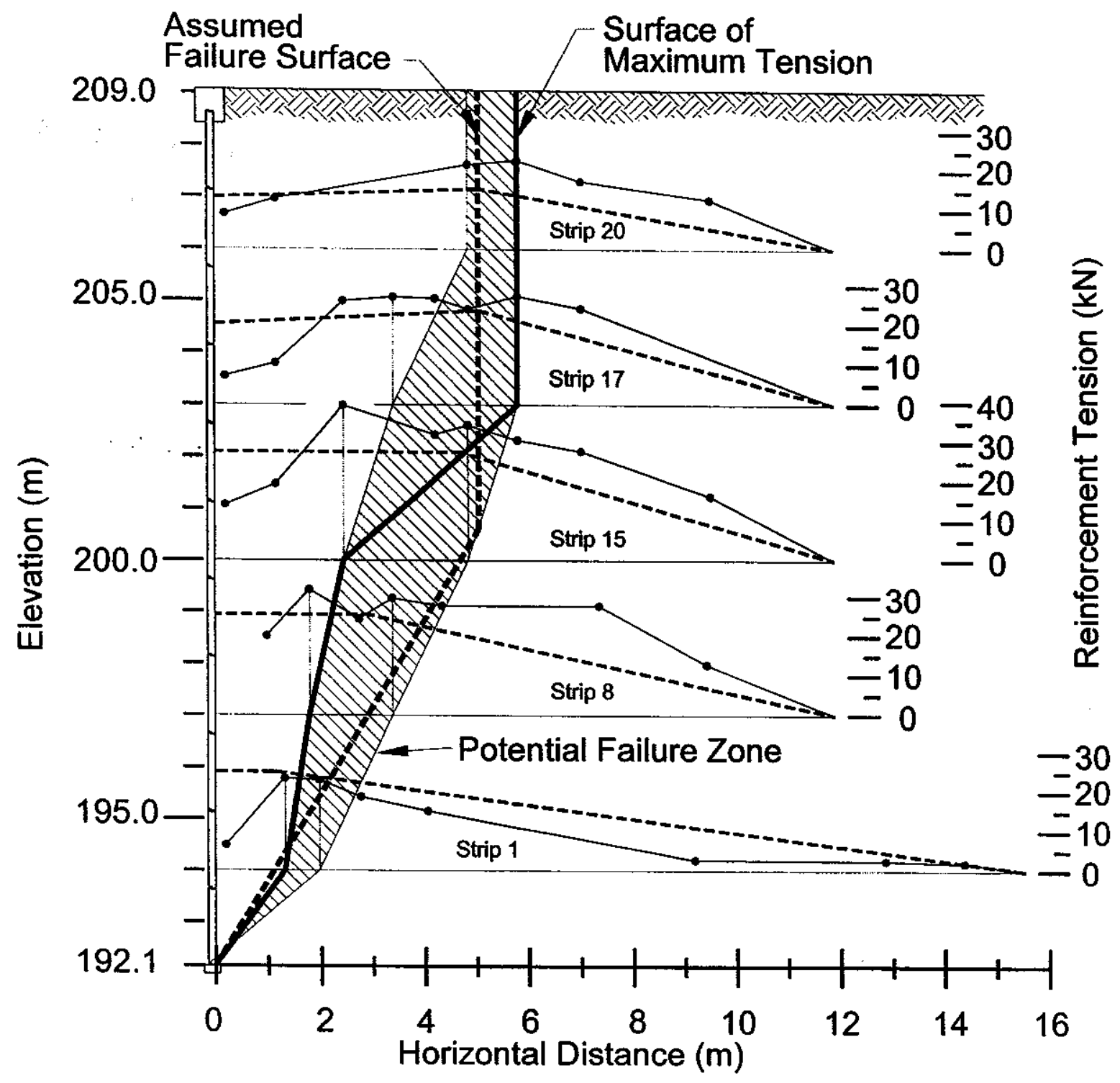

-------- Design Model

Figure 10

Distribution of tension in reinforcement and location of potential failure surface. 


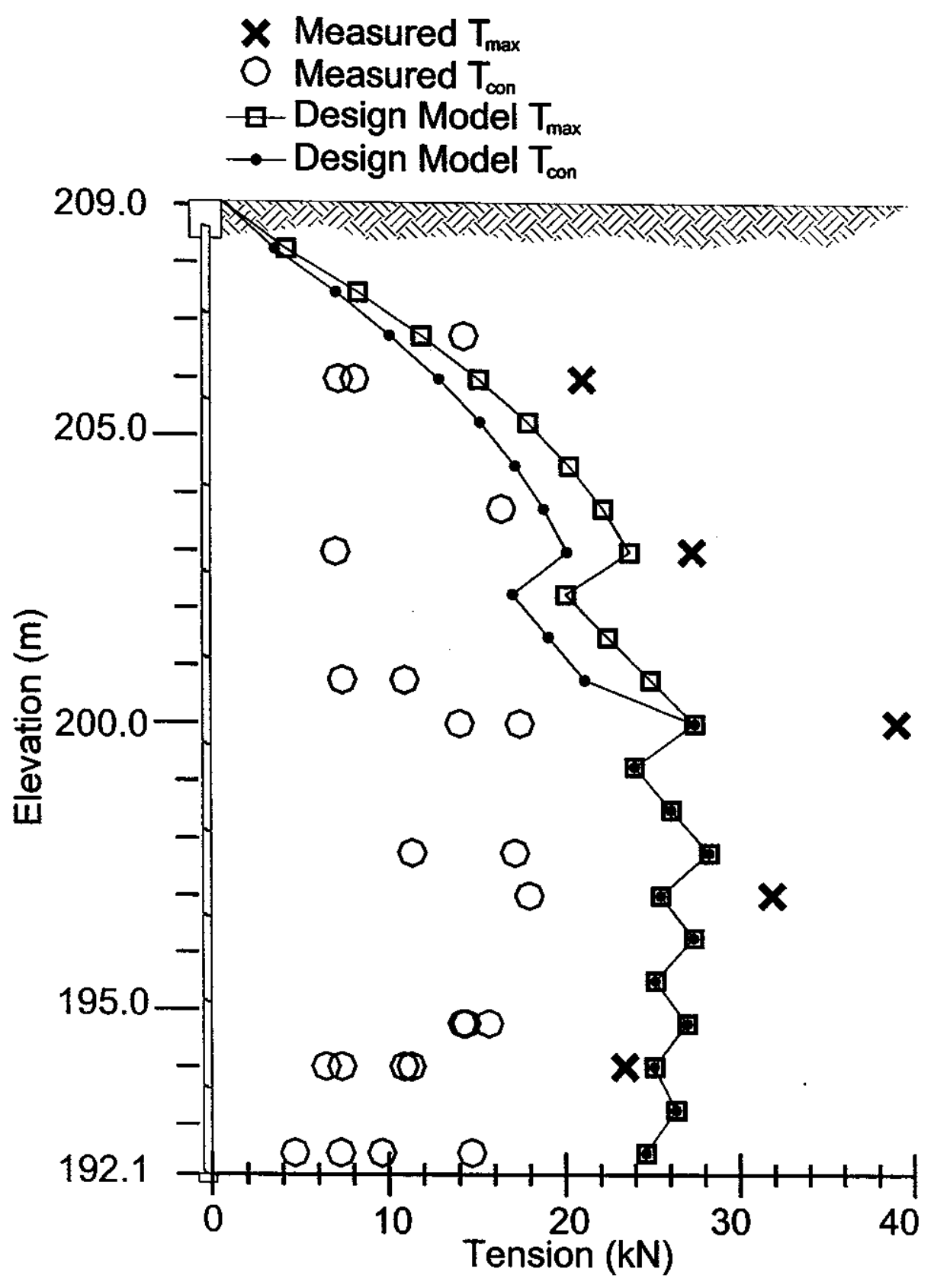

Figure 11

Values of connection tension and maximum tension in the reinforcement. 


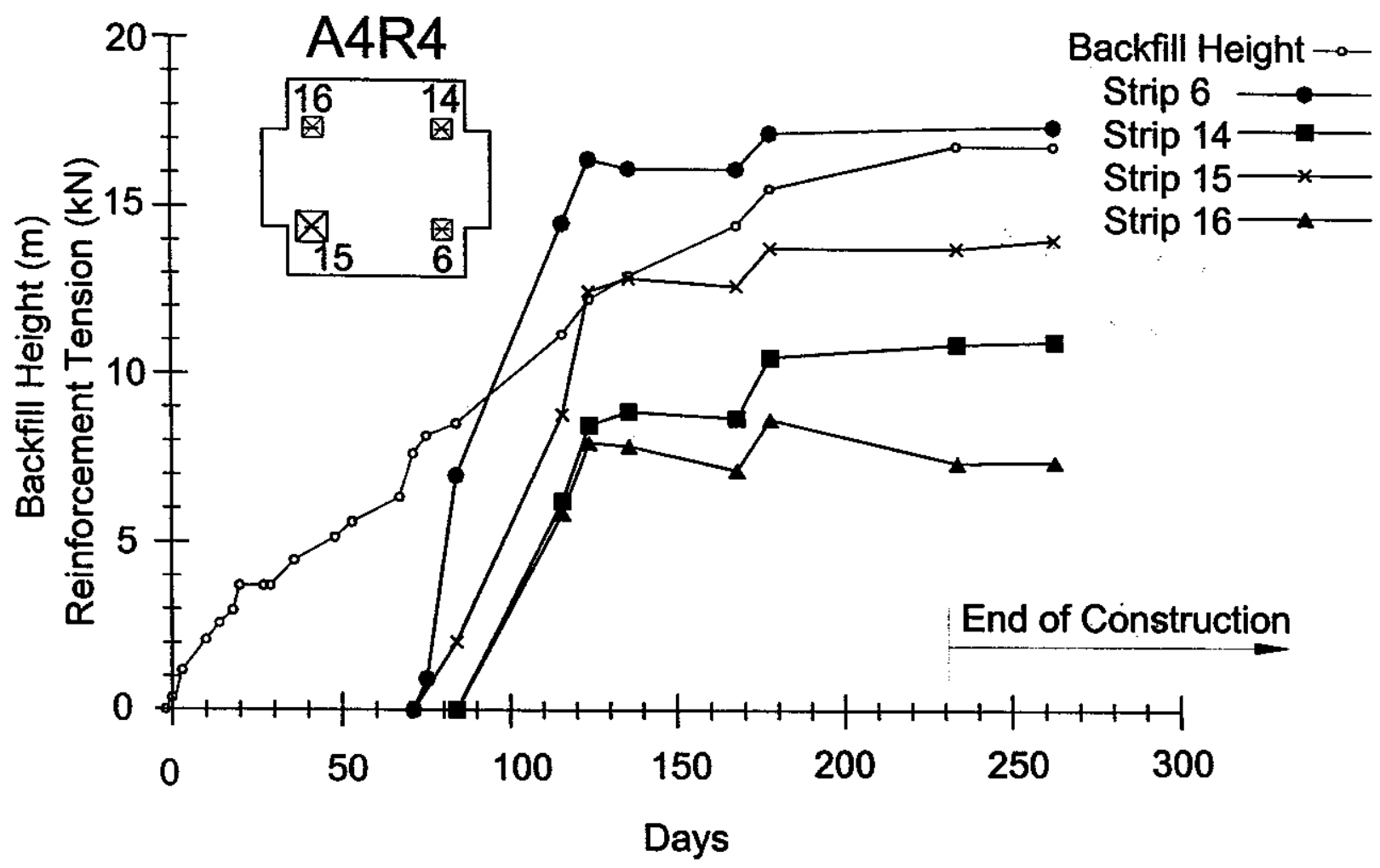

Figure 12

Development of tension in strips connected to panel A4R4. 


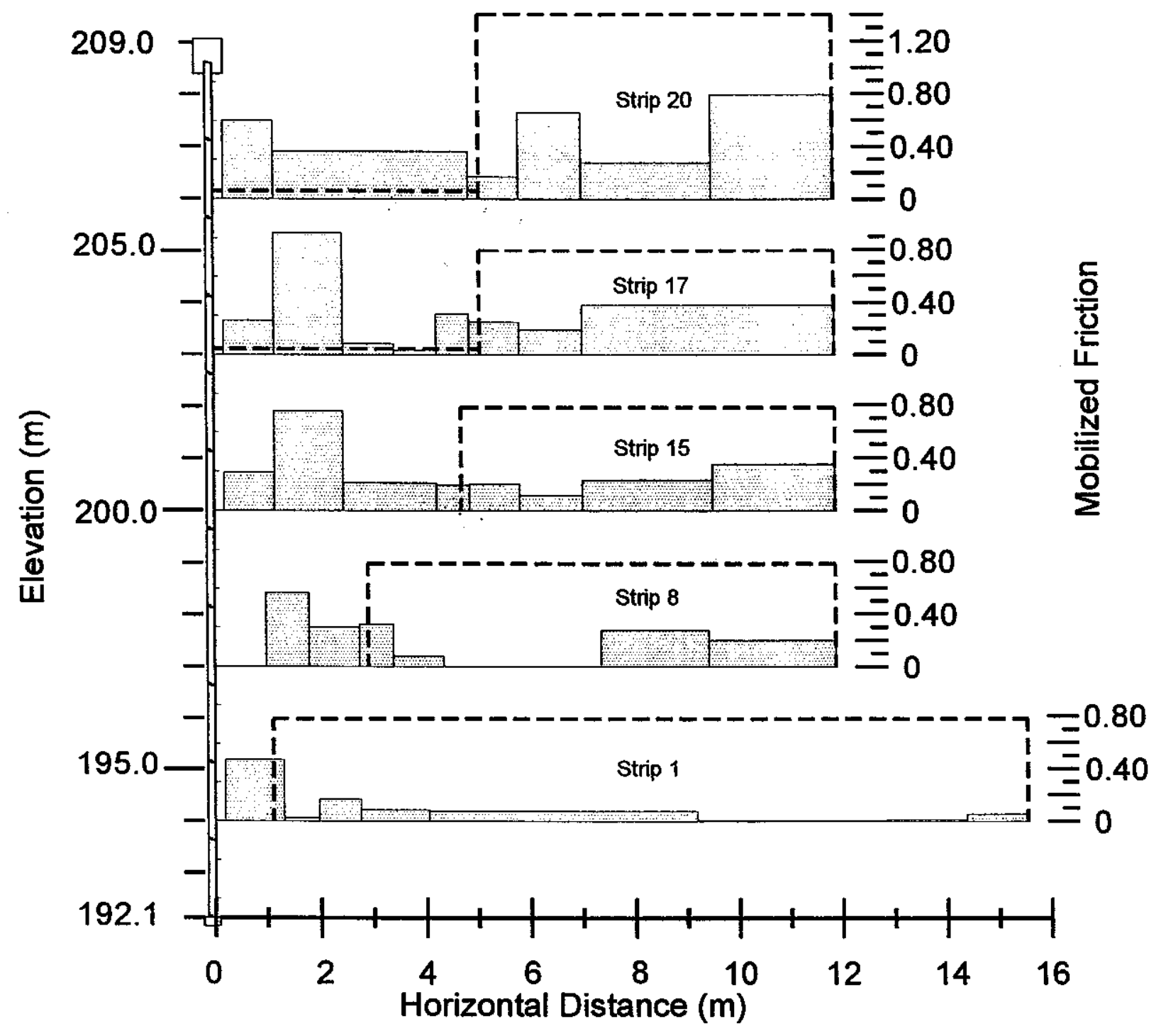

- - - - Design Model

Figure 13

Distribution of mobilized apparent soil-reinforcement friction coefficient in reinforcement. 


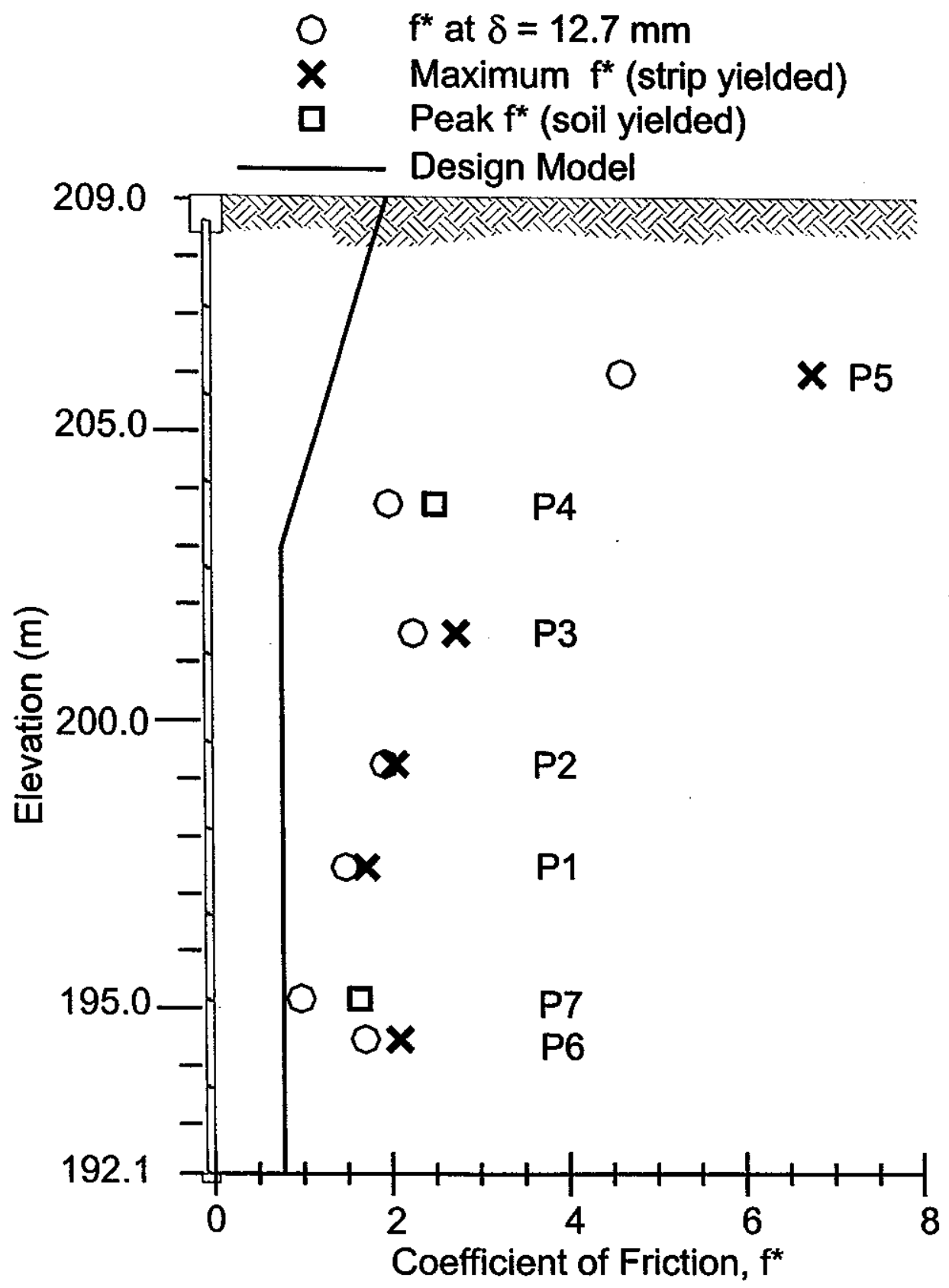

Figure 14

Values of apparent soil-reinforcement friction coefficient vs. elevation. 


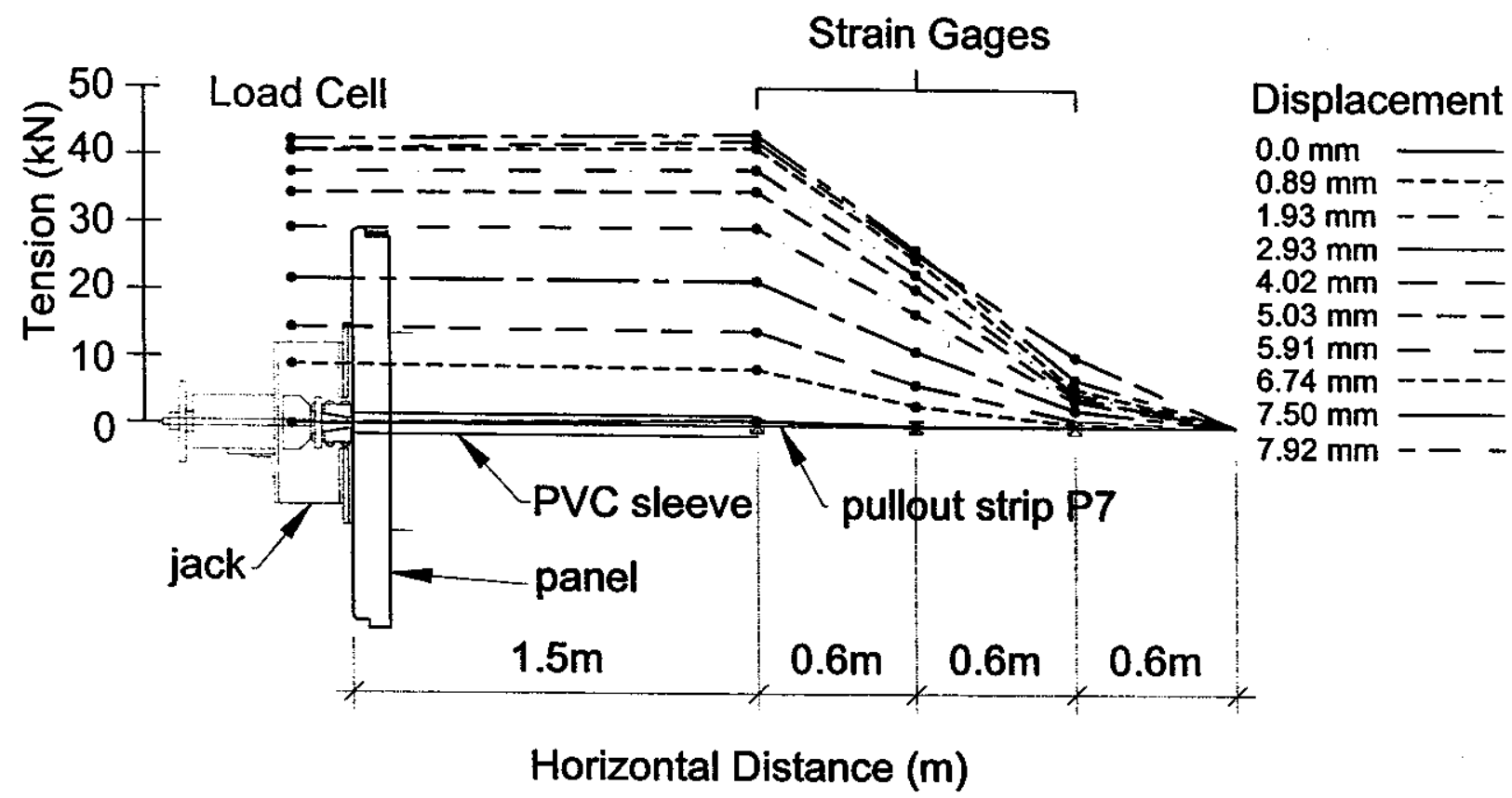

Figure 15

Development of tension in the reinforcement during pullout test P7. 


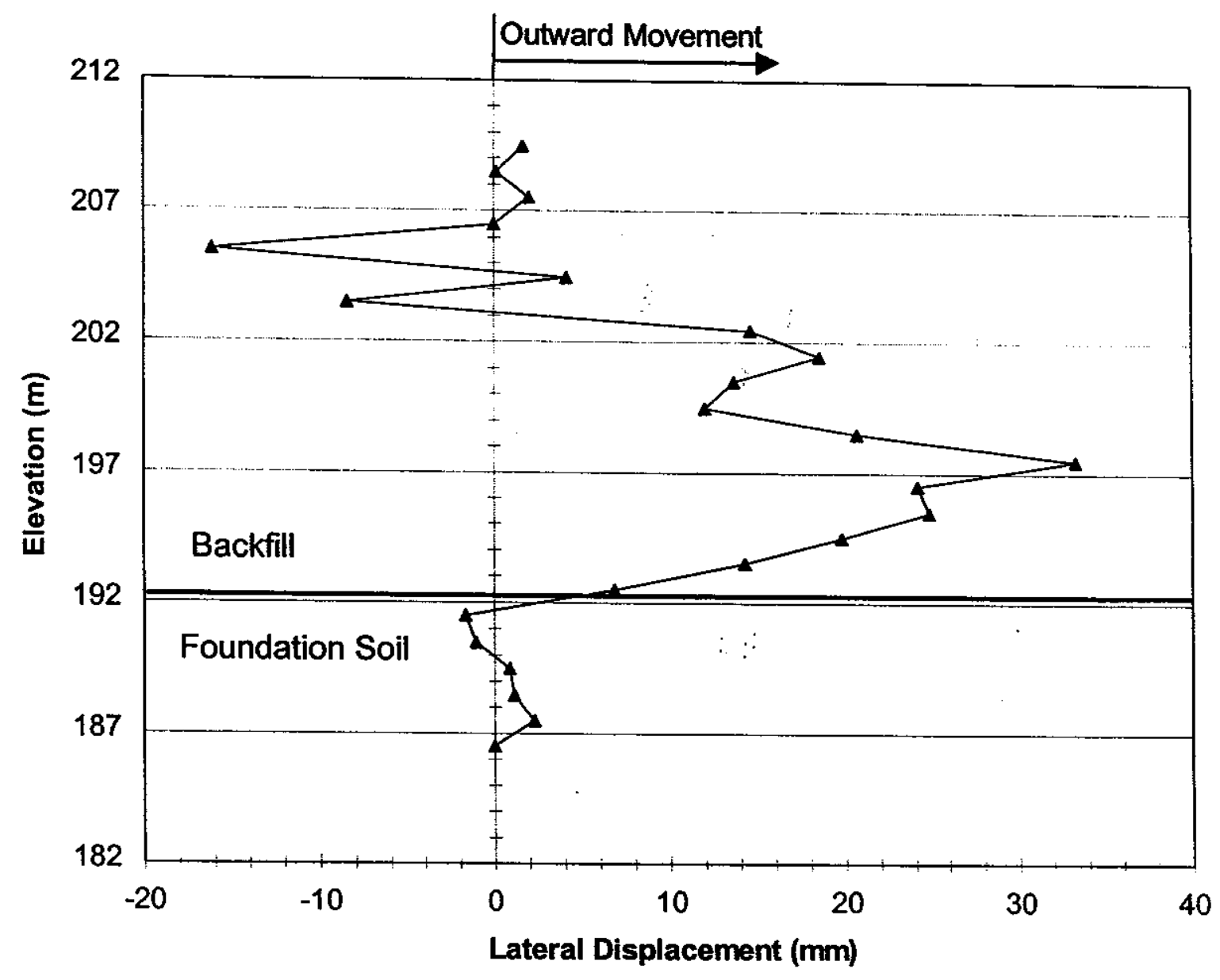

Figure 16

Displacement of facing as recorded by inclinometer Il. 